\title{
In Search of Effective Principal Appraisal
}

\author{
Patricia Chapman
}

\author{
A thesis \\ submitted in partial fulfilment of the requirements for the \\ Master of Education \\ Victoria University of Wellington
}

2008 


\section{Acknowledgements}

This thesis has had a long gestation period and its eventual delivery is due in no small part to the generous support and advice I have received from family, friends and colleagues, with the following deserving special mention.

I have been incredibly fortunate to have had Liz Jones as my supervisor. Her insightful feedback, patience and good humour gave me just the boost I needed each time we met. I have been lucky to have another highly skilled "midwife" for this thesis in Susan Kaiser whose expertise and careful attention to detail has made such a difference to its presentation.

My late husband Will gave me every encouragement to tackle this research but the diagnosis of his terminal illness led to it being put on hold for several years. It fell to another very special partner, Hans Lehmann to get me motivated enough to pick it up again, and to keep me motivated when I realised the scale of what I had undertaken and frequently felt overwhelmed by the quantity of data.

My three wonderful daughters, Helen, Isabel and Susie have lived with "mum-the-student" for much of their lives. Their own academic achievements have made me very proud.

My wonderful group of friends of whom I have seen far too little during the months I have been focused on getting this thesis completed. In particular Alison and Mary whose resilience in coping with adversity has inspired me and whose friendship has enriched my life.

Last, but by no means least, I am indebted to the principals and chairs who contributed to the research by completing the survey or discussing their experiences with me. I hope that the findings may be of some use in helping to ensure principal appraisals that are satisfying and well supported. 


\section{Abstract}

\section{In search of effective principal appraisal}

The board of trustees of each New Zealand state and integrated school is responsible for the performance appraisal of its principal. Empirical data on the effectiveness of the appraisal for principals and boards is scarce. This research set out to describe principal appraisal within a region containing approximately one tenth of New Zealand schools. A survey to collect quantitative and qualitative data on the 2006 appraisal was completed by the principal and/or chair of just under half the schools in the region. The results suggest four critical success factors: the way in which the appraiser is selected and their personal qualities; the fairness and clarity of the process; the specific expectations that principals and chairs have of the outcome; and the completeness and congruity of principals' and chairs' understanding of appraisal. The reported experiences were mostly positive. However, understanding and resourcing of effective practice was found to be limited. A professional external appraiser and good interpersonal chemistry are dominant contributors to a satisfying appraisal experience. A functioning process with adequate resourcing and time for evidence gathering and evaluation, appear to be important appraisal prerequisites but do not guarantee a satisfying outcome. Unsatisfying appraisal experiences can be traced to a lack of clear understanding of appraisal aims and practice, together with resources to support their development. It is further compounded by the transient nature of boards. Four key action programmes are suggested to address shortcomings and recommendations are outlined for key stakeholders. 


\section{Table of Contents}

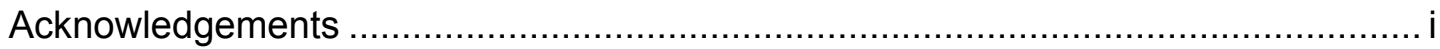

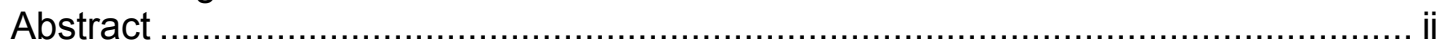

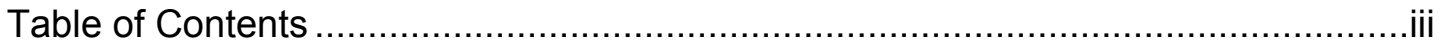

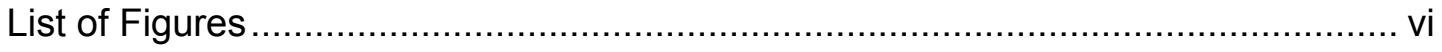

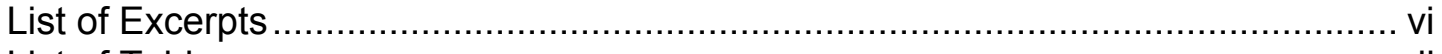

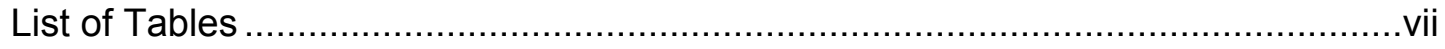

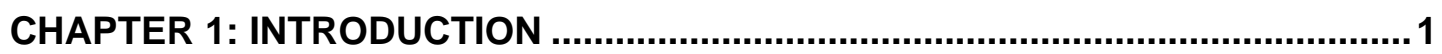

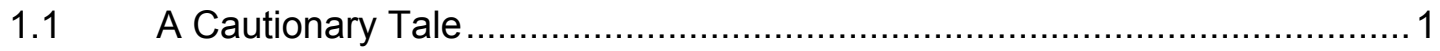

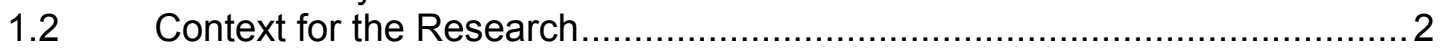

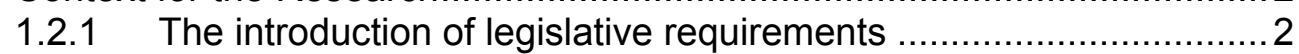

1.1.2 Advice and guidance for BOT on principal appraisal .....................5

$1.3 \quad$ The Significance of this Study .......................................................... 10

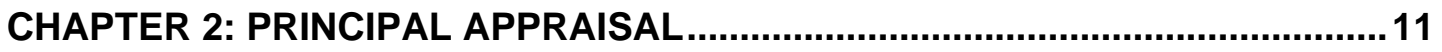

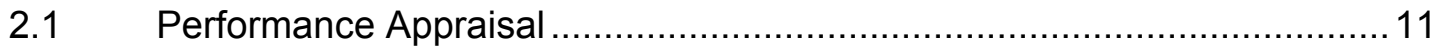

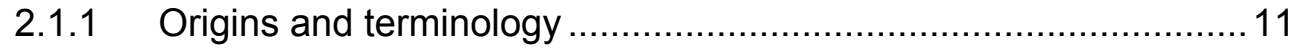

2.1.2 Effective practice............................................................... 12

2.1.3 Appraisal in education....................................................... 14

2.1.4 Principal appraisal............................................................. 18

2.1.5 Conclusion ..................................................................... 21

2.2 Appraisal in other Education Systems: Analysis of Different System

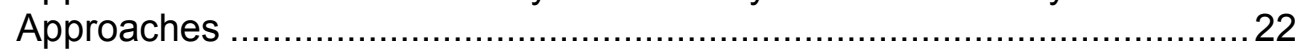

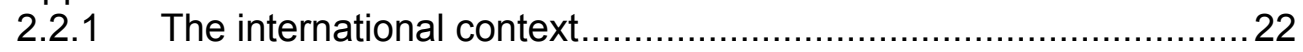

2.2.2 England and Wales............................................................ 23

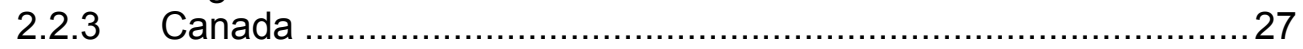

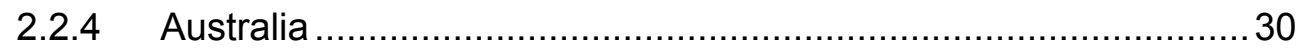

2.2.5 The implications for principal appraisal in New Zealand ...............32

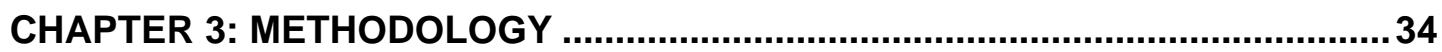

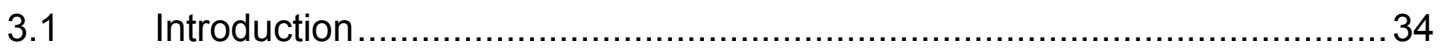

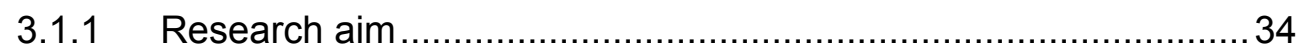

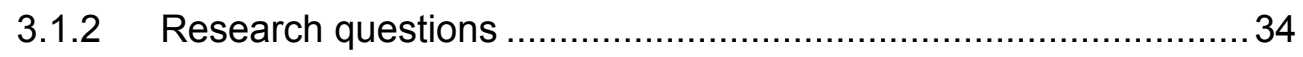

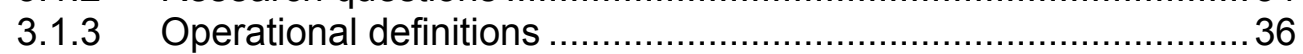

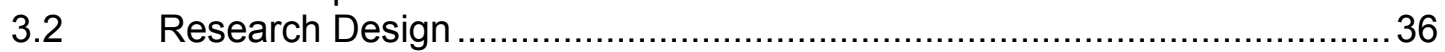

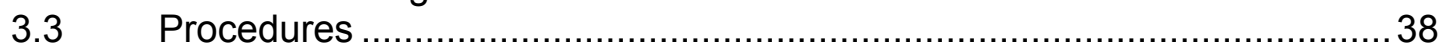

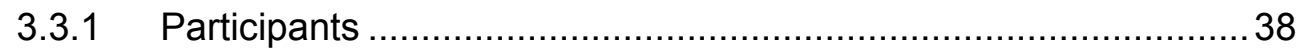

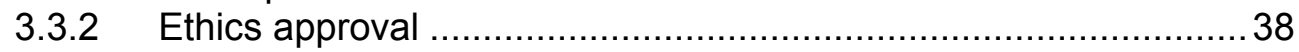

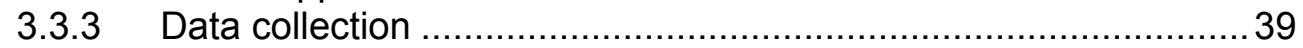

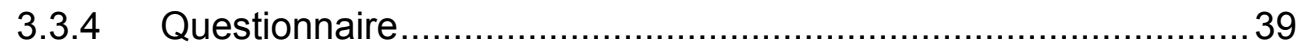

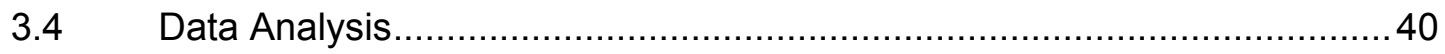

3.4.1 Factual information ......................................................... 40

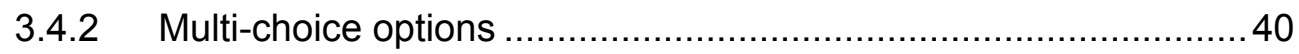

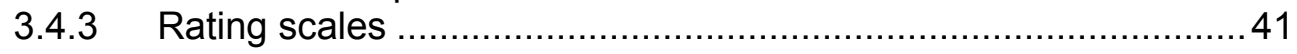

3.4.4 Qualitative data ............................................................. 41

3.4.5 Presentation of findings ..................................................... 42

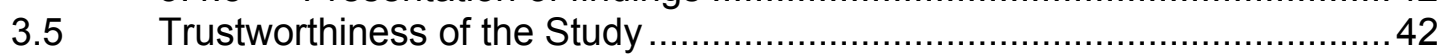

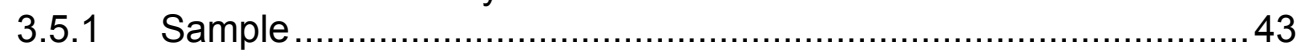

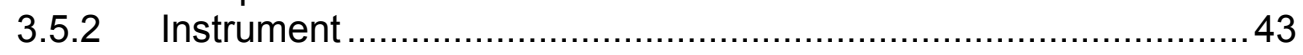

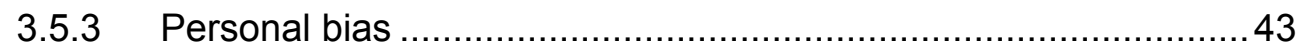

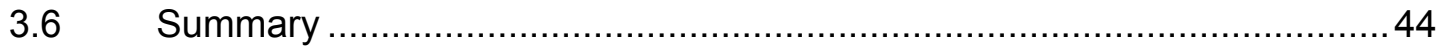


CHAPTER 4: RESULTS

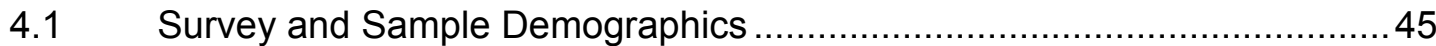

4.1.1 Response rates ................................................................ 45

4.1.2 Representativeness of the sample....................................... 45

4.2 Who is appraising school principals in this region? ................................48

4.2.1 Appraiser selection ........................................................... 49

4.2.2 Appraisal by chair and external appraiser (CE) .........................50

4.3 Who makes the decision about who will carry out the appraisal? .............50

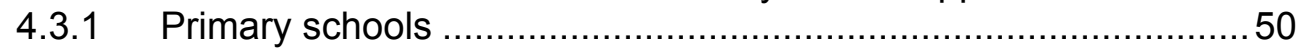

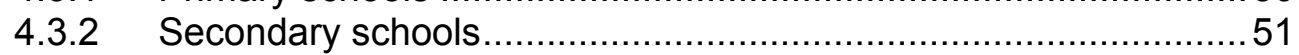

4.4 What qualities are being sought in an appraiser? .............................. 52

4.4.1 Ideal qualities in an appraiser .............................................. 52

4.4.2 Appraisers' possession of important qualities............................53

4.4.3 Training and experience of chairs .............................................55

4.5 What role does a performance agreement play in the appraisal process?...56

4.5.1 Determining the focus of the agreement ..................................56

4.5.2 Linkages to key BOT documentation and processes..................57

4.6 How comprehensive is the appraisal? ................................................5

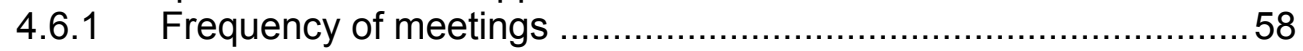

4.6.2 Sources of appraisal evidence .................................................59

4.7 Are appraisal outcomes shared with the BOT and if so in what form? .......63

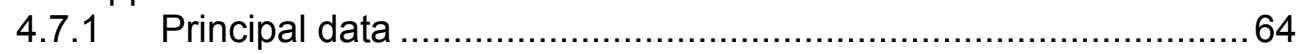

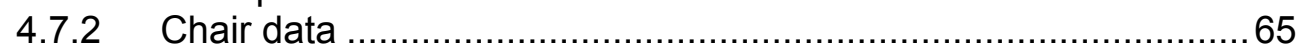

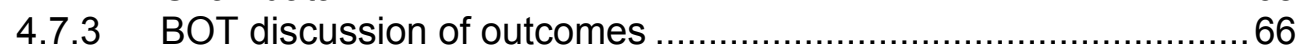

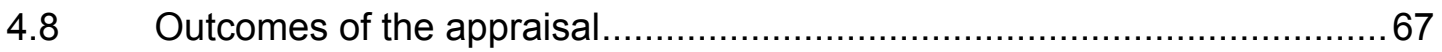

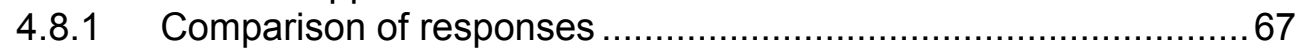

4.8.2 Comparison of paired responses .............................................. 76

4.9 What aspects of the appraisal process are most and least satisfying? ............78

4.9.1 Most satisfying .................................................................. 79

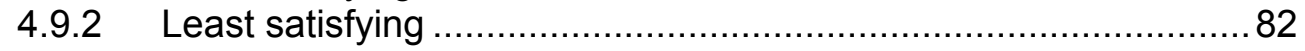

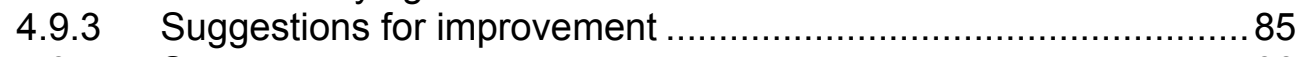

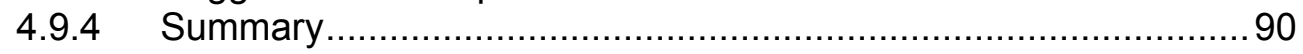

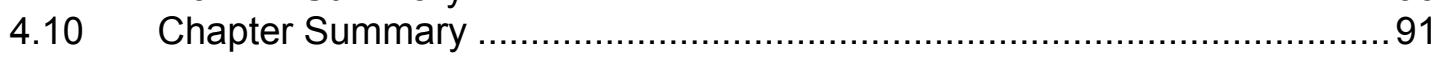

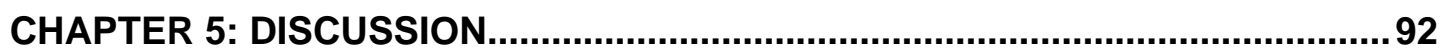

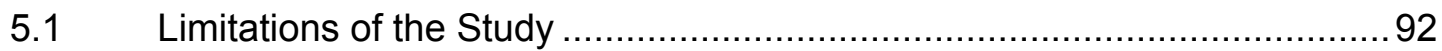

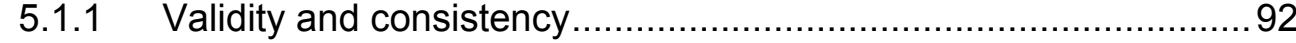

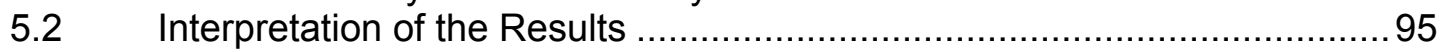

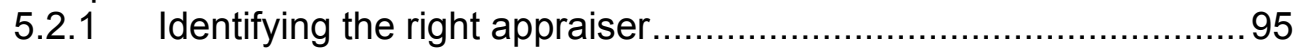

5.2.2 A manageable, documented process .....................................97

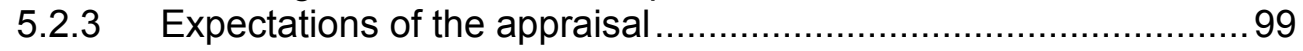

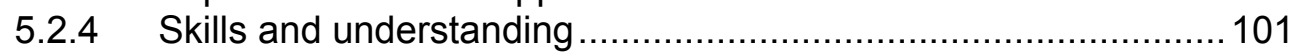

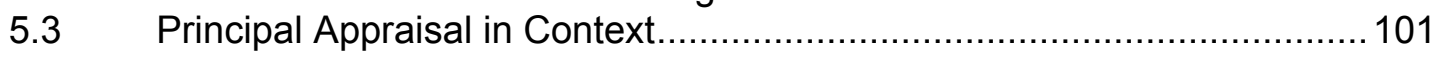

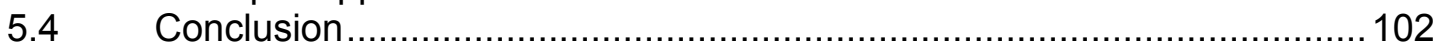

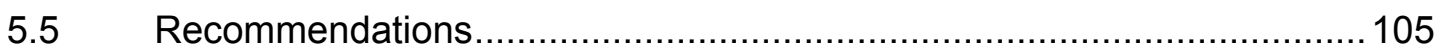

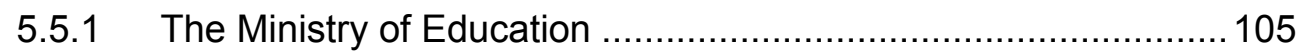

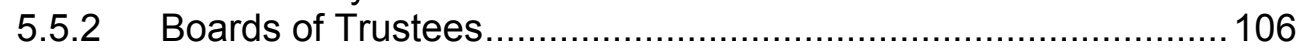

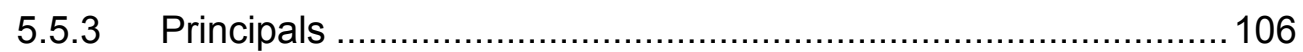

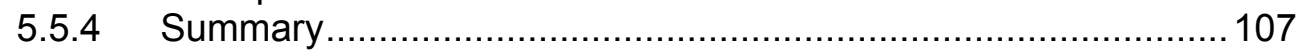

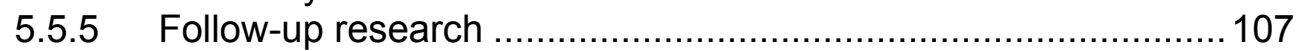

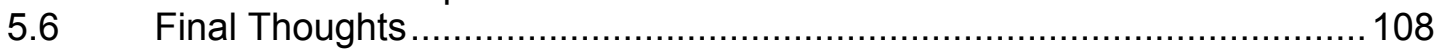

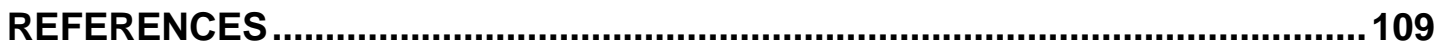


APPENDICES

Appendix A: Letter to accompany survey

Appendix B: Research Project Information Sheet

Appendix C: Principal Survey

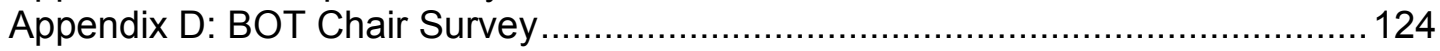

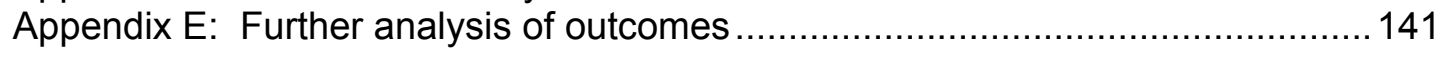

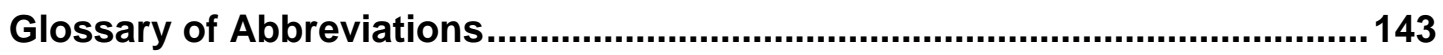




\section{List of Figures}

Figure 4.1: Distribution of principal and chair responses compared to MOE decile data for region

Figure 4.2: Distribution of schools by number of students in comparison with MOE data for the region which includes schools in the sample

Figure 4.3: Ideal qualities an appraiser should possess as identified by principals and chairs 53

Figure 4.4: Chair self-ratings of their qualities as an appraiser (CA and CE) .......54

Figure 4.5: Training and experience of chairs .............................................. 55

Figure 4.6: Sources of appraisal evidence from principals .................................60

Figure 4.7: Sources of appraisal data from primary chairs ..............................6 61

Figure 4.8: Sources of appraisal data from secondary chairs ..........................62 62

Figure 4.9: Dissemination of appraisal report from principal data........................64

Figure 4.10: Dissemination of appraisal report from chair data ............................65

Figure 4.11: Comparison of matched principal and chair ratings ..........................76

\section{List of Excerpts}

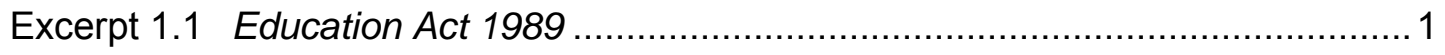

Excerpt 4.1: Good Practice Framework, MOE, 2007 ...................................... 48

Excerpt 4.2: Good Practices in Principals' Appraisal, ERO, 2002 ......................... 52

Excerpt 4.3: Good Practice Framework, MOE, 2007 ........................................ 56

Excerpt 4.4: Good Practice Framework, MOE, 2007 ........................................59

Excerpt 4.5: Good Practice Framework, MOE, 2007 .........................................63 


\section{List of Tables}

Table 4.1: Response rates for questionnaire 45

Table 4.2: Length of time as principal of current school .....

Table 4.3: Length of time as chair of current board ....................................... 48

Table 4.4: Choice of appraiser from principal and chair data .............................49

Table 4.5: Selection of appraiser: primary principal responses ..........................51

Table 4.6: Selection of appraiser: secondary principal responses .....................51

Table 4.7: $\quad$ Ratings for appraiser possessing important appraisal qualities based on up to three qualities identified by each respondent .....

Table 4.8: Links between performance agreement and key documentation

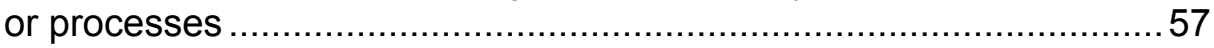

Table 4.9: Chair responses on frequency of meetings .................................... 58

Table 4.10: Principal responses on frequency of meetings ................................5 59

Table 4.11: Principals with EA/EC appraiser responses on frequency of meetings

Table 4.12: Whether principal present at board discussion of appraisal outcomes

Table 4.13: Distribution of ratings for appraisal process link with strengthened relationships

Table 4.14: Distribution of ratings for appraisal process link with school goals ......68

Table 4.15: Distribution of ratings for appraisal process link with principal strengths.

Table 4.16: Distribution of ratings for appraisal process link with principal performance improvement.

Table 4.17: Distribution of ratings for appraisal process link with principal professional development

Table 4.18: Distribution of ratings for link between appraisal and principal job satisfaction.

Table 4.19: Distribution of ratings for time spent on the appraisal being worthwhile.

Table 4.20: Distribution of ratings for cost effectiveness of EA involvement

Table 4.21: Distribution of ratings for confidence level of chairs undertaking the appraisal

Table 4.22: Coding framework for reflections on the appraisal ...........................78

Table 4.23: Coding of most satisfying aspects of the appraisal ...........................79

Table 4.24: Coding of least satisfying aspects of the appraisal............................ 82

Table 4.25: Coding of suggestions for improvement ......................................... 85

Table 5.1 Profiles of satisfying and unsatisfying appraisals ........................... 103 


\section{CHAPTER 1: INTRODUCTION}

\subsection{A Cautionary Tale}

"I won't be completing your survey" said the Principal as he showed me into his office and invited me to sit down. Our meeting, which had been arranged before my survey was sent out, was not related to appraisal and I had not planned to discuss it but he was keen to explain his reasons. He told me that the appraisal carried out by a committee of the board in 2006 had been his "worst experience in 30 years of teaching," hence his reluctance to even reflect back on that experience in order to complete the survey. He now had a largely new board, was developing good working relationships, and was keen to put the events of the previous year behind him.

\section{The Education Act 1989: Sections 75 and 76}

A school's board has complete discretion to control the management of the school as it thinks fit;

A school's principal is the board's chief executive in relation to the school's control and management and has complete discretion to manage as the principal thinks fit the school's day to day administration.

\section{Excerpt 1.1 Education Act 1989}

The Education Act clauses in Excerpt 1.1 above, which provided the legal framework for the Tomorrow's Schools reforms (Government of New Zealand, 1988), have been much debated in the ensuing years. "Boards govern, principals manage" is a widely accepted summation, although the precise nature of the relationship will depend on the specific context, including the size and location of the school and the background, experience and expectations of those involved. As part of its governance role, the board of trustees (BOT) is responsible for the outcomes of the principal's management of the school. A failure to provide a safe learning environment or quality teaching will result in a reprimand for the board by the Education Review Office (ERO). Evaluating the performance of the principal is therefore a vital process for the BOT, making it essential that an effective, but fair, appraisal is carried out and reported to the board. 
The "worst experience" cited above is a more extreme example than any described by respondents to this survey. However, the literature suggests this example of "appraisal that has gone wrong" is not an isolated one (Piggot-Irvine \& Cardno, 2005, p. 95). This research aimed to provide a description of how the performance of principals in a group of schools was appraised in 2006 in order to gain insights into what made it a positive or negative experience for both principals and chairs. It also sought to identify factors that would make the appraisal more satisfying for its participants.

The introduction of mandated requirements for teacher and principal appraisal in New Zealand in the 1990s was influenced by developments in other parts of the world, particularly the UK. Comparisons with the developments in England and Wales, and also in Canada and Australia, will be made in Chapter 2. Chapter 3 sets out the methodology used in this research; the results are analysed in Chapter 4 and discussed in Chapter 5.

\subsection{Context for the Research}

\subsubsection{The introduction of legislative requirements}

The school self-management introduced by New Zealand's 1989 education reforms has resulted in a system of state school administration that is unique in the world. Every three years parents and caregivers of students in each school community elect between three and seven representatives to their school's BOT. A staff trustee is elected at the same time by school employees. In secondary schools a student trustee is elected annually to serve for one year.

The BOT of each state and integrated school is the employer of its staff, although the terms and conditions of employment, including pay, are determined by nationally negotiated collective agreements. Responsibility for personnel matters is largely delegated to the principal, with trustee involvement occurring in line with the board's policies and procedures. As well as being an employee of the BOT, the principal is a member of the board by virtue of his or her position. The principal's role is a complex and multi-faceted one, combining professional leadership of the school with chief executive. However the BOT, through its charter, is accountable for ensuring the curriculum is delivered in a safe environment by competent teachers. 
In 1995 ERO (ERO, p. 24) concluded that "managing staff performance in schools is fundamental to the delivery of high quality education." At that time the requirements for performance management in schools were implied rather than specific. National Administration Guideline 2, issued in 1993 as part of the National Education Guidelines, required boards to "promote high levels of staff performance" (MOE, 1993, p. 20). The State Sector Act 1988 also required BOT as good employers to ensure "opportunities for the enhancement of the abilities of individual employees" (Sec 79, 2e). However, many schools had yet to implement performance appraisal. A 1992 survey of Auckland and Northland secondary schools showed only $35 \%$ had formal appraisal systems (Peer \& Inkson, as cited in Timperley \& Robinson, 1996, p. 22). In ERO's opinion, many boards needed clearer direction about managing staff performance.

The State Sector Act (1988, Sec. 77c) contained the provision for the Secretary for Education to "prescribe matters that are to be taken into account by employers in assessing the performance of teachers". This provided the basis for the 1995 Draft National Guidelines for Performance Management in Schools. I was involved as a facilitator in the consultation process which saw these introduced to schools. The draft has been criticised as being too "loose and open ended for schools" (Piggot-Irvine \& Cardno, 2005, p. 40). My own recollection, as part of a team brought together by the Ministry of Education (MOE) to develop the wording for the subsequent Performance Management in Schools (PMS) regulations, was that the draft was seen as too prescriptive. This view is based on the reactions of principals and teachers attending workshops on the draft that I was involved in facilitating. The fact that the 39 page draft was distilled down to a single page of "minimum requirements for the appraisal and assessment of teachers" would seem to support this view (MOE, 1997a, p. 2).

The PMS framework allowed boards the flexibility to "design performance appraisal systems appropriate to their school and community" (MOE, 1997b, p. 1). It is noteworthy that MOE documentation and advice to schools (and as a result schools' documentation) has tended to use the terms performance management, appraisal and assessment interchangeably from this point.

Responsibility for carrying out teacher appraisal must be delegated to a "competent person or persons" (MOE, 1997a, p.2). Principals are included in the Education Act definition of teacher and in this instance it is the board itself that is responsible for ensuring that a staff member is appraised. 
The focus of the PMS requirements was on appraisal for professional growth and development and incorporated these key features:

- identification of an appraiser in consultation with the appraisee;

- a performance agreement that included at least one development objective for which the employer would provide requisite support;

- annual appraisal against the requirements of the position;

- $\quad$ self-appraisal; and

- an appraisal interview and report (MOE, 1997a).

The emphasis changed as a result of the 1998/9 Collective Employment Contract (CEC) negotiations between the MOE and the teacher unions (the New Zealand Education Institute [NZEI] representing the primary sector and the Post Primary Teachers' Association [PPTA] the secondary teaching profession). These resulted in the introduction of Interim Professional Standards for principals, deputy and assistant principals, and teachers which the MOE advised were to be incorporated into schools' performance management systems (PMS) from 1999 (MOE, 1998). Standards for principals were listed under six dimensions: ${ }^{1}$ professional leadership, strategic, staff and relationship management, finance and asset management, statutory and reporting requirements (MOE, 1999). Boards were advised they must ensure the principal's performance agreement reflected all aspects of the Professional Standards (MOE, 1999).

Piggot-Irvine and Cardno (2005) have noted that "a system of appraisal is intended to benefit those who are already competent" (p. 18). Professional standards introduced a requirement for competency to be demonstrated annually, ratcheting up the "minimum" requirements of PMS. The standards have been criticized for increasing MOE control (Fitzgerald, Youngs, \& Grootenboer, 2003). Stewart (2000) sees the appraisal process as an example of the contradictions inherent in decentralised control of schools. Policy introduced ostensibly to increase school effectiveness constrains self-management. The flaw, as Stewart sees it, is in imposing an "industrial model" of thinking about a school rather than viewing it as a "learning community" (p. 9).

1 Primary Principal Standards were revised and reduced to four dimensions in July 2008 as part of collective employment agreement negotiations between MOE and NZEI. 
The professional standards were introduced towards the end of a major MOE focus on school performance management and the development of the appraisal skills of participants in the process. A culmination of these initiatives was the commissioning of a literature review by Fullan and Mascall from the University of Toronto. Human Resource Issues in Education proposed a model for human resource development that put "the Learning Profession at the heart of...a teaching and principal force capable of learning on a continuous basis" (Fullan \& Mascall, 2000, p. 3). This model reflected the emphasis in policies developed during the first decade of the $21^{\text {st }}$ century on the role of the principal as the leader of learning, with a corresponding downplaying of the manager/administrator element of the role. It is an interesting distinction when the responsibility for principal appraisal rests with a largely lay body more likely to have personal experience of management and administration than the leading of learning.

In my experience of working with BOT for over 17 years, the responsibility for ensuring principals are appraised has typically been delegated to the chair ${ }^{2}$ or a personnel committee of the board. They may conduct the appraisal themselves or involve an outside agent for all or part of the process. Consultants, with varying degrees of understanding of the principal's role, provide appraisal services which range from undertaking the full appraisal on the board's behalf to providing advice on a board led process (Piggot-Irvine \& Cardno, 2005). Anecdotal evidence suggests this has led to a wide variety of practice, ranging from the highly effective to the merely compliant - a case of "going through the motions". However, little descriptive information of the processes used, and the attitudes and opinions principals and chairs have of these, has been available.

\subsubsection{Advice and guidance for BOT on principal appraisal}

A large amount of information directed at BOT is sent to schools, published in the fortnightly Education Gazette and put on websites such as Te Kete Ipurangi (www.tki.org.nz) and Education Counts (www.educationcounts.govt.nz). It would be unrealistic to assume that this information reaches the chair, let alone all trustees. Added to this, requirements for principal appraisal were first introduced in 1996 making it unlikely that resources distributed up to a decade ago will be readily available to new board chairs. It is often up to chairs to track down hard copies or surf the net for on-line versions. This summary of the key sources of guidance

\footnotetext{
${ }^{2}$ The role will be referred to as chair but the terms chairman or chairperson are also in usage.
} 
focuses in particular on who should appraise, the basis for the performance agreement, and reporting on the appraisal.

\subsubsection{Ministry resources}

PMS requirements, 1996

After being officially gazetted, these regulations were published in the Education Gazette of 10 February 1997.

\section{PMS Guidelines Series 1 - 5, 1997}

Distributed with the Education Gazette and since made available on the MOE website, these expanded the PMS requirements for different audiences and provided practical examples. The MOE commissioned practitioners delivering Teacher Appraisal Skills contracts to research and write these (I compiled PMS5 on the appraisal of teachers with specialist responsibilities). The series included two issues specifically related to principal appraisal. Their usefulness is limited because they pre-date the introduction of Professional Standards. It is also not known how successful this distribution method was for reaching trustees.

- PMS 2: Issues for Rural Schools and Small Schools with Teaching Principals, March 1997

Boards were advised to consider involving a consultant every second or third year and/or combine with other schools to contract a consultant to conduct appraisals for the cluster. The many demands on a teaching principal's time need to be taken into account in setting objectives and planning for appraisals. It is noted that "a summary report is recorded" but does not give details (MOE, 1997c, p. 6).

\section{- $\quad$ PMS 3: Appraisal of the Principal, May 1997}

The importance of the principal/board chair relationship in effective appraisal is stressed, although others may be involved in or contribute to the appraisal. Selectively focusing on different aspects of the principal's management and leadership role each year is suggested as a way of making the process manageable. A similar approach is suggested for setting expectations in relation to school development and personal professional development. A brief report on the appraisal outcomes, approved by the principal and chair, "could be tabled and discussed (in committee ${ }^{3}$ ) at a board meeting" (MOE, 1997d, p. 9).

\footnotetext{
${ }^{3}$ Section of the meeting from which the public are excluded and which is minuted separately.
} 
Principal Performance Management, 1999

A 41 page resource for boards of trustees and principals outlining MOE expectations for the integration of Professional Standards with PMS. It notes that school Operating Grants have been increased by $\$ 845$ plus GST to enable an outside consultant to be used. The board's overall responsibility for the process is stressed and suggestions for the consultant's role include: training the board, identifying professional development and "providing one-to-one management training for the principal" (MOE, 1999, p. 10). Sample performance agreements and indicators are included based on job descriptions, professional standards, performance objectives and development objectives. Any discussion of the appraisal by the board should be in-committee and focused on process and outcomes.

\subsubsection{New Zealand School Trustees Association (NZSTA) Guidelines for Boards of Trustees}

The Management of the Principal by the School Board of Trustees, 1999

Managing Principal Appraisal, (2 ${ }^{\text {nd }}$ edition), 2005

The second edition provides a detailed examination of the requirements for appraisal, some of the issues it raises, and suggestions for carrying out the process. In discussing the question of employing a consultant, NZSTA notes the appraisal of the board's chief executive has both formative and summative aspects. It discourages the practice of the principal identifying a neighbouring principal to undertake the appraisal. The notion of principals as appraisers is not ruled out but "any practising Principal should demonstrate 'best practice' or near to it" (NZSTA, 2005, p. 14). Best practice is not defined but a flow chart for the appraisal is included, setting out the steps it should follow. Boards using a consultant are encouraged to work with them in order to learn from the experience. It is recommended the whole board be involved in drafting a "broad outline performance document" (p. 11) which is finalised with the principal before presentation to the board for approval. The principal should absent him/herself from the meeting during board discussion on the agreement. A manageable number of objectives should be related to school improvement. It is suggested boards give thought to what constitutes good performance in order to develop indicators. NZSTA states the final report should go to the full board in committee. 
In addition to the above resources NZSTA:

- is contracted by the MOE to provide industrial advice to boards in relation to any personnel matters;

- has an MOE contract to deliver free training and support to boards in some areas; and

- delivers cost-recovery training and support throughout the country including workshops on principal appraisal.

\subsubsection{Education Review Office}

Good Practices in Principals' Appraisal, June 2002

This is part of ERO's series of National Reports that draw on evaluations of individual schools. The pros and cons of internal/external appraiser are discussed with guidelines included for employing a consultant. Evidence of experience and qualities to look for are listed. Text boxes contain actual examples and reinforce the importance of getting the right person. Alternative approaches, such as "principal portfolios" (Stewart, as cited in Education Review Office, 2002) and panels of principals engaging in collaborative appraisal processes are also outlined. The following are listed as elements that should be included in an agreed, countersigned and dated annual performance agreement:

(i) a purpose statement and the school's mission statement;

(ii) a context statement;

(iii) the period the agreement is to cover;

(iv) a disputes resolution process;

(v) the professional standards for principals;

(vi) performance objectives linked to the strategic plan and other short-term board priorities;

(vii) development objectives; and

(viii) a job description. (ERO, 2002, p. 3)

Minuted reporting to the board should provide a summary of the appraisal process and key findings. ERO concludes that "good practice" schools have moved beyond compliance, actively review and refine appraisal to suit their context and use it as "one of many tools contributing to school improvement" (Education Review Office, 2002, p. 16).

\subsubsection{Practical training and support}

The MOE lets contestable contracts for board training and support (BTAS) that provide for whole board, individual trustee, cluster and workshop delivery, prioritised for use with at-risk boards. There are currently three providers covering the country: 
NZSTA, Multiserve Cognition Trust and Victoria University of Wellington (VUW). I am the BTAS Project Director for VUW.

The philosophy underpinning all VUW trustee training is that the governance/ management partnership is unique in each school and needs to be discussed and negotiated so that there is a shared understanding of how it works in that context. A two-and-a-half hour Principal Appraisal workshop is offered several times a year as well as more generic content coverage in The Role of the Chair workshops. Individual trustees, usually chairs, are also given advice and guidance on principal appraisal. Workshop participants develop an action plan for appraisal, using a template provided. The pros and cons of various choices of appraiser are considered and handouts include a copy of ERO's good practice checklist and choosing a consultant guidelines (Education Review Office, 2002).

Chairs are encouraged to consider the merits of alternating appraisal by a consultant with appraisal by the chair. The experience of working with an external appraiser can be a valuable learning opportunity for an inexperienced chair, providing a model to follow once they become more confident in their role. Involving another trustee in the process helps ensure the knowledge is shared and is useful in succession planning for the chair role. Chairs also contact me when seeking an external appraiser and a list, which has been compiled in conjunction with stakeholder groups, is supplied. The list provides no guarantee about the quality of the service, only that those named are known to have had experience of principal appraisal.

A slide/handout illustrates the way the performance agreement incorporates government priorities for education, the board's priorities as expressed in its strategic plan, and the principal's own development needs. Reporting to the BOT is handled by exploring what currently happens, and whether it is effective. If little information is going to the board, trustees are encouraged to explore the reasons. The emphasis is on encouraging an open and transparent process that allows trustees to contribute to the drafting of the performance agreement, be aware of the outcome of the appraisal, and have an opportunity to discuss reporting on the appraisal. 


\subsubsection{A collaborative development:}

Managing Principal Appraisal (Performance Review) - Good Practice Framework (GPF), Ministry of Education, 2007

During 2007 the MOE brought together experts and stakeholders to develop a framework for principal appraisal that reflected legislative requirements and good practice. As well as proving an invaluable resource for trustee training and support, this timely document has provided a benchmark for evaluating the findings of this research and determining the extent to which "good practice" is a reality. Its usefulness to date may have been restricted by its limited distribution. It is available on the NZSTA website but eighteen trustees attending VUW chair and principal appraisal related training in March and April 2008 were unaware of its existence.

Earlier advice to boards has been criticised for focusing too much on process and not enough on the ethical issues of principal appraisal (Edwards, 2001). For instance:

- Whose meanings and whose values should drive the principals' appraisal process?

- How open should the process be?

- What level of involvement should be available for all members of the governing body? (Edwards, 2001, p. 65).

By emphasising the importance of consultation and fairness in a documented and negotiated process, the GPF goes some way to reinforcing the values and "notion of natural justice" espoused by Edwards (2001, p. 65) but it does not really address the questions he raises. In my experience these are rarely discussed until issues arise which threaten the trust and respect necessary for effective governance/management partnerships.

\subsection{The Significance of this Study}

This study is intended to provide insights into the way in which legislative requirements were implemented in one region of New Zealand in 2006. The release of the GPF after the survey had been conducted, but before the results were fully analysed, has enabled espoused good practice to be used to benchmark actual practice. The findings therefore provide interesting insights for policy makers into any gaps between regulation and implementation and identify factors which may need to be addressed in order for appraisal to be as effective a tool as it is intended to be. 


\section{CHAPTER 2: PRINCIPAL APPRAISAL}

This chapter defines key terminology, reviews theory, research and policy development in appraisal and considers the implications for the education sector. After looking at general international trends in teacher and principal appraisal, the experience of English speaking education systems with varying degrees of school self-management (England and Wales, Australia and Canada) are explored:

\subsection{Performance Appraisal}

\subsubsection{Origins and terminology}

Performance appraisal emerged in the 1970s from the foundations of management by objectives (MBO) (James \& Colebourne, 2004). A 1989 OECD report defined appraisal as the "forming of qualitative judgments about an activity, a person or an organisation" (p. 98). However, Coens and Jenkins (2000) stress that appraisal focuses on the performance of the individual rather than that of the organisation. According to the OECD definition, where appraisal is of an individual it is based on an assumption of competency: in other words that the appraisee is capable of satisfactory performance. Assessment, which is often used synonymously with appraisal (Piggot-Irvine \& Cardno, 2005), implies the use of measurement and/or grading based on known criteria, against which the individual's competence is determined (OECD, 1989). Additional features distinguishing appraisal from other organisational development tools include it being:

a mandated process in which, for a specified period of time, all or a group of employees' work performance, behaviours, or traits are individually rated, judged, or described by a person other than the rated employee and the results are kept by the organisation. (Coens \& Jenkins, 2000, p. 14)

Although performance management (PM) is also used interchangeably with appraisal, $\mathrm{PM}$ is more accurately the umbrella term for a range of personnel management policies that include the recruitment, appointment, professional development and discipline of staff as well as their appraisal (MOE, 1997b). Piggot-Irvine and Cardno (2005) use PM in this sense, defining it as "an integrated and diverse set of organisational activities that are aimed at achieving strategic organisational aims" (p. 20). Other sources take a different perspective: for example a 2000 review of PM in the UK suggested that appraisal was out of favour "because it implied looking back, whereas the emphasis in performance management is on the future" (Middlewood, 2001, p. 188). 
Other terms used in the sense of appraisal include:

- Evaluation, for instance in multiple sources cited in Sinnema and Robinson (2007). Determining desired competencies is the first of three steps in a definition of evaluation by Harris and Monk (as cited in Thomas, Holdaway, \& Ward, 2000). Further steps describe performance in terms of these competencies and make a judgement based on the fit between competencies and performance. Together, these steps form what could be seen as key components of an appraisal process.

- Review as in performance review is used in New Zealand principals' collective employment agreements and in recent MOE Good Practice Guidelines on principal appraisal (2007a). Review meeting is sometimes used in reference to the meeting to discuss the outcomes of the appraisal process.

Whilst different terminology is used in the complex process of making judgements about employee performance, the term appraisal will be used in this description except where a source is quoted directly. Characteristics of appraisal include selfassessment and the identification of the individual's development needs. Ideally the employee is actively engaged in the process, drawing on "a wide range of knowledge of various forms including contextual knowledge" in order to reflect on their practice and how it might be improved (Eraut, as cited in James \& Colebourne, 2004 , p. 46). The process is aided by the initial setting of targets or standards against which performance can be measured.

\subsubsection{Effective practice}

Through describing appraisal practice, this research aims to determine the extent to which it is perceived by participants as being effective, that is "having an intended or expected effect" (http://www.thefreedictionary.com). Effective outcomes of the appraisal can be seen on two levels: firstly, whether the process went well (contained expected elements, provided feedback and so on); and, secondly whether principal performance contributed to improved school performance. The latter is much harder to determine and depends not only on what data are gathered and the means of gathering data but "on the standards by which the judgements are made" (Stewart, 2000, p. 56). 
Although examples of best practice can be found in human resource literature, there is a tendency towards "one size fits all" models of performance appraisal that fail to take account of context (Simmons \& Iles, 2001, p. 8). Bowles and Coates (as cited in James \& Colebourne, 2004) note that the need to consider context is one of the factors which make appraisal of performance so challenging and complex. The importance of "practical diversity" that takes context into account has been identified in reports of varyingly successful practice in school appraisals in Australia, New Zealand, Canada and the United Kingdom (Thomas et al., 2000, p. 221). The significance of cultural context was also highlighted in a study of over 300 appraisal systems which concluded that:

\footnotetext{
There is no such thing as the perfect performance review system. None are infallible, although some are more fallible than others. The relative success or failure of performance review ... depends very much upon the attitudinal response it arouses. (Long, as cited in Bush \& Middlewood, 2005, p. 173)
}

Gaining stakeholder input into developing performance objectives and designing evaluation measures has been shown to contribute to system effectiveness (Winstanley \& Stewart-Smith, as cited in Simmons \& Iles, 2001). Bush and Middlewood (2005) viewed staff empowerment as a valid alternative to an hierarchical approach. Crowther, Kaagan, Ferguson and Hann (cited in Bush \& Middlewood, 2005) suggested that employee empowerment is central to the concept of a learning organisation. Essentially though, appraisal is a compulsory process. The extent to which something that is mandated can enhance motivation is questionable. Taking the relationship for granted and assuming one follows the other can compromise the effectiveness of appraisal outcomes (Coens \& Jenkins, 2000).

Management literature identifies a number of theories of motivation including process theories which concentrate on the influence of the effort individuals put into tasks. Management by objectives (MBO), a foundation stone for appraisal, stresses the motivating effect of goal setting (Drucker, 1954). Adam's Equity theory is based on individuals weighing up their own effort and reward in comparison to others (Gilbert, 1995). Significantly for schools as organisations, a sense of community spirit has been identified as a "fundamental prerequisite to developing the capacity for change in individuals, institutions or societies" (Hallinger, 1997, p. 29).

Content theories relate to the needs of the individual. Herzberg, Mausner and Synderman's (1993) motivation-hygiene theory of job attitudes uncovered a 
somewhat counterintuitive force behind motivation: "the opposite of job satisfaction is not job dissatisfaction but, rather, no job satisfaction; and similarly, the opposite of job dissatisfaction is not job satisfaction, but no job dissatisfaction" (Herzberg, 2003, p. 6). The theory distinguishes between extrinsic hygiene factors, which are satisfying but not motivating, and intrinsic motivating agents which, if present, contribute to both job satisfaction and motivation. Herzberg suggested motivation cannot be nurtured in an environment which lacks adequate extrinsic rewards. Furthermore, a satisfying job-environment is a prerequisite for motivation but cannot in itself produce motivation. Motivation relies on intrinsic rewards provided by the job content, prompting a need for jobs to be "enriched" to provide opportunity for personal growth (Gilbert, 1995).

In a school context, examples of the hygiene factors would include board policy, salary, relationships and status whilst motivating agents would be related to recognition and personal growth, as well as the work setting and job responsibilities. The role of a school principal is certainly varied but whether appraisal helps provide intrinsic motivation for experienced practitioners, through affirmation and support for professional development, may be debatable.

A review of the performance management systems operating in three very different types of organisations in the UK (Toyota UK Ltd, Derbyshire Building Society, Royal Air Force) suggested a blend of factors is important for effective appraisal (Crane, 2005). The report concluded that effective processes cannot be developed in isolation but must be "an integral part of quality assurance, support and training throughout the organisation" (p. 27). Crane also found a correlation between staff with high levels of intrinsic motivation using their initiative and aspiring for high quality in their work and "organisations with relationships based on mutual respect, collaboration and consultation" (p. 27).

\subsubsection{Appraisal in education}

The link between economic prosperity and an educated workforce has been a driver in moves to hold teachers accountable for the quality of their teaching (Middlewood \& Cardno, 2001). It is therefore not surprising that governments have looked to the world of business and industry for models of managing teacher performance, including the notion of linking pay and performance. However, faith that this would provide the answers may have been misplaced. A 2001 OECD research report 
concluded appraisal was "not working effectively in many schools" (as cited in Mulford, 2003, p. 10). It noted that strengthened links between appraisal and remuneration, as has occurred in the UK, may not be the solution. The report was critical of the tendency for education systems to "mandate improvement in the school system" leading to initiatives that peter out within a few years (Hargreaves, Early, Moore \& Manning, as cited in Harris, 2005, p. 417).

Processes for making judgements about employee performance can have a range of purposes including "selection and advancement, control, accountability, ensuring the achievement of organisational goals, and professional development" (Duke, as cited in Mongan, 1999, p. 3).

James and Colebourne (2004) identify three key purposes:

a) accountability - the linking of individual performance to the achievement of organisational goals;

b) developmental - increasing the skills, abilities and competencies that will lift performance; and

c) strategic - requiring the management of the organisation to own and integrate the process into its practice.

Conflicting drivers for appraisal is a recurring theme and one which often lies behind revision of regulations. The introduction of appraisal in education systems has been characterised by a tension between appraisal for accountability and for professional growth and development. West-Burnham (2001) saw the roots of 1990s UK appraisal policy as formative, and linked to professional development. Bush and Middlewood (2005, p. 174) also see the "underpinning function" of appraisal as formative, that is providing practitioners with feedback that enables them to further develop their practice. The authors perceive an element of anti-professionalism inherent in "imposed schemes" (p. 175) as opposed to mechanisms enabling employees to identify areas for improvement within their own particular context.

A useful strategy for reconciling dual purpose is to view development and accountability as two ends of a continuum (Middlewood \& Cardno, 2001). If obstacles to reconciliation are confronted, discussed and addressed, then performance appraisal can contribute meaningfully to achievement of the school's strategic objectives, including enhanced student achievement. Middlewood and Cardno also suggest effective performance appraisal is predicated upon there being 
an "ethos of trust" (2001, p. 135). Cardno's subsequent work with Piggot-Irvine (2005) concluded that a supportive and constructive environment is the best context for teaching, learning and professional growth. Strategies for building such a climate include fostering openness, honesty, and equity of opportunities (PiggotIrvine \& Cardno, 2005). These qualities might be seen as at odds with frameworks based on legal prescription. Indeed critics of PM processes in schools point out that they have more to do with conformity and control than improved educational quality (Eunson, Wright, as cited in Mongan, 1999). This view is supported by the fact teachers must be assessed for registration, evaluated against professional standards, and attested for pay progression as well as having their performance appraised (Fitzgerald, Youngs, \& Grootenboer, 2003).

A tool to assist with understanding the developmental/accountability, or formative/summative tension in teacher appraisal was developed in earlier work of mine (Chapman, 2000) and is illustrated in Figures 2..1 and 2.2.

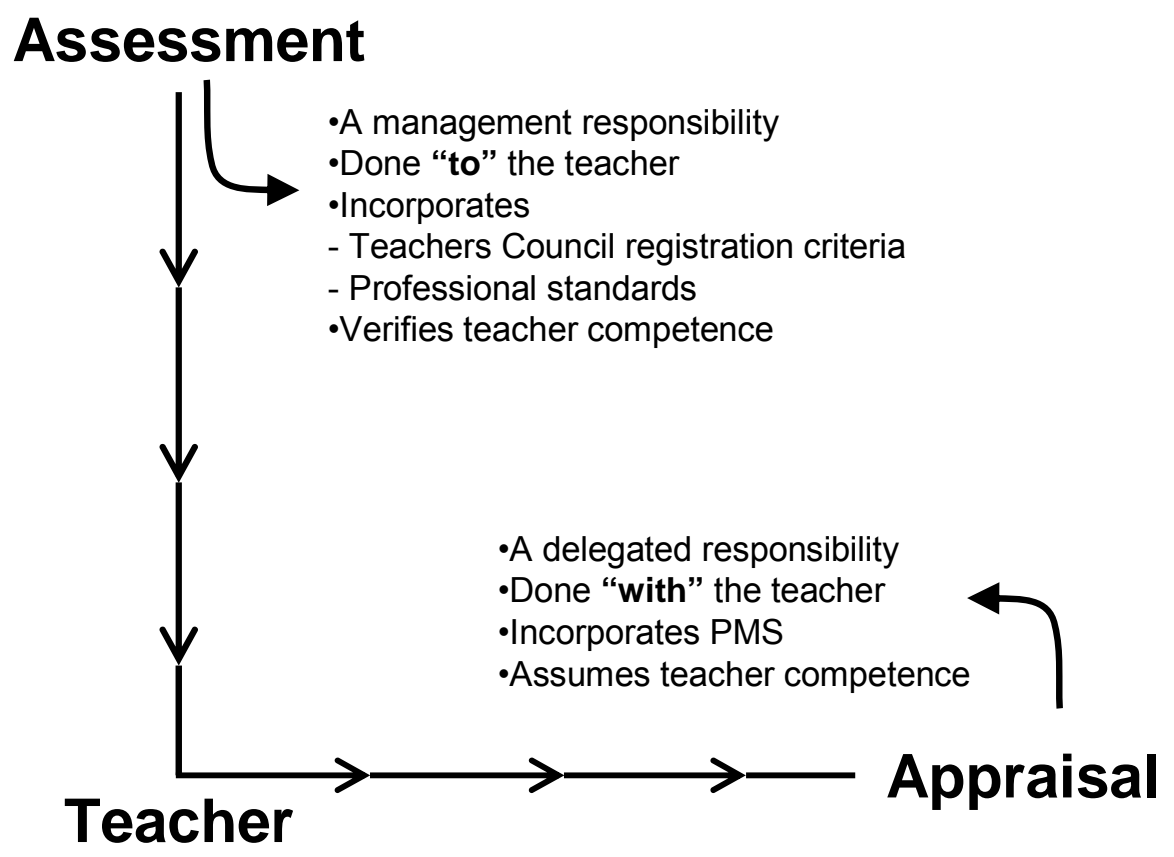

Figure 2.1. Teacher Appraisal vs. Teacher Assessment

In Figure 2.1 the horizontal axis represents an open-ended or formative appraisal process undertaken with the teacher whilst the vertical axis represents summative, "top down" assessment that is done to the teacher. The model illustrates Middlewood and Cardno's finding that appraisal in the New Zealand school sector is required to "serve several purposes simultaneously" (2001, p. 6). 


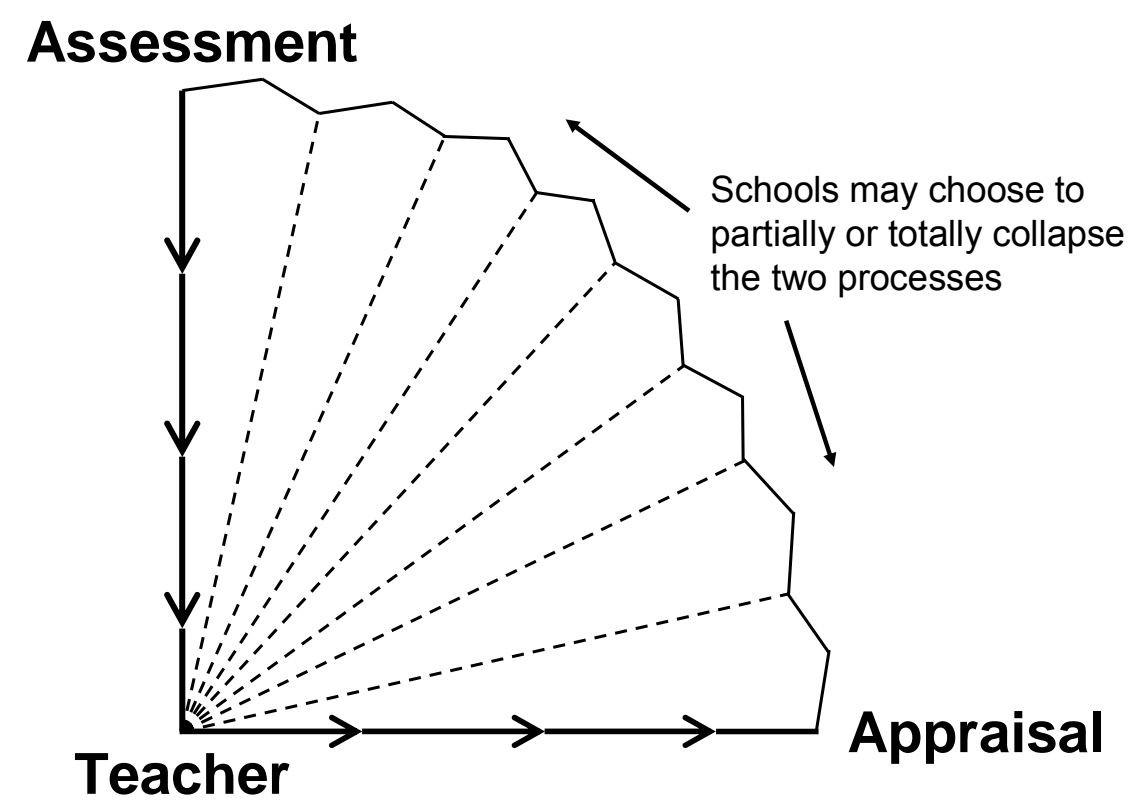

Figure 2.2. The 'Fan Model' of Teacher Appraisal/Assessment

Figure 2.2. shows that when closed up like a paper fan, it looks like a single process; opened, it is possible to see that the two structures are joined by fragile folds of paper. Whilst these hold together the fan/appraisal system functions well but if too much pressure is put on one side/axis, the paper tears and functionality is destroyed. An example would be the link, through attestation (signed confirmation by the principal that professional standards at the appropriate level have been met) to remuneration. This does not sit comfortably with a formative and developmental model of appraisal. It has been suggested that aspects such as performance pay and progression belong "in an entirely different system from appraisal and there should be separate procedures within schools for such decision-making" (Piggot-Irvine \& Cardno, 2005, p. 14). The MOE directive to integrate professional standards, which are linked to pay progression, into processes which had been designed with a developmental imperative, has been seen as cementing accountability as the prime role of appraisal in New Zealand schools. (Piggot-Irvine \& Cardno, 2005).

Middlewood and Cardno (2001) identified three contextual factors impacting on the relationship between developmental and summative drivers: culture and tradition, previous history of teacher appraisal, and political imperatives. From an employee's perspective there are also three factors that underline the importance of relating management of performance to professional development:

- knowing what is required to be done;

- receiving guidance, support and challenge when required; and

- receiving regular feedback about progress and achievement (Middlewood \& Cardno, 2001, p. 13). 
This section has identified and defined terminology related to appraisal and identified factors around the notion of effectiveness. It has also begun to explore issues around context and purpose impacting on appraisal in schools. A review of the literature on the appraisal of managers concluded that it "is one of the most difficult areas of human resource management," particularly in the public sector where there is limited control over achieved outputs (Mongan, 1999, p. 3). It could be seen to be even more of a challenge in schools, where leadership success is dependent upon the achievement outcomes of students. Issues around principal appraisal are further explored in the following section.

\subsubsection{Principal appraisal}

The New Zealand Good Practice Framework (Ministry of Education, 2007a) acknowledges that principal appraisal has a dual purpose:

- Accountability - of the principal for leading and managing the school, achieving agreed goals, and ensuring the quality of teaching and learning.

- Development - of the principal against agreed goals, and to ensure the development of the school and the ongoing improvement of student achievement.

Professional development in the context of school leadership has been defined as “learning opportunities that engage educators' creative, critical and reflective capacities" and which lead to strengthening their own and other educators' practice (Kochan, Bredeson, \& Riehl, 2002, p. 291). Targeted, relevant professional development is vital for engaging school leaders' "critical and reflective capacities" resulting in the strengthening of practice (Kochan et al., p. 3). An effective appraisal system not only identifies areas which would benefit from development, it goes a step further by making "suggestions about how this can occur and be supported" (Middlewood \& Cardno, 2001, p. 13). The latter may be a considerable challenge for New Zealand's lay BOT members.

A number of studies have failed to find specific research on the effectiveness and impact of any type of principal appraisal (Dempster \& Lindsey, as cited in Jericho, 2004). A survey of UK headteachers found many felt their appraisal experience compared unfavourably to what they understood to be "best practice" in industry and commerce (Hancock \& Hellawell, 1998, p. 265). However, just what constitutes best practice is unclear. Ginsberg and Thomson (as cited in Thomas et al., 2000 p. 216) 
concluded that "research on principal evaluation emphasizes the lack of empirically supported information about best practices". A more recent study of principal evaluation instruments concluded that investigation of principal performance assessment in the literature was limited (Catano \& Stronge, 2007). The authors also noted that principal appraisal is made more challenging when there is a lack of clear agreement as to what the role entails.

Thomas et al. (2000, pp. 4-5) note the development of differing approaches to principal appraisal:

- input or job description focused, identifying what the principal is expected to do;

- competency based, related to the principal's skills and personal qualities;

- outcomes or results based, identifying what will happen as a result of what the principal does, particularly in terms of improved student achievement;

- best practice approach, linked to research-based findings on the links between the principal's role and school effectiveness.

The latter highlights an issue raised by West-Burnham (2001) around the distinction between headship, about which innumerable sets of standards have been developed in different parts of the world, and the more intangible qualities of effective leadership. In 1996 the Interstate School Leaders Licensure Consortium in the US developed six broad standards, each with indicators, for school leaders including non-teaching administrators and district superintendents (Institute for Educational Leadership, 2006). Standard 5 states: "a school administrator is an educational leader who promotes the success of all students by acting with integrity, fairness and in an ethical manner" (p. 23). Although widely used in North America, the standards have been criticised for not making the connection between leadership performance and improved student achievement sufficiently explicit. West-Burnham (2001) suggested qualities such as "emotional intelligence" or "moral confidence," which are particularly difficult to assess through target setting, are essential for transformational school leadership (p. 26).

Of a more positive note are insights into factors that can enhance the appraisal process. For instance, principals are more likely to be committed to, and derive benefit from, appraisal systems when they are involved in the process of developing them (Harrison \& Peterson, as cited in Clayton-Jones, McMahon, Rodwell, Skehan, Bourke \& Holbrook, 1993). Other studies have also concluded that where 
appraisees feel a sense of ownership of the process, they are more likely to see it as effective (Darling-Hammond, and Fontana, as cited in Jericho, 2004). Jericho concluded that "meaningful consultation over the process, clarity of process and a shared trust" are required if both parties' needs are to be met (p. 30). Adequate resourcing is also crucial (Clayton-Jones et al., 1993).

A variety of data are drawn on in principal appraisal with student test scores widely used in the US (Jericho, 2004). The complex nature of the job and its contextspecific demands have suggested the need for a flexible approach to evidence gathering (Piggot-Irvine, 2003). This view was shared by Heck and Marcoulides (1996, p. 26) who advocated "multiple data sources including 'psychometrically sound' observation of performance."

Based on research in the US, Anderson recommended school systems wishing to use principal evaluation for both accountability and development pay attention to the importance of "observation by supervisors" (as cited in Thomas et al., 2000, p. 221). Such a system would present challenges in New Zealand's devolved education system which has no regional authorities. Should observation of leadership and management practice occur in the appraisal, it is likely to be carried out by a peer or a lay BOT member.

Stewart (2000) believed boards want reassurances that in carrying out his or her role, the principal is having a positive effect on outcomes for students. He proposed a conceptual job description as a mechanism for identifying the important aspects of the role which include facilitating "the learning community" and developing school culture (Stewart, 2000, p. 162). Pedagogy and culture are two of the four dimensions in the 2008 revised primary principal professional standards.

A 360 degree appraisal approach sees the appraisee at the centre of a circle, with data on their performance gathered from all directions (U.S. Office of Personnel Management 1994). Challenges to using this approach in principal appraisal include: determining include: determining who should be asked for feedback, the purpose of asking them, and designing questions that can be answered objectively (Piggot-Irvine \& Cardno, 2005). Piggot-Irvine and Cardno suggest that whilst there is a place for surveying parents as part of strategic planning or marketing, principal appraisal is a function of the board's governance role vested in it through the election process and the community does not need to be directly involved. Edwards (2001) 
takes a more open and inclusive approach, proposing the involvement of a wider group of stakeholders. He notes, however, that the principal's privacy must always be a consideration and provides guidelines for considering the ethical concerns in principal appraisal. Confidentiality, and assurances of anonymity can be an issue in obtaining honest feedback from staff. This underlines the need for trust in the integrity of the appraiser. A further issue with staff surveys is an assumption that staff have a "shared understanding of the value of the criteria" (Hampton, 2005, p. 7).

Self-appraisal is the only mandated aspect of evidence gathering that is specified in the New Zealand regulatory framework for appraisal. Clayton-Jones et al. (1993, p. 112) cited multiple sources highlighting the vital importance of self-appraisal in reflective practice. This relates both to "reflection-on-action", or learning from past experience and "reflection-in-action" which involves examination of practice as it occurs (Schön, as cited in Hellawell \& Hancock, 1998). There is strong evidence to suggest effective principals need to be "reflective leaders who are life-long learners" (Southworth, as cited in Stewart, 2000, p. 158). The relationship between effective appraisal and reflective practice warrants further study in its own right.

\subsubsection{Conclusion}

The terminology of performance management may have become "part of the professional language" in New Zealand schools (Fitzgerald et al., 2003, p. 92) but the types and methods of evidence gathering are one aspect of approaches that can differ between individual self-managing schools. Rising public expectations of education are contributing to policy makers seeking to strengthen the link between student achievement and school leadership (Firestone \& Riehl, as cited in Middlewood \& Cardno, 2001; Sinnema \& Robinson, 2007). Determining the nature of the relationship is complex and challenging (Hallinger \& Heck, as cited in Sinnema \& Robinson, 2007). However, creating "high stakes" evaluation processes may not be conducive to nurturing continuous professional growth. The next section examines principal appraisal in different education jurisdictions faced with the challenge of creating appraisal systems that meet political and professional demands. 


\subsection{Appraisal in other Education Systems: Analysis of Different System Approaches}

\subsubsection{The international context}

The moves to decentralise decision making that occurred in education systems in the United Kingdom, New Zealand, Australia and Canada from the late 1980s have been variously attributed to efforts to raise student achievement, cut costs or "appease critical parents and the community" (Voisin, 2003, p. 3). In the 1980s and 1990s new public management (NPM) was seen as the agenda, whilst the emphasis in the new millennium has focused on organisational learning (Mulford, 2003). Critics of decentralisation highlight the flaws of a market driven approach that "assumes an ideal set of responses from school leaders" (Leithwood, 2001, p.48). However, in OECD countries there is now acceptance that schools must be connected to the communities they serve if they are to be effective (Mulford, 2003).

Comparing the New Zealand experience with other jurisdictions is complicated by their context specific nature. This is partly relates to terminology: for instance boards of trustees (New Zealand), boards of governors (England and Wales) and school councils (Australia, Canada) have different powers and responsibilities as well as titles; UK literature refers to headteacher appraisal whereas in the USA it is principal performance evaluation. A further complicating factor in any comparison with the USA is that there principals are largely administrators and do not have the same degree of responsibility for teaching as headteachers in other parts of the world (Cullen, 1997).

Notwithstanding these differences, some comparison is warranted because the introduction of teacher and principal appraisal in New Zealand in the 1990s was heavily influenced by developments in other parts of the world, particularly the UK. An examination of the developments that have occurred in England and Wales may therefore shed light on the characteristics of effective systems, and the challenges faced in implementing them. To further expand the picture, these facets are also explored in Canadian and Australian states, two other Commonwealth education jurisdictions where elements of school self-management exist. An analysis of the way principal appraisal works in these systems provides a point of comparison with the New Zealand experience. 


\subsubsection{England and Wales}

Mandatory appraisal of headteachers was introduced in England and Wales in 1991 (Bartlett, 2000). The regulations have since been revised twice: the 2000 Performance Management Framework (PMF), introduced following the election of a Labour Government (Department for Education \& Employment [DfEE], 2000), was itself refocused in 2006 as part of the "new professionalism agenda" (Training \& Development Agency for Schools, 2008 slide 4).

In 1991 the Local Education Authority (LEA) or Board of Governors for grantmaintained schools was responsible for appointing two peer appraisers to oversee a two-year cycle. The PMF saw the timeframe reduced to one year and gave an increased role to boards. However, boards were also directed to appoint an external adviser (EAdv.) to assist two or three governors to undertake the appraisal (National Association of School Governors, 2005a). The requirement for boards to seek expert advice was strengthened by the 2006 Education and Inspections Bill which replaced EAdv. with School Improvement Partners (SIP), once again appointed by the local authority $\left(\mathrm{LA}^{4}\right)$. Whilst SIP provide advice on all stages of the process, they, like EAdv., have an advisory function and it is the governors who review the head's performance (National Governors' Association, 2007).

From the outset, sector reaction to compulsory appraisal was mixed. A 1995/96 survey of 26 primary heads found opinions ranging from "the positive, confident and cooperative to the cautious and defensive" (Hancock \& Hellawell, 1998, p. 256). A third of principals expressed misgivings about governing bodies having any involvement in the process, including sighting appraisal documentation. A 1997 evaluation found a narrower view of appraisal than government had intended (Cullen, 1997). Most heads saw it as being about their own professional development rather than improving the quality of education. A key issue for heads was the inadequacy of resourcing, in terms of both time and money. They wanted greater interaction with the appraiser and derived the greatest benefit from professional reflection with a peer. This was an aspect appraisees and appraisers in both these studies were enthusiastic about. A critical factor was the provision of appraiser training and the care taken to match them with principals. This enhanced

4 In 2004, agencies with responsibilities for children were brought together and the functions of LEA became subsumed within LA. 
appraiser credibility and helped reduce the likelihood of personality clashes with the appraisee (Williams \& Mullen, as cited in Clayton-Jones et al., 1993).

As early as 1991 Mortimore and Mortimore (as cited in Cullen, 1997, p. 121) had warned that appraisal regulations fell short of "improving the quality of teaching and learning in schools". The PMF was intended to increase the ability of LEA to challenge and support schools to raise standards (DfEE, as cited in Swaffield, 2008). Greater emphasis was placed on outcomes for students, with at least one performance objective needing to be related to pupil progress (Department for Education \& Skills [DfES], 2003). A link was also created between teacher and headteacher performance and pay progression (Haynes, Wragg, Wragg, \& Chamberlin, 2003). This raised the stakes and is unlikely to have allayed governors' apprehension about having to make a judgement on the head's overall performance (DfES, 2003). Gann (2003), a performance management consultant as well as a chair of governors, raised concerns that governing bodies were limiting their focus to the agreed objectives, rather than performance overall. Taking a wider perspective, he believed, required commonsense rather than professional judgement and he suggested a checklist for the types of data governors should expect heads to produce. These included evidence on pupil progress and the head's role in implementing the board's strategic vision (Gann, 2003).

Despite the involvement of EAdv., heads' concerns were heightened by the increased role of boards in their appraisal (Crawford \& Earley, 2004). They continued to resent governor involvement, questioning their understanding and motives (Kerry, 2005). Misgivings about governors' understanding may have been well founded as LEAs provided little in the way of training and it was not until 2003 that training resources for boards were produced by the DfES. There was criticism of government for not doing enough to support the implementation of "an overtly industrial accountability system" overseen by lay people (Kerry, 2005, p. 490).

The conclusion of a 2003 survey of secondary school heads was summed up by the report's title What gets measured gets done (Wilson, Croxson, \& Atkinson, 2006). Linking overall school performance to improved student achievement was deemed a worthy objective but the narrow focus of the value-added performance measures (PMs) led to heads concentrating on these in order to make their schools look good in published rankings or league tables. PMs were also criticised for failing to take account of contextual factors including resourcing levels (Wilson et al., 2006). 
Another survey of heads' reactions to the PMF found resentment towards a system imposed with inadequate consultation, and irritation and frustration about the extra workload (Crane, 2005). Attempting to reduce "highly complex relationships" to "technical competencies" also contributed to PMF failing to have the impact it was designed for (Crane, 2005, p. 9). This study concluded that determining whether the aim of the appraisal was control or "commitment and professionalism", was critical (Crane, 2005, p. 9). The issue of meaning and purpose also came through strongly in Brown's (2005) investigation into PMF implementation. Other findings included variance in the content and quantity of objectives; lack of clarity as to what was meant by overall performance and the criteria for measuring it, and considerable variance in the quality and quantity of training.

Given there are around 23,000 headteachers in England alone (Brown, 2005) the training of appraisal advisers has been a major undertaking. By the end of 2003, over 3,000 EAdv. had been accredited, almost $70 \%$ of whom were current or previous headteachers (Crawford \& Earley, 2004). The SIP who have replaced them must be current or recently serving heads who possess high standards of integrity and behaviour (Department for Children Schools \& Families, [DfCSF], 2007). Applicants go through a formal assessment process to ensure they interact well, have knowledge and experience of effective strategies for school improvement, and understand the principles and practice of quality assurance systems (DfCSF, 2007). As well as being trained by the National College for School Leadership, SIP are required to participate in up to four days professional development and networking each year (Sassoon, 2006).

Feedback from those with involvement in an appraiser capacity suggests it was "one of the most valuable professional development opportunities they had experienced" (Cullen, 1997, p. 118). In a 2004 survey, 18 EAdv. commented on how professionally rewarding they had found the experience and suggested their involvement had to some extent ameliorated principals' earlier concerns (Crawford \& Earley, 2004). EAdv. believed heads regarded them as "an independent professional mentor with no axe to grind" (Crawford \& Earley, 2004, p. 382). A frustration was that their advisory role limited their ability to tackle "an ineffective head controlling a weak governing body" (Crawford \& Earley, 2004, p. 383). However, this study also found instances of EAdv. colluding with, rather than challenging, the head, echoing the "mutual back-scratching" which Hellawell and Hancock had detected signs of six years earlier (1998, p. 226). Whilst studies have 
concluded that a degree of appraisee ownership of the process is positive, this should not be to the extent that they control it. Restricting an EAdv.'s involvement in any one school to a maximum of three years was an attempt to minimise this effect.

Despite such shortcomings, Sassoon (2006) described revision of the PMF as "fiddling with a system that is working perfectly well." He cited a survey undertaken by Cambridge Education Associates (the contracted provider of EAdv. training) showing high levels of satisfaction with the model. The claims that changes were necessary because heads were drowning in paperwork and that "single conversations" would be easier to manage than the multiple ones involved in the governor/EAdv. partnership were refuted. In his experience, EAdv. completed much of the documentation and provided valuable in-service training for heads as well as governors. A further concern was the lengthy phase-in period. For 2006 there were only enough trained SIP for secondary schools. Prior to September 2007 when the revised regulations were fully implemented, primary governors were directed to appoint their own consultant, perhaps a former EAdv. to support them in the process - at their own cost (Sassoon, 2006).

Perhaps not surprisingly the DfES had a somewhat different perspective, indicating that the 12 week consultation period, which began towards the end of the school year and concluded during the summer holidays, had suggested there was support for the changes (Teaching Times, 2006). The first revised appraisal plans for heads were not required to be completed until the end of 2007 . It is therefore too soon to judge the outcome but 60 heads involved in a trial were positive about SIP involvement (Halsey, Judkins, Atkinson \& Rudd, as cited in Swaffield, 2008). However, Swaffield's own interviews with secondary heads led her to conclude they found 'SIPs' narrow focus on data was unhelpful" (p. 15). Another concern was that requiring SIP to report to both governing bodies and LEA potentially diminished their capacity to develop open, trusting relationships with heads. This type of relationship is characteristic of a mentoring and coaching approach which has been identified as an effective element support for leadership development (Bush \& Glover, as cited in Swaffield, 2008).

Initially most of the annually elected board chairs waived their right to receive a copy of the appraisal statement (Cullen, 1997). The PMF made it mandatory for the chair to receive a copy and make it available to governors involved in determining the head's pay (National Association of School Governors, 2005b). The link with pay underlines the challenge headteacher appraisal presents for the approximately 
350,000 governors of England's state schools. Appointed for a four-year term, governors include LEA nominees, school staff, and co-opted community members as well as parents (Hancock \& Hellawell, 1998). A 2007 report found schools in disadvantaged areas had particular difficulty finding governors with the time and expertise to carry out the role (Frean, 2007). Even where recruitment is not an issue, commonsense alone cannot equip governors for handling the "technical and delicate" aspects of headteacher appraisal (Hancock \& Hellawell, 1998, p. 257). There have been calls to educate and train both parties, perhaps going as far as training paid, professional governors to sit on boards (Hellawell \& Hancock, 1998). However, policy to date has largely focused on the training of external professional advisers.

This analysis of developments in England and Wales suggests the message that legislation alone does not effect change (Fullan, 1991) has been less well heeded than in New Zealand where the requirements for appraisal have remained constant for almost 10 years. ${ }^{5}$ The need to look at the human element is perhaps a key lesson to be learned from the UK experience. Continued legislative tinkering will have little impact without buy-in from participants who have the requisite skills and resources to do what is asked of them.

\subsubsection{Canada}

Devolution from Westminster has seen appraisal in the UK take on increasingly diverse forms in England, Wales, Scotland and Northern Ireland. In Canada, where the Constitution Act (1867) gave each of the 10 provinces and three territories power to enact its own education laws, the situation is even more complex. In 1967 a Council of Ministers of Education was established to increase coordination and cooperation across authorities responsible for Canada's 15,500 schools (Council of Ministers of Education, 2008). However, within each province, school district boards (SDB) develop their own policies and procedures for principal and teacher performance appraisal. Whilst this could lead to inconsistent practices it also allows for appraisal to take account of local context (Thomas et al., 2000).

A study of 67 school systems in Alberta found each SDB largely determined its own processes (Thomas et al., 2000). It noted the purpose of appraisal was primarily

5 In July 2008 the Primary Principal Professional Standards were revised from six to four dimensions as part of Collective Employment Agreement negotiations between NZEI and the MOE. 
summative, although this type of evaluation was less likely to occur beyond the first year of the principalship. In some districts formative aspects, relating to expected improvements in principals' performance, were identified (Thomas et al., 2000). The length of cycles varied from one to five years, with time constraints and work pressure identified as areas of dissatisfaction and reasons for low frequency. Eleven different sources of data were gathered, with over $70 \%$ of principals and superintendents identifying student achievement and staff surveys, and a slightly fewer number of parent and student surveys. Half of 63 respondent principals indicated that specific characteristics relating to the school and its community affected the process. The most commonly cited suggestions for improvement related to the frequency, focus, and purpose of the appraisal. Principals wanted more meaningful feedback through greater involvement of stakeholders and central office staff. Superintendents expressed a wish for principals to see appraisal as a process linked to their role in achieving school goals. The researchers concluded their findings supported "the use of a combination of evaluation approaches, multiple data sources" and cognisance of "cultural and contextual variables", factors identified in the literature as linked to successful appraisal (Thomas et al., 2000, p. 234).

The value of an objective appraisal was borne out by a survey of $227(11 \%)$ of Alberta principals which found "no difference in the self-reports of highly effective and less effective principals (Adams \& Townsend, 2006, p. 52). This raises concerns that without evidence-based feedback, principals may be mistaken in thinking things are going well. The need for evidence-based appraisal was further reinforced by a finding that "leaders of poor-performing organisations" tend to "overrate their abilities and their effectiveness" (Kruger \& Dunning, as cited in Adams \& Townsend, 2006, p. 52). This also suggests self-appraisal, a mandatory but non-specific element in New Zealand PMS requirements, needs to be handled carefully and triangulated with other evidence.

Normore $(2004$, p. 2) reported that in some Canadian school districts "professional growth portfolios" were being used in appraisal to encourage "reflective practice and directed self-improvement" in aspiring as well as incumbent school leaders. Ontario education officials saw this complementing mentoring programmes for principals and aspirant principals and leading ultimately to improved student learning. Another study warned that too narrow a focus "on externally mandated accountability measures" inhibited leaders' ability to bring about educational change appropriate to 
their school context (Newman, King \& Rigdon, as cited in Normore, 2004, p. 2). A characteristic of the more successful schools observed was the principal remaining "connected with daily classroom operations, relying on internal accountability practices" (Normore, 2004, p. 2).

A survey of 800 principals in Ontario led Leithwood and Montgomery (as cited in Thomas et al., 2000, p. 220) to conclude that appraisal took too restrictive a view of principalship. This warning seems to have been heeded by the Ontario MOE. During 2007 and 2008 it has been field testing a model for principal and vice principal appraisal, developed in consultation with stakeholders, in 12 SDB. (Government of Ontario, 2008a). The approach is based on an annual plan that identifies strategies for the appraisee's growth and development. The final summative report uses a rating scale to assess overall performance. The intention is to evaluate the trial and refine the model if required.

The involvement of community representative governing bodies in education in Canada has been at the "weak" end of the spectrum compared to the UK or New Zealand (Voisin, 2003). In Ontario, school councils, elected annually for a one-year term, were first introduced in 1996. A government review in 2000 confirmed their fairly limited role but established their right to raise issues of importance (Ontario State Government, 2001). As in the state of Victoria, employer functions are carried out by SDB but councils must be consulted on policy development and review. Councils also have a key role in SDB principal selection processes (Government of Ontario, 2008b). A study of 15 Ontario secondary principals found councils had had a very limited impact on school culture and student achievement (Voisin, 2003). However, many reported having good working relationships with their chairs and acknowledged that including them in information sharing led to improved decision making and community relationships.

The involvement of a community representative body is more limited in Canada than in either the UK or New Zealand and responsibility for the appraisal lies with the SDB. The Ontario trial seems a far-sighted strategy and it will be interesting to evaluate the effectiveness of the system that emerges, in particular whether consultation with principals increases their commitment to the process. 


\subsubsection{Australia}

In Australia, the introduction of performance appraisal has been linked to Federal and State Government calls during the 1980s for "qualitative improvement and enhanced accountability in schooling" (Clayton-Jones et al., 1993, p. 111). In New South Wales (NSW) an Effective Schools Development Program was implemented in 1986. After it was reviewed two years later, responsibility devolved from the Department of School Education to geographic groupings, or "clusters" of schools overseen by a cluster director (CD) (Clayton-Jones et al., 1993, p. 113). A CD administered Principal Appraisal Scheme trialled in NSW in 1991 was made up of four stages: planning, progress review, annual review, and development plan implementation. Principals and CD were trained in the preparation of development plans and objective performance review (Clayton-Jones et al., 1993, p. 115). A survey of 122 principals involved in a trial in the Hunter Valley showed an overall favourable response. Key benefits highlighted were feedback and a focus on professional development. Principals were comfortable discussing performance with $C D$ and with having school goals for improved student achievement as the context for their appraisal. Respondents were less supportive about the performance indicators used and wanted measurement strategies investigated (Clayton-Jones, McMahon, Rodwell, Skehan, Bourke, \& Holbrook, 1991).

A performance management programme for principal class officers, which included deputy and assistant principals, was introduced in the State of Victoria in 1994. The process, which was linked to remuneration, was reviewed and amended and by 1998 had a greater emphasis on professional development (Mongan, 1999). Principals met with their designated Regional Principal Consultant (RPC) at the start of the year and maintained contact during the year. Specific Result Areas (SRA), usually four in number and related to the school's charter, the principal's vision for the school and departmental priorities, were negotiated and assigned evaluation weightings (Department of Education, as cited in Mongan, 1999). Following principal self-evaluation, an end of year meeting was held at which the RPC could request further evidence to verify outcomes and report the principal's score to the regional manager (Mongan, 1999).

Interviews with 31 Victorian principals led Mongan to conclude that any perceived benefits, such as more effective planning and documentation, were outweighed by concerns. There was frustration that the process focused too much on "achievement in 
purely statistical terms" and failed to recognise the complexity of the role (Mongan, 1999, p. 14). Principals saw tenuous links between their involvement in appraisal and improved student learning outcomes. The study led to a recommendation that any further modifications to the programme be based on consultation and piloting, with the profession involved in defining "the competencies and standards on which performance can be profiled and improved" (p. 15). A further examination of the programme in 2001 again highlighted its failure to establish links with improved educational outcomes (Mongan \& Invargason, as cited in Mulford, 2003).

Victoria launched a revised process, essentially appraisal for growth and development, in 2007 (Department of Education and Early Childhood \& Development, 2008). The developmental aspects are "premised on strong relationships ... with reciprocal responsibility and support" (p. 5). Multiple sources of feedback are encouraged including outcomes from leadership programmes. The school's Designated Officer (DO), appointed by the Department, is responsible for negotiating development plans that identify actions, related professional development and evidence to be used for evaluation. In line with the strategic plan this may cover a period of up to four years, making it an extended appraisal process. Strategic objectives in which the principal will pay a significant leadership role are linked to relevant domains of the state's Leadership Framework for principal officers. Although an external person, the DO has a relationship with the school, understands its context and has a broad brief to enhance leadership capacity. Principals must prepare a self-evaluation for the DO prior to an annual review meeting. In preparing this, principals are encouraged to seek support and challenge from "critical friends" who may include the School Council President as well as other professionals and the DO (p. 8). There has been greater devolution of decision making in Victoria (whose expertise and experience New Zealand drew on when introducing its 1989 reforms) than in other states but it is still limited (Lingard, Hayes, \& Mills, 2002). Victorian school councils may have some input into principal selection but otherwise have no formal role in staff management processes.

The 1987 Better Schools report proposed devolution in Western Australia (WA) with the MOE implementing school accountability through performance management and the establishment of District Superintendents (O'Brien \& Down, 2002). There was an increase in "community control and performance management" following the release of the Hoffman Report in 1994 (O'Brien \& Down, 2002, p. 116). In Queensland, school councils were recommended in the Leading Schools reforms 
announced in 1997 (Lingard et al., 2002). Although the reforms were overturned by the incoming Labour Government, the provision for councils was retained for consultation with the sector. In the restructuring that followed, school communities were able to opt for different levels of self-management, with school councils mandatory for those with most autonomy (Pointing, 2005). Like New Zealand BOT, school councils have a strategic, rather than operational focus but the details are not precisely defined or commonly understood (Pointing, 2005). Although responsible for monitoring the school's performance, processes for doing this have not been determined and councils have no employer functions (Pointing, 2005).

The extent to which governing bodies have input into the principal's appraisal varies between states in Australia but tends to be more limited than in New Zealand. As in England and Wales, there appears to be a tendency for legislation to be regularly reviewed and revised, albeit with some attempts made to consult participants.

\subsubsection{The implications for principal appraisal in New Zealand}

There is an inherent tension between appraisal for accountability and appraisal for professional development in principal appraisal, with governments tending to favour the former and the profession the latter (Jennings \& Lomas, as cited in Isherwood, Johnson, \& Brundrett, 2007). This brief examination of education jurisdictions suggests that notwithstanding attempts to make it a developmental experience, appraisal is used largely as a tool for accountability in relation to the principal's role in improving outcomes for students. Efforts to make this complex link more explicit mean processes are subject to regular, politically initiated review and revision. In New Zealand there has, by comparison, been remarkably little "tinkering" with the legislative requirements. The 1996 PMS guidelines and 1998 Professional Standards for Principals have remained the basis for principal appraisals, with the primary principal standards updated as part of collective employment negotiations in mid2008.

Isherwood et al. (2007, p. 73) suggest governing bodies play a key role in brokering a marriage between accountability and development, and highlight the advantages of having both elements in "a coherent system." In the education systems of the three countries looked at, where governing bodies have delegated responsibilities for the process there is usually a provision enabling or requiring them to incorporate professional expertise. Gane and Morgan (as cited in Edwards, 2001) have noted 
the considerable developmental benefits which appraisers with an education background gain from involvement in the process, and this is borne out by research in the countries examined for this review. For New Zealand BOT charged with this important responsibility there has been limited, readily available, affordable, professional advice and guidance. This increases the risk of BOT becoming the "meat in the sandwich" as they balance legislative requirements that require them to account for and monitor the principal's performance, with the developmental support required of them as good employers.

Research conducted by Wilson (as cited in Middlewood, 2001) found New Zealand principals critical of the appropriateness of the current instrument for their appraisal in terms of both accountability and development. Their greatest priority was not to lose control of the process. An ideal system would need to take this into account whilst avoiding employee capture. Used carefully, principal appraisal is a valuable means for governing bodies to ensure they are on track to meet legal obligations and their stated strategic direction, through the efforts of their chief executive. In the hands of the unwary, it can either become a case of going through the motions or a devastating tool for smashing fragile governance/management partnerships. 


\section{CHAPTER 3: METHODOLOGY}

\subsection{Introduction}

This chapter sets out the purpose of the research and the research questions. It defines key terminology and describes the research design framework. The methods used to collect and analyse data are described.

\subsubsection{Research aim}

The research objective was to determine the extent to which the implementation of principal appraisal in New Zealand schools has resulted in a system that is effective in terms of:

- accountability: providing assurances that the principal is contributing to the effective performance of the school, and

- participant satisfaction: for both the principal as appraisee and BOT chair representing the appraiser.

The research aimed to provide comprehensive descriptive data on principal appraisal carried out during 2006 in a region comprising approximately $10 \%$ of $\mathrm{New}$ Zealand state and integrated schools.

As well as quantifiable data, it was envisaged that analysis of respondents' comments might provide insights into the challenges and issues around principal appraisal. It was hoped these would enable the development of recommendations and evaluation of initiatives for clarifying or supporting effective practice in principal performance appraisal.

\subsubsection{Research questions}

The overall research questions were stated as:

Q.1 How is the performance of principals of primary and secondary schools in the chosen region appraised?

Q.2 What are the attitudes and opinions of principals and chairs of boards of trustees about this process? 
These main research questions were subdivided into the following detailed questions:

\section{Sub-questions to Q1:}

1. (a) Who is appraising school principals in this region?

- To what extent are external appraisers being contracted to undertake all or part of the process?

1. (b) Who makes the decision about who will carry out the appraisal?

- What input does the principal have in the decision?

- What input does the BOT have in the decision?

1. (c) What qualities are being sought in an appraiser?

- To what extent are those carrying out appraisals perceived as possessing these qualities?

1. (d) What role does a performance agreement play in the appraisal process?

- Do all principals have a performance agreement?

- If so, who is involved in negotiating it?

- What linkages are there between performance expectations, BOT strategic objectives and principal professional development opportunities?

1. (e) How comprehensive is the appraisal?

- How frequently do principals and appraisers meet to evaluate performance?

- What sources of data are used?

- Who has an opportunity to comment on the principal's performance?

\section{Sub-questions to Q2:}

2. (a) Are appraisal outcomes shared with the BOT and if so in what form?

- Is a written report prepared and if so who gets to see it?

- Is the outcome brought to a BOT meeting?

- Is the principal present at any discussion of the appraisal outcome by the BOT? 
2. (b) What aspects of the appraisal process are most and least satisfying?

- For principals?

- For board chairs?

- How might the process be improved?

\subsubsection{Operational definitions}

As noted in previous chapters, terminology in this field is subject to differing interpretations and definitions. In gathering and analysing data for this research the following definitions have been used.

\section{Performance management (PM)}

An integrated and diverse set of organisational activities that are aimed at achieving strategic organisational aims (Cullen, 1997; Piggot-Irvine \& Cardno, 2005, p. 20).

\section{Performance management systems (PMS)}

The 1996 gazetted guidelines for the implementation of appraisal in New Zealand schools.

\section{Appraisal}

An aspect of performance management that involves the forming of qualitative judgements about individual performance. In New Zealand schools appraisal must include the features outlined in the PMS guidelines.

\section{Performance Agreement (PA)}

A written document containing the criteria for performance appraisal as required by principal collective employment agreements.

\subsection{Research Design}

A cross-sectional survey that was primarily descriptive in nature was undertaken in order to explore "conditions or relationships that exist" (Best, as cited in Cohen, Manion \& Morrison, 2000, p. 169).

The research aimed to provide factual descriptions of a specific performance management process from the view point of its main participants. This required 
quantitative data, measuring variables through counting or scaling to enable comparisons. In order to gain a deeper understanding, descriptions were enhanced through the participants' opinions on the qualities, positive or negative, of the process and how it could be improved. To this end, the survey also included open-ended questions that were coded into categories before further analysis, resulting in a "mixed method" or multi-method approach (Punch, 2005, p. 241) within the survey framework.

There are several models for linking the two approaches. Miles and Huberman's (1994) description of integrating the collection of quantitative and qualitative data in fieldwork design most closely matches that followed in this research. Rationale for combined approaches outlined by Bryman (cited in Punch, 2005, p. 242) include:

- general picture, using quantitative data to fill in gaps in a qualitative study; and

- $\quad$ structure and process, using qualitative data to flesh out process aspects of the structural features identified through quantitative research.

The latter aligns with the view that qualitative research is about verstehen, that is attempting "to capture data on the perceptions of local actors 'from the inside"" (Miles \& Huberman, 1994, p. 6). Whilst all methods have limitations, combining quantitative and qualitative methods is a pragmatic way of limiting the potential weaknesses of a single approach (Zeller, as cited in Punch, 2005).

A quantitative approach has the advantage of objectivity, enabling description to be generated "in a systematic and comparable way" (Punch, 2005, p. 238). It also reduces the potential for researcher bias. Survey research is primarily a quantitative approach that allows for "examination of a phenomenon" in a range of settings (Pinaonneault \& Kraemer, 1993, p. 78).

A qualitative approach has greater context sensitivity, making it "well suited for studying naturally occurring real-life situations" (Punch, 2005, p. 238). By gathering both types of data and linking them in the analysis, a richer picture is generated, with quantitative data providing structure and qualitative data producing greater insight into processes and their meanings.

The purpose of a descriptive survey is to describe responses to questions by a sample group in terms of proportions and percentages (Punch, 2005). The survey undertaken also contained elements of explanation (Pinaonneault \& Kraemer, 1993) in that it sought to identify what causal relationships might exist between variables. 
Within the sample group for this survey there were three "discrete" or "categorical variables" (Punch, 2005, p. 86):

- Role: principal or chair

- Sector: primary or secondary

- Appraiser: chair appraiser (CA), external appraiser (EA) or chair plus external appraiser (CE).

In addition to these there were "continuous" or "measurable" variables (Punch, 2005 , p. 86) such as frequency of meetings or sources of evidence. The study aimed to explore "relational analysis" (Cohen et al., 2000, p. 169), for instance whether the dependent variable of principal satisfaction varied in relation to the independent variables of appraiser type or school sector.

A self-administered written questionnaire was selected as the most appropriate tool for gathering data from as many principals and chairs of schools in the selected region as possible with the minimum of intrusion on their time.

\subsection{Procedures}

\subsubsection{Participants}

The target group for the study was approximately 2,600 state and integrated schools throughout New Zealand. The sample chosen to represent the target group were principals and chairs of 258 state and integrated schools in a specific region representing approximately $10 \%$ of the schools. Of these, 222 were primary or intermediate and 41 secondary schools.

\subsubsection{Ethics approval}

Approval for the survey was granted by the Faculty of Education Sub-committee of the Human Ethics Committee of Victoria University. The accompanying letter and information sheet (see Appendices A and B) set out the purposes of the research and steps to be taken to ensure participant confidentiality. 


\subsubsection{Data collection}

Questionnaires for principals and chairs (see Appendices C and D) were sent to school addresses in separate envelopes on 12 April 2007, which fell during school holidays. Principals were asked to return surveys by 4 May and chairs by 7 May. The extra few days allowed for correspondence to be collected from the school or forwarded to the chair. Triennial trustee elections at the end of March 2007 meant a transition to new boards and chairs was happening at this time. The accompanying letter asked that the questionnaire be passed to the person chairing the board in 2006. Despite this, some new chairs contacted me during May and June to apologise for being unable to respond.

Following the analysis of the data, four principal appraisers were approached and gave their consent for their responses to questions about their appraiser experience to be used to check the findings of the research.

\subsubsection{Questionnaire}

The questionnaire used closed, open and multi-choice questions to obtain factual information, as well as descriptions of attitudes, opinions and behaviour (Punch, 2005). For some of the latter, rating scales were used to obtain "affective responses, focusing on the evaluative dimension" (Punch, 2005, p. 100). These were bipolar, five-level Likert scales used in single-item mode (i.e., assessments of independent, single statements). The expression of agreement/disagreement was applied to items that were either given statements or qualities selected by the participants themselves. The item scales were presented in numeric form (1 to 5 ) on a continuum line and supported by "Smiley emoticons" that reflected graduations from positive (happy) to negative (sad) assessment values. This multiple presentation was chosen to assure the best possible equidistance between pairs of adjacent levels. However, because it was not possible within the scope of the study to fully calibrate the scales, they were considered to be ordinal level measurements. The use of arithmetic statistics (e.g. means and variances) was avoided other than as a comparison to median and mode during work-inprogress analyses. Instead, frequency distributions across scale values were used. 
Qualitative data were collected in a semi-structured form through the provision of comment opportunities throughout the questionnaire and a final reflective question.

The Principal questionnaire contained seven question categories: background information; appraiser; performance agreement; data gathering; reporting; outcomes; and reflection.

The Chairperson questionnaire had an additional question category relating to the appraiser role. Question 2 directed respondents to answer the remainder of the survey in one of three colour coded sections, depending on the nature of their involvement in the appraisal of their school's principal in 2006, as established in Question 1 (See Appendix D).

\subsection{Data Analysis}

The following explains the analysis of the four different types of question format used in the survey.

\subsubsection{Factual information}

This included contextual data about the school and respondent as well as establishing if an appraisal occurred and if so whether or not it was related to a performance agreement. Where possible, factual information was compared with MOE statistics to establish the representative nature of the sample.

\subsubsection{Multi-choice options}

These were used to determine: appraiser type and selection; performance agreement negotiation and linkages; frequency of meetings; sources of data; and reporting methods. The chair survey also sought information on preparation for the appraisal role. For each question a range of responses was listed with an opportunity for respondents to add additional ones.

Responses were counted and findings displayed in tables or bar graphs comparing categorical variables. 


\subsubsection{Rating scales}

Two questions sought responses on a five-point Likert rating scale to enable a summated response (Punch, 2005).

The first asked respondents to identify the three most important qualities in an appraiser then make an assessment of the extent to which the appraiser, or CA themselves, possessed these. In order to code qualities, responses were read, reread and ten different categories of response identified. These were assigned codes and the frequency for each was counted and presented as a bar graph comparing principal and chair responses. Frequency of ratings for the extent to which the appraiser possessed these qualities were also counted and percentages calculated in order to compare principals and EA chair perceptions of EA, and principal and CA/CE chair perceptions of CA appraisal qualities.

The second use of a rating scale was to clarify attitudes to aspects explored in other questions. A series of positive statements (eight for principals, nine for chairs) sought a response on a five point scale. Responses were counted in each category and the median, mode and variability calculated. Where paired responses had been received from the principal and chair of the same school, comparisons were made and any differences of two or more on the rating scale for an item were examined and summarised in a bar graph. Initial plans to report details of paired ratings and comments had to be revised in order to ensure confidentiality for respondents. Chair responses to the statement: I am confident about my ability to undertake the appraisal of a principal, were analysed to determine the percentage of responses from three different groups of chairs (CA, EA, CE).

\subsubsection{Qualitative data}

The final question in the survey was an open one in three parts asking respondents to identify which aspect of the appraisal they found most and least satisfying and what suggestions they could make for improving the process.

A conceptual structure (Miles \& Huberman, 1994, p. 63) for analysing comments was developed by taking an inductive approach. Comments were read and re-read one by one and descriptive codes were identified and refined. In a second round of 
coding four overarching categories (interpretive codes in Miles \& Huberman's terminology) emerged and their properties were defined (see Table 4.22). Patterns for most and least satisfying aspects of the appraisal process, as well as suggestions for its improvement, were then developed utilising relevant descriptive codes.

Each comment was referenced to as many pattern codes as were relevant, for instance, the "most satisfying" comment "affirmation - I'm doing a good job; professionalism of appraiser; documented process; reflected my needs" was assigned codes relating to feedback (IFB), appraiser qualities (AQEA) and the quality of the process (PQ), (see Table 4.23). Respondents were divided into three groups:

- Principals $(\mathrm{N}=104)$

- $\quad C A(N=26)$

- $\mathrm{EA} / \mathrm{CE}(\mathrm{N}=29)$

Weightings, based on the number of respondents who made comments in each part of the question, were used to calculate percentages displayed in tables, discussed and illustrated with quotes.

\subsubsection{Presentation of findings}

As identified in the previous discussion, displays, in the form of graphs and tables were used to present frequency distributions and analysed data and enable between-group and within-group comparisons. This explored what, if any, interaction existed between appraiser type, school sector and outcomes, including levels of satisfaction with the appraisal. Patterns, trends or issues that might support conclusions and recommendations were identified.

\subsection{Trustworthiness of the Study}

The following section outlines strategies to increase validity and internal consistency of the research. 


\subsubsection{Sample}

As large a sample group as possible was necessary to help ensure the validity and reliability of the study. The target group of schools selected contained a range of school type and represented approximately $10 \%$ of New Zealand state and integrated schools. In order to improve the external validity of the sample, steps were taken to increase the response rate from chairs following an early indication that this was considerably lower than for principals. The date for survey returns was extended to 30 June 2007. Contact was also made with schools where the principal had already sent a response with a further invitation to the chair to participate.

It appears the timing of the survey was an issue for chairs. The overall response is discussed in Chapter 4 and the implications of this for the research are explored in Chapter 5 .

\subsubsection{Instrument}

The questionnaire was piloted with three BOT chairs and three principals in March 2007. The key objective of the trial was to test the validity and reliability of the instrument, specifically to:

- assess the clarity of question wording;

- ascertain that the meaning of the questions and evaluations was understood by the participants in exactly the same way as it was intended by the researcher;

- test that the rating scales were worded correctly and could be interpreted by the participants as a valid means of expressing agreement with the pre-given statements or options; and

- verify the time it would take to complete the questionnaire (the target was no more than thirty minutes).

The findings resulted in some minor revisions to wording and confirmed the estimate of time was realistic.

\subsubsection{Personal bias}

The data were gathered by an uninvolved observer using a paradigm that accepted participant perceptions as a form of reality. However, it is relevant to note personal knowledge and insights which underpinned the research design. Key ideas from 
the literature and my own knowledge of current school practices helped to inform the development of research questions and design a survey tool that would gather information relevant to exploring these. Personal knowledge and experience also added validity to the interpretive framework.

Data verification methods for triangulation of the data, that is using more than one type of measurement to support, or at least not contradict, a finding were considered in the design of the study. Miles and Huberman (1994, p. 267) identify five types of triangulation: by data source, method, researcher, theory and data type, the following aspects of which were reflected in the research.

- Data source (persons): sending questionnaires to both chairs and principals meant two different perceptions of reality were sought. Although the corroborative effect of this may have been limited, the two viewpoints contributed to the cohesiveness of the data.

- Data source (places): the survey was sent to a range of different types and sizes of schools in urban and rural settings.

- $\quad$ Researcher: coding was peer reviewed by a colleague; four principal appraisers provided comment on the extent to which the findings were consistent with their experience, helping to identify possible areas where further research is warranted.

- Theory: the basis for the study, construction of questions and analysis of the findings and their implications were informed by a review of appraisal theory and practice in the literature.

- Data type: both qualitative and quantitative data were collected.

\subsection{Summary}

This chapter has outlined the research design and data collection methods. It has also described the data analysis process. The following chapter presents the findings of this analysis. Chapter 5 will follow up on the rationale for the approach taken by considering its constraints and limitations. 


\section{CHAPTER 4: RESULTS}

This chapter outlines the survey findings and considers the relevance of the data in answering the research questions.

\subsection{Survey and Sample Demographics}

\subsubsection{Response rates}

Surveys were sent to the principal and chair of 258 state and integrated schools. A total of 159 responses were received from 121 schools: 100 primary and 21 secondary, a $46.9 \%$ response.

Almost twice as many principals $(40.3 \%)$ as chairs $(21.3 \%)$ responded. The relatively low response from chairs was in part due to the survey arriving in schools at a time of board turnover following triennial trustee elections. Responses were received from both the principal and chair of $30 \%$ of responding schools (see Table 4.1). The response rate was slightly higher in the secondary sector, with at least one response from just over half $(51.2 \%)$ of secondary schools compared to $45.7 \%$ of the primary. Two of the 85 primary principals indicated they were not appraised in 2006 but provided information based on previous experience.

Table 4.1: Response rates for questionnaire

\begin{tabular}{|l|c|c|}
\hline \multicolumn{1}{|c|}{ Responses } & \% Primary N=217 & \% Secondary N=41 \\
\hline Principals & 39.2 & 46.3 \\
\hline Chairs & 19.4 & 31.7 \\
\hline Principals and Chairs of same school & $\mathbf{1 2 . 8}$ & $\mathbf{2 6 . 8}$ \\
\hline Principal or Chair only & 34.1 & 24.4 \\
\hline
\end{tabular}

\subsubsection{Representativeness of the sample}

The schools surveyed comprise approximately $10 \%$ of the national total of 2573 state and integrated schools at 1 July 2006 (MOE, 2008a) making it a potentially significant sample from which to draw wider inferences. The actual response represents approximately $4.7 \%$ of all New Zealand schools. 


\subsubsection{Decile}

The MOE allocates a decile rating to each school based on indicators for determining the social-economic status of its catchment area. Low decile numbers, assigned to less well-off communities, attract the highest level of funding. MOE figures show almost a third of this region's schools are deciles 9 and 10 . Whilst all deciles were represented in the survey (see Figure 4.1), this tendency towards higher deciles was reflected, with $40 \%$ of responses coming from deciles 9 and 10 . Responses from decile 7 schools are particularly high in comparison to regional data.

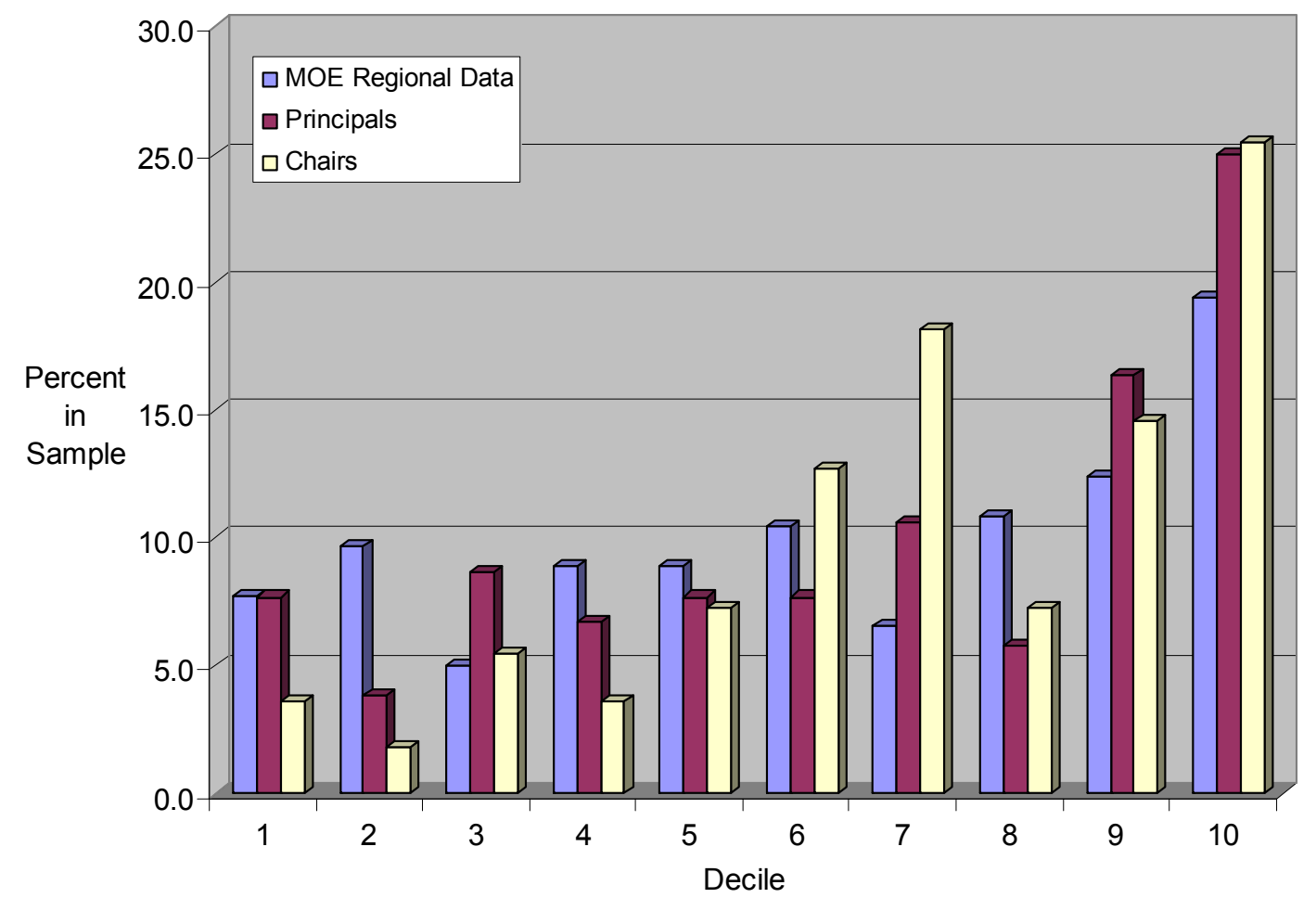

Figure 4.1: Distribution of principal and chair responses compared to MOE decile data for region

\subsubsection{Size of school}

Principals were asked for the approximate roll of the school at 1 July $2006^{6}$. Analysis of responses shows a range of school size characterised by a median of 250 students. However, an average of 320 students indicates the distribution is slightly skewed towards larger schools. Figure 4.2 shows the distribution of responding schools by number of students compared with all schools in the MOE region in which they are situated.

${ }^{6}$ Date at which roll returns are sent to the Ministry for funding and staffing calculations. 


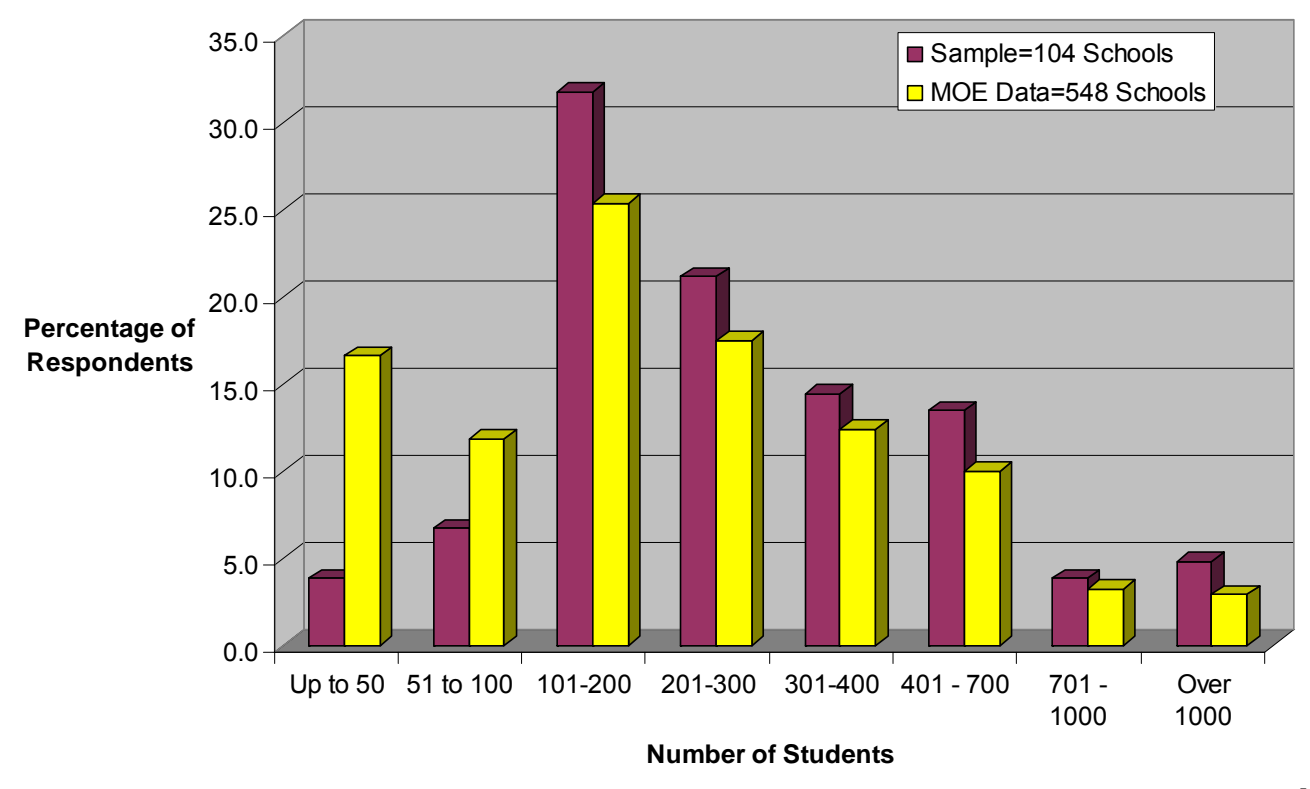

Figure 4.2: Distribution of schools by number of students in comparison with MOE data for the region which includes schools in the sample

The sample aligns well with the MOE region, with the exception of the smallest schools. An explanation for this is that the region also includes rural areas where schools tend to be smaller. The sample, however, has a greater proportion of urban areas where schools tend to be larger. The comparison in Figure 4.2 indicates that the schools responding to the survey are representative of the range of school size within the sample region.

\subsubsection{Experience in role}

Respondents were asked to indicate how long they had been in their role at the school.

\section{Principals}

As Table 4.2 shows, over a third (37.6\%) of primary school principals (PP) had been in their schools for 10 years or more and $12.8 \%$ for 15 years or more, suggesting a high level of experience. Over $21 \%$ of secondary school principals (SP) had served in their schools for 10 years or longer. Under $20 \%$ of all principals had been in their current role for less than two years. 
Table 4.2: Length of time as principal of current school

\begin{tabular}{|l|c|c|}
\hline \multicolumn{1}{|c|}{ Time in role } & $\begin{array}{c}\text { \% Primary Principals } \\
(\mathbf{N = 8 5})\end{array}$ & $\begin{array}{c}\text { \% Secondary Principals } \\
\mathbf{( N = 1 9 )}\end{array}$ \\
\hline Up to 2 years & 19.8 & 15.8 \\
\hline $2-5$ years & 25.6 & 47.4 \\
\hline $6-9$ years & 17.4 & 15.8 \\
\hline $10-14$ plus & 24.4 & 15.8 \\
\hline 15 years and over & 12.8 & 5.3 \\
\hline
\end{tabular}

\section{$\underline{\text { Chairs }}$}

There appears to be higher turnover of Secondary chairs (SC) with half of EA and $42.9 \%$ of CA being in their role for less than a year compared to around a third of Primary chairs (PC).

Table 4.3: Length of time as chair of current board

\begin{tabular}{|l|c|c|c|c|c|}
\hline Time in role & $\begin{array}{c}\text { \% } \\
\text { Secondary } \\
\text { CA }(\mathbf{N = 7})\end{array}$ & $\begin{array}{c}\text { \% } \\
\text { Primary CA } \\
(\mathbf{N = 1 9 )}\end{array}$ & $\begin{array}{c}\text { \% } \\
\text { Secondary } \\
\text { EA (N=6) }\end{array}$ & $\begin{array}{c}\text { \% } \\
\text { Primary EA } \\
\left(\mathbf{N = 1 3 ^ { 7 } )}\right.\end{array}$ & $\begin{array}{c}\text { \% } \\
\text { Primary CE } \\
(\mathbf{N}=\mathbf{9})\end{array}$ \\
\hline $\begin{array}{l}\text { Less than 1 } \\
\text { year }\end{array}$ & 42.9 & 26.3 & 50.0 & 38.5 & 33.3 \\
\hline $1-3$ years & 57.4 & 52.6 & 33.0 & 46.2 & 55.6 \\
\hline $4-8$ years & 0.0 & 15.8 & 15.7 & 15.4 & 11.1 \\
\hline 9 years plus & 0.0 & 5.3 & 0.0 & 0.0 & 9.0 \\
\hline
\end{tabular}

\subsection{Who is appraising school principals in this region?}

\section{Good Practice Framework MOE 2007}

\section{Delegations}

1. The board may resolve to delegate to a trustee or a committee of the board the management of the appraisal process.

2. When the board delegates in this manner, the board retains the responsibility and accountability for the actions of any delegate.

\section{Excerpt 4.1: Good Practice Framework, MOE, 2007}

This question explored the extent to which external appraisers are being contracted to undertake all or part of the process.

\footnotetext{
${ }^{7}$ An additional respondent in this group did not provide information.

${ }^{8}$ As at end Term 12006.
} 


\subsubsection{Appraiser selection}

All chairs, SP and $96.5 \%$ of PP indicated there had been an identified appraiser for 2006. Of the three PP without an identified appraiser, one had subsequently been appraised by the chair; a second had been seconded out of the school during 2006 (and responded to the survey in relation to their 2005 appraisal) and a third commented:

BOT couldn't get organised at my previous school.

Table 4.4: Choice of appraiser from principal and chair data

\begin{tabular}{|l|r|r|r|c|}
\hline \multicolumn{1}{|c|}{ Appraiser } & \multicolumn{2}{c|}{ Primary } & \multicolumn{2}{c|}{ Secondary } \\
\hline \multicolumn{1}{|c|}{ Type } & No & \% & No & \% \\
\hline CA: Chair & 29 & 29.0 & 6 & 28.5 \\
\hline CA: Chair plus trustee(s) & 4 & 4.0 & 7 & 33.3 \\
\hline CE: Chair plus external & 15 & 15.0 & 1 & 4.8 \\
\hline EA: External & 50 & 50.0 & 7 & 33.3 \\
\hline No appraiser & 2 & 2.0 & 0 & 0.0 \\
\hline & $\mathbf{1 0 0}$ & $\mathbf{1 0 0}$ & $\mathbf{2 1}$ & $\mathbf{1 0 0}$ \\
\hline
\end{tabular}

The data show PP were more likely to have an external appraiser (EA) than their secondary colleagues (see Table 4.4). In 100 primary appraisals, 65\% involved an EA, with $15 \%$ working alongside the board chair (CE). In secondary, $38.1 \%$ of appraisals involved an EA, one of these being on a CE basis.

Just under $30 \%$ of PC and SC were the sole appraiser. However, secondary boards were more likely to keep the process "in house" because a further third of appraisals were undertaken by the chair plus at least one other board member, something which only occurred in $4 \%$ of primary appraisals.

Principals were asked for details of EA background. Of the 57 EA appraising PP, $38.6 \%$ were identified as current or former principals, $18.8 \%$ as education consultants and $5.9 \%$ as being from the Catholic Education Office. SP did not provide this information. 


\title{
4.2.2 Appraisal by chair and external appraiser (CE)
}

CE chairs were asked to comment on the division of work. Two-thirds indicated the appraiser did most of the work. Two chairs said the workload had been evenly balanced, for instance:

I did most of work in initial set-up and mid-year senior staff interviews. External appraiser did a good deal of work on Professional Standards etc and end of year report.

In a further instance, the chair had appraised management and leadership, the EA the teaching and learning aspect of the teaching principal's role. This chair outlined how the process came together:

\begin{abstract}
I facilitated the process, the appraiser advised me on the framework she used. Once contract signed - appraiser carried out appraisal and wrote report. Principal and I met and agreed what reported to board (with advice/input from appraiser as well). Now writing process for 2007/8 in full consultation with principal.
\end{abstract}

\subsection{Who makes the decision about who will carry out the appraisal?}

This question explored the amount of input the principal and the BOT had into determining who would undertake the appraisal.

\subsubsection{Primary schools}

Data in Table 4.5 suggest almost half $(49.4 \%)$ of PP had a significant input into EA selection. In two instances this was through shortlist preparation. The proportion of principals with significant input into appraiser choice rises to two-thirds when "mutual choice" is added to the previous category. This could be seen as ensuring appraisee buy-in and ownership of the process. It could also be seen as the appraisee exerting undue influence over their appraisal.

In a quarter of primary schools $(24.7 \%)$ the board had a greater degree of influence, either determining that the chair would undertake the appraisal $(12.9 \%)$ or providing a shortlist for the principal (11.8\%). Of the remainder, $16.5 \%$ indicated the selection had been mutually agreed upon and $7.1 \%$ referred to the selection being linked to board policy. In two instances commissioners undertook the role of the BOT in 
completing the appraisal. For analysis purposes these are treated as chairs in order to maintain confidentiality.

Table 4.5: Selection of appraiser: primary principal responses

\begin{tabular}{|l|c|}
\hline \multicolumn{1}{|c|}{ Method } & \% Principals (N=85) \\
\hline Principal chose or provided shortlist & 49.4 \\
\hline Board chose or provided shortlist & 11.8 \\
\hline Board chose chair & 12.9 \\
\hline Commissioner & 2.4 \\
\hline Mutual choice & 16.5 \\
\hline Policy determined & 7.1 \\
\hline
\end{tabular}

Over half $(52.55 \%)$ of EA and CE chairs indicated selection was largely principal choice. Just under a quarter $(23.8 \%)$ said this was a continuation of a previous appraiser and/or had been decided before they became chair. Less than $20 \%$ indicated the board had chosen the appraiser, and the remainder that the principal had been provided with a shortlist to choose from.

\subsubsection{Secondary schools}

Although the sample is smaller, it appears SP had less influence on the choice of EA. The principal's choice or shortlist was the basis of selection in just under a third of schools. The same proportion of boards determined there would be a CA and a further $10.5 \%$ chose or shortlisted EA.

Table 4.6: Selection of appraiser: secondary principal responses

\begin{tabular}{|l|c|}
\hline \multicolumn{1}{|c|}{ Method } & \% Principals (N= 19) \\
\hline Principal chose or provided shortlist & 30.0 \\
\hline Board chose or provided shortlist & 10.5 \\
\hline Board chose chair & 30.0 \\
\hline Commissioner & 0.0 \\
\hline Mutual choice & 15.0 \\
\hline Policy determined & 10.0 \\
\hline
\end{tabular}

Six CE chair responses showed that in four instances the principal made the decision; selection was negotiated by the principal and chair in one instance, and by the board and chair in another.

Overall findings from both sectors suggest principals have considerable influence over appraiser selection, particularly in primary schools. This may suggest that 
guidance from the board's in-house professional adviser is highly valued in this important decision making.

\subsection{What qualities are being sought in an appraiser?}

Respondents were asked to identify the three most important qualities an appraiser should have and the extent to which appraisers were perceived as possessing these. For CA and CE this involved self-evaluation.

\subsubsection{Ideal qualities in an appraiser}

\section{Selecting and briefing a consultant (ERO, 2002)}

Qualities to look for:

- Good listener

- Curious person who questions things

- High professional standards

- Receptive and retentive mind

- Simple, clear, succinct communicator

- Sees you as a peer - won't be manipulated by you or try to give you what you want

- Able to get along with a range of people

- Adventuresome - shows signs of being able to offer something new to take your school forward

Excerpt 4.2: Good Practices in Principals' Appraisal, ERO, 2002

Principals and chairs were asked to identify the three most important qualities in an ideal appraiser. Responses were analysed and ten different categories identified.

The quality most frequently listed by principals was personal experience of principalship: $21.7 \%$ cited this compared to $16.3 \%$ of chairs (see Figure 4.3 ). Around $15 \%$ of all respondents indicated understanding the role was important but did not specify this was dependent on experience in the job; indeed in their ratings some CA principals indicated their chair possessed this quality. Relevant experience is not listed as a quality to look for in the ERO list in Excerpt 4.2 but in a later section of the document "evidence of experience" is recommended. 
Around a fifth of chairs $(21.1 \%)$ identified aspects of the appraiser's personal integrity as most important. This was only slightly less important for principals with $17.1 \%$ mentioning this quality.

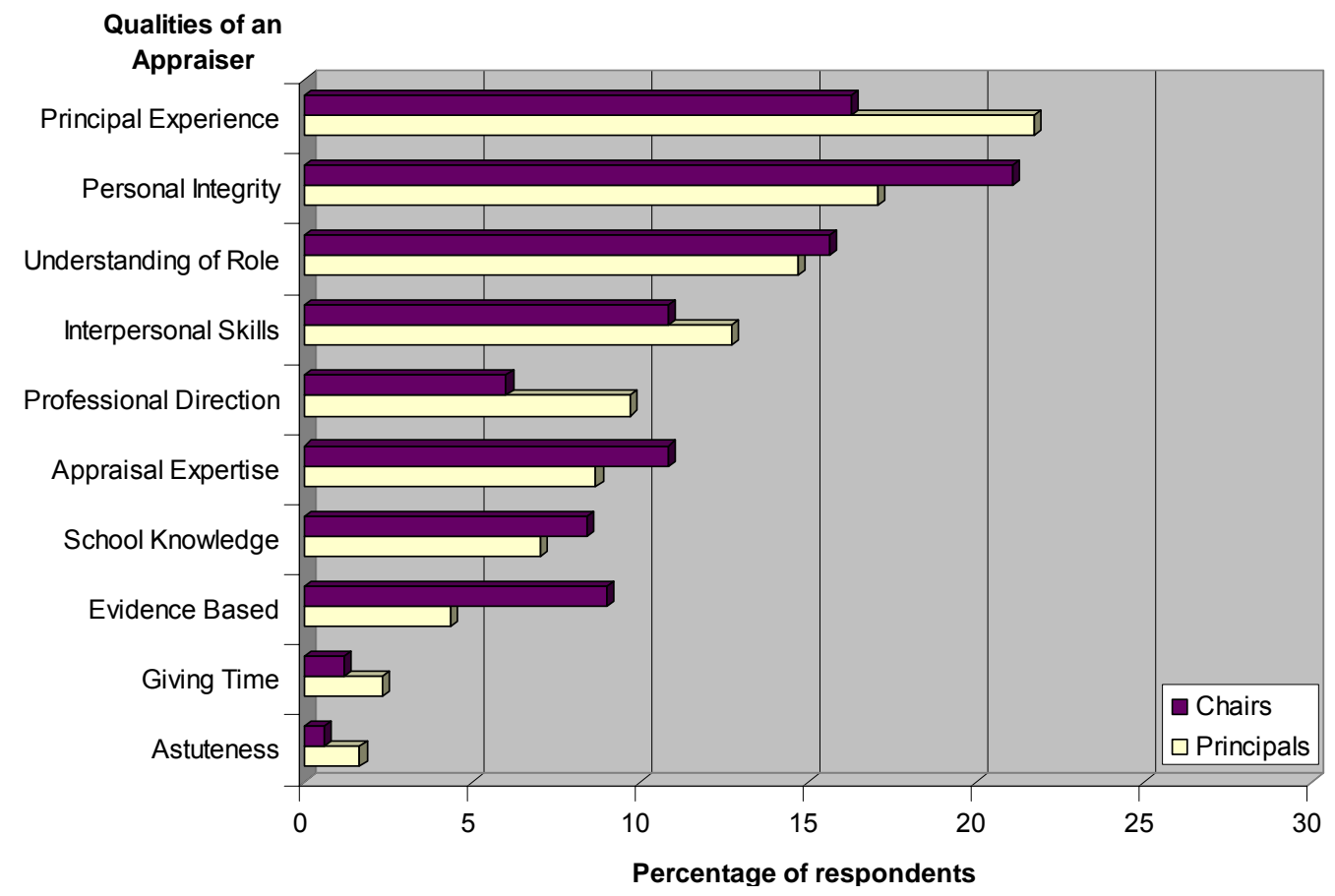

Figure 4.3: Ideal qualities an appraiser should possess as identified by principals and chairs

\subsubsection{Appraisers' possession of important qualities}

Respondents were asked to rank the extent to which the appraiser in 2006 possessed each of the important qualities deemed to be most important, using a five point differential rating scale:

$$
\begin{array}{ll}
1=\text { not at all. } & 2=\text { hardly. } \quad 3=\text { to a limited extent. } \\
4=\text { to a satisfactory extent. } & 5=\text { completely. }
\end{array}
$$

Table 4.7: Ratings for appraiser possessing important appraisal qualities based on up to three qualities identified by each respondent

\begin{tabular}{|c|c|c|c|c|}
\hline Ratings & $\begin{array}{c}\text { \% All CA } \\
\text { Principals N=37 } \\
\text { Total no } \\
\text { ratings=101 }\end{array}$ & $\begin{array}{c}\text { \% All EA/CE } \\
\text { Principals } \mathbf{N = 6 5} \\
\text { Total no } \\
\text { ratings=187 }\end{array}$ & $\begin{array}{c}\text { \% All CA } \\
\text { Chairs N=27 } \\
\text { Total no } \\
\text { ratings=78 }\end{array}$ & $\begin{array}{c}\text { \% All EA/CE } \\
\text { Chairs } \mathbf{N}=\mathbf{2 9} \\
\text { Total } \text { no } \\
\text { ratings=87 }\end{array}$ \\
\hline $\mathbf{1}$ & 0.0 & 0.0 & 0.0 & 2.4 \\
\hline $\mathbf{2}$ & 5.9 & 0.0 & 2.6 & 2.4 \\
\hline $\mathbf{3}$ & 7.9 & 4.8 & 15.4 & 4.7 \\
\hline $\mathbf{4}$ & 30.7 & 25.7 & 51.4 & 23.5 \\
\hline $\mathbf{5}$ & 55.4 & 69.0 & 30.8 & 67.1 \\
\hline
\end{tabular}


Respondents were asked to identify and rate three qualities but some provided fewer than three. In the case of CA principals for example there were ten less than the maximum of $111(37 \times 3)$. The actual number of rated qualities was used to calculate the percentages in Table 4.7.

Data were analysed to determine any differences between primary and secondary responses. As Table 4.7 shows, the vast majority of principals indicated their appraiser possessed qualities they deemed important completely, or to a satisfactory extent. Where an EA was involved (including in CE appraisals), this was the case for $100 \%$ of SP and $94.3 \%$ of PP. Chairs were also largely positive about the qualities of EA with $93.8 \%$ of secondary and $89.9 \%$ of primary rating them 4 or 5 on the scale. CE chairs were asked for two assessments: the extent to which they, and the EA they worked with, possessed the important qualities. The final column in Table 4.7 shows their ratings of EA, with self-assessment incorporated in Figure 4.4 .

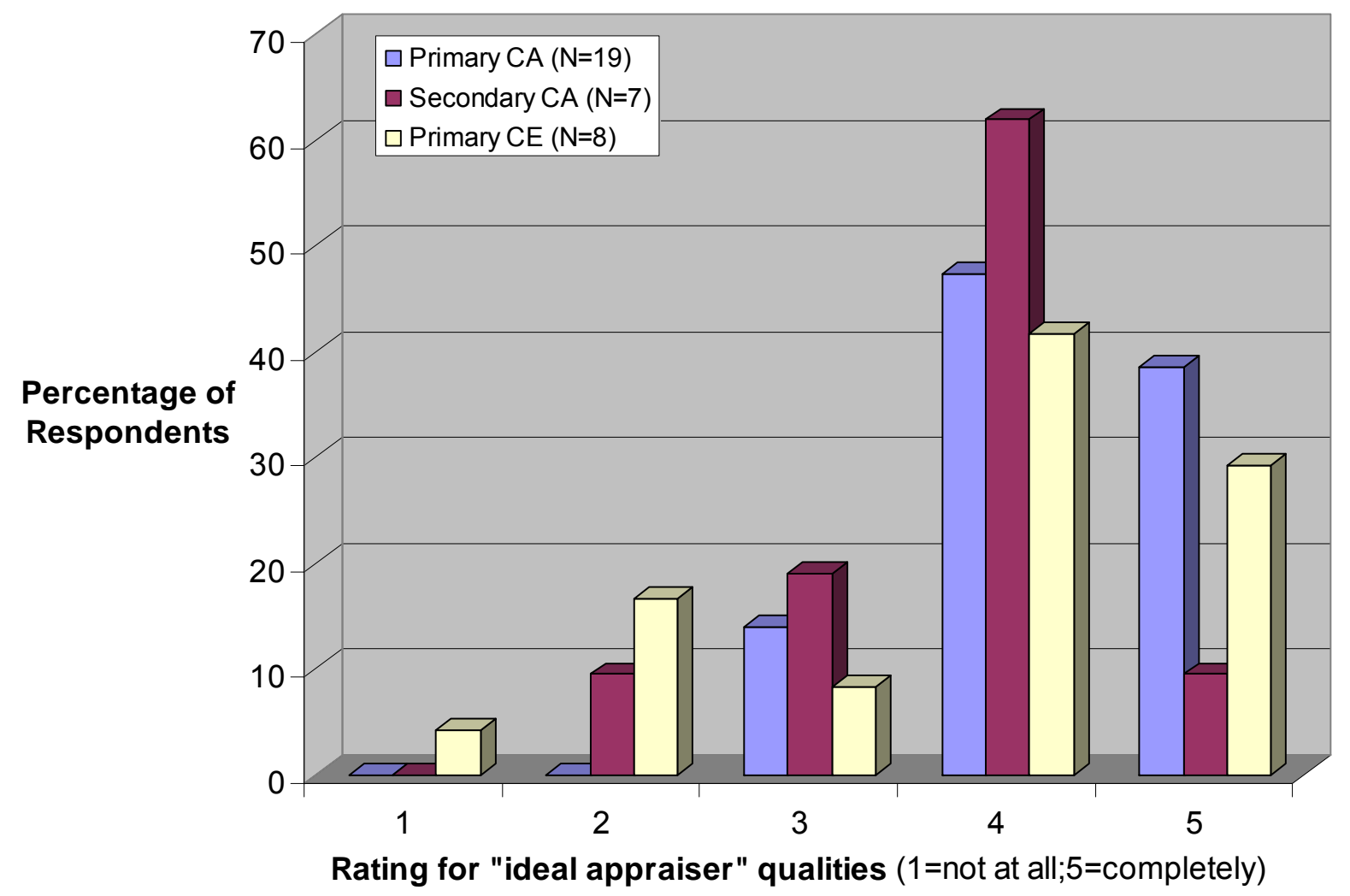

Figure 4.4: Chair self-ratings of their qualities as an appraiser (CA and CE)

Figure 4.4 shows the majority of chairs were positive about their own abilities with $86 \%$ of PCA and over $70 \%$ of other chairs agreeing or strongly agreeing that they possessed the requisite qualities. Secondary were most likely to take a neutral 
stance $(19 \%)$ whilst the largest group with low ratings of 1 or 2 were PCE (20.9\%). Further insights into chairs' confidence in undertaking the appraisal were gathered in the Outcomes section of the survey (see p. 75).

Principals also agreed that CA possessed the important qualities, with little difference between secondary $(89.3 \%)$ and primary (86.1\%). This gives a strong indication that most CA principals believed their chairs possessed the requisite qualities for carrying out the appraisal.

\subsubsection{Training and experience of chairs}

CA and CE were asked to indicate the extent of their training and experience for the appraisal. Just over half (57.1\%) of SC and $73.7 \%$ of PC undertaking the appraisal alone or with a fellow trustee in 2006 had previous experience of principal appraisal.

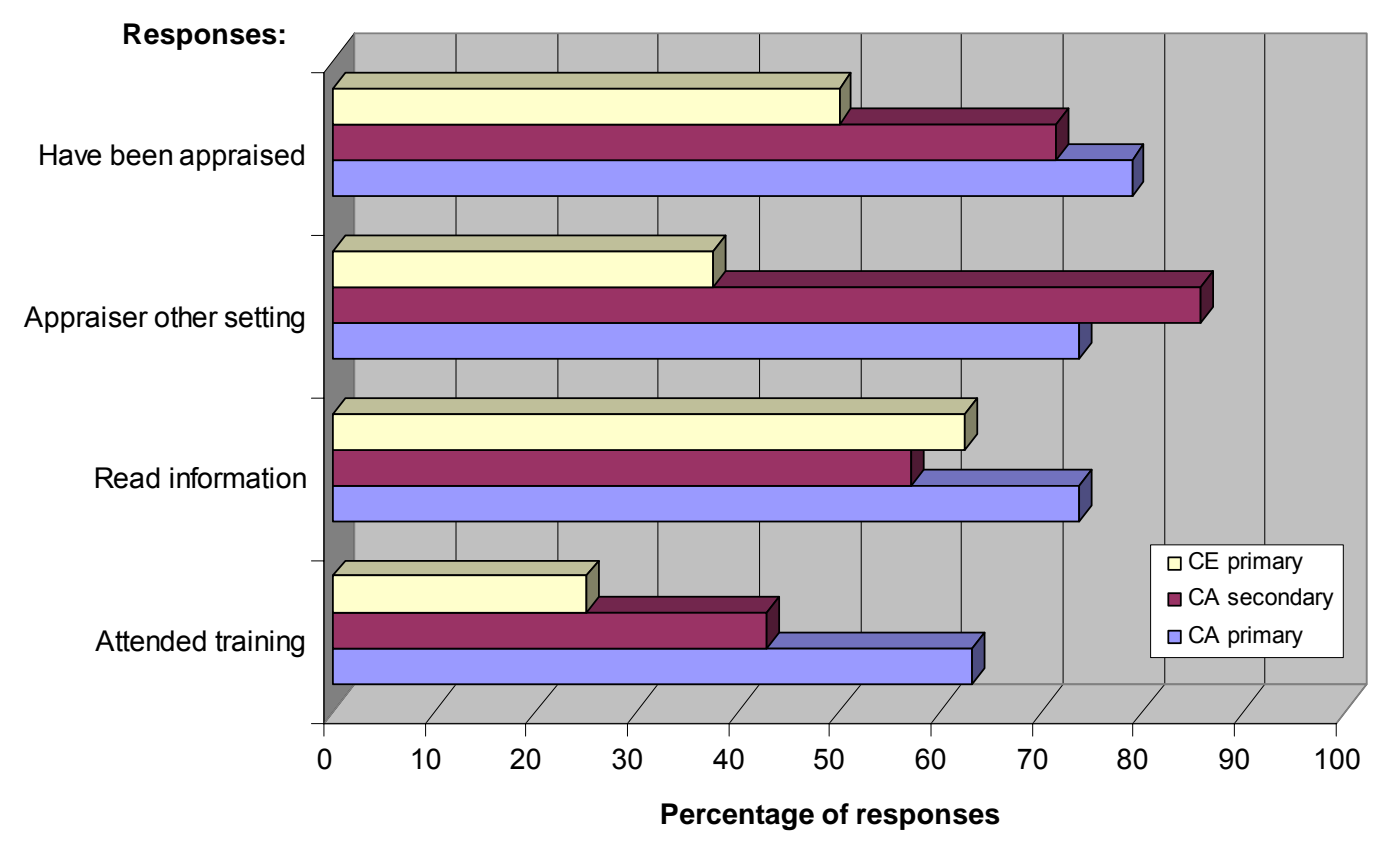

Figure 4.5: Training and experience of chairs

Other types of preparation are shown in Figure 4.5 PCA were most likely to have attended training (two-thirds compared with $43 \%$ of SCA). Around a quarter of CE had also attended training. 


\subsection{What role does a performance agreement play in the appraisal process?}

\section{Good Practice Framework (MOE 2007)}

Purpose

2. Appraisal is based on the annual performance agreement.

3. The performance agreement contains annual objectives for the principal (including one or more professional development objectives) and all the professional standards relevant to the role.

4. The performance agreement is future focused and must reflect the school's strategic and annual plans, and the principal's job description.

\section{Excerpt 4.3: Good Practice Framework, MOE, 2007}

This question sought to confirm whether all principals have a performance agreement and if so who is involved in its negotiation. It also explored linkages between performance expectations, BOT strategic objectives and principal professional development opportunities.

Collective employment agreements for principals require that the criteria for performance review be contained in a written performance agreement. Ninety-five percent of principals indicated they had such an agreement.

\subsubsection{Determining the focus of the agreement}

Less than a quarter of chairs (23.4\%) indicated the board had input into the agreement. However, just under half of chairs (48\%) themselves contributed, either as the appraiser or in conjunction with an EA.

Where the board did have input, the extent ranged widely, as comments from two primary principals illustrate:

Discussed with chair during our weekly meetings and asked board for input as a whole during a board meeting. More conferring = more effectiveness. (CE)

Wrote my agreement/goals - board ratified them. (CA)

SP reported a higher degree of board input: over two-thirds $(68.4 \%)$, compared to under half $(48.2 \%)$ for PP. Twenty percent of PP and $5.3 \%$ of SP indicated that 
they had largely determined what was in their performance agreement with this figure averaging out to $11.5 \%$ across both sectors.

Referring to an appraisal carried out by an EA, a PC commented that the performance agreement was:

basically a detailed set of tasks such as 'attend this meeting', 'write this report' etc.

This underlines the danger of the BOT handing over this important aspect to a consultant appraiser. The next section of the survey looked at the relationship of the performance agreement to other processes.

\subsubsection{Linkages to key BOT documentation and processes}

Table 4.8: Links between performance agreement and key documentation or processes

\begin{tabular}{|l|c|c|c|}
\hline Respondent Groups & \% Charter goals & \% Annual plan & \% Principal PD \\
\hline Primary CA & 94.7 & 100 & 84.2 \\
\hline Primary EA & 78.6 & 85.7 & 78.6 \\
\hline Primary CE & 77.8 & 100 & 100 \\
\hline Secondary CA & 71.4 & 71.4 & 57.1 \\
\hline Secondary EA & 100 & 83.3 & 83.3 \\
\hline Average all chairs & $\mathbf{8 4 . 5}$ & $\mathbf{8 8 . 1}$ & $\mathbf{8 0 . 6}$ \\
\hline \multicolumn{4}{|l|}{} \\
\hline Primary Principals & 92.9 & 89.4 & 81.2 \\
\hline Secondary & 73.7 & 94.7 & 78.9 \\
\hline Average all Principals & $\mathbf{8 9 . 4}$ & $\mathbf{9 0 . 4}$ & $\mathbf{8 0 . 8}$ \\
\hline
\end{tabular}

Responses indicate most performance agreements were linked to the charter, annual plan and principal professional development. As one PCA put it:

All three are critical for a well rounded individual performing to the board's required standards.

Linkages were strongest in relation to the annual plan, with $88.1 \%$ of all chairs and $90.4 \%$ of principals reflecting an expectation that the board's chief executive play a key role in the achievement of annual targets and objectives. Linkages were least explicit in responses from SCA but even here almost three-quarters $(71.4 \%)$ indicated a link to the charter and annual plan and over half $(57.1 \%)$ a link to professional development. 


\subsection{How comprehensive is the appraisal?}

This question sought insights into the comprehensiveness of the appraisal by gathering information on frequency of appraisal meetings, sources of data and exploring who has an opportunity to comment on the principal's performance.

\subsubsection{Frequency of meetings}

Respondents' ability to answer this multi-choice question was complicated by the need to differentiate between regular principal/chair meetings and appraisal meetings. Over a third $(36.8 \%)$ of PCA indicated they met with the principal regularly, a typical comment being:

Met with principal privately most weeks during term time and followed up on specific goals at some of those meetings.

This issue also came up in principal responses, for example an SP CA said meetings had been held:

Formally only at the beginning and end of the process, but we meet every week, so issues came up regularly.

At the same time, chairs not involved in the process were less likely to have reliable information as to the frequency of meetings between the principal and appraiser as this comment from a PC indicated:

Believe they met 3 times.

Table 4.9: Chair responses on frequency of meetings

\begin{tabular}{|l|c|c|c|c|c|c|}
\hline Group & \% Once & \% Twice & \% 3 times & \% Per term & \% Monthly & \% Other \\
\hline Secondary (13) & 22.7 & 7.2 & 15.5 & 40.5 & 7.2 & 7.2 \\
\hline Primary (42) & 12.0 & 14.6 & 23.5 & 28.5 & 3.5 & 17.9 \\
\hline All chairs (55) & $\mathbf{1 6 . 2}$ & $\mathbf{1 1 . 6}$ & $\mathbf{2 0 . 3}$ & $\mathbf{3 3 . 3}$ & $\mathbf{5 . 0}$ & $\mathbf{1 3 . 6}$ \\
\hline
\end{tabular}

Collated responses show no clear pattern, with anything between a one-off and regular monthly appraisal meetings occurring. Chair data indicate once a term meetings are $12 \%$ more likely in secondary than primary appraisals (Table 4.9). Principal responses indicate meetings are held each term in $18 \%$ more primary than secondary appraisals (Table 4.10).

${ }^{9}$ For instance "several times" 
Table 4.10: Principal responses on frequency of meetings

\begin{tabular}{|l|c|c|c|c|c|c|}
\hline Group & \% Once & \% Twice & \% 3 times & \% Per term & \% Monthly & \% Other* \\
\hline Secondary (19) & 15.8 & 31.6 & 10.5 & 26.3 & 5.3 & 10.5 \\
\hline Primary (85) & 15.3 & 11.8 & 10.6 & 44.7 & 8.2 & 9.4 \\
\hline All Principals (104) & $\mathbf{1 5 . 6}$ & $\mathbf{2 1 . 7}$ & $\mathbf{1 0 . 6}$ & $\mathbf{3 5 . 5}$ & $\mathbf{6 . 8}$ & $\mathbf{1 0}$ \\
\hline
\end{tabular}

Table 4.10 data show over half of PP $(52.9 \%)$ had at least one appraisal meeting per term compared to just under a third of their secondary colleagues (31.6\%). Sixteen $(15.3 \%)$ of principals indicated they met only once with their appraiser raising possible questions about the rigor and depth of the process.

Because of the complication of regular principal/chair meetings, information on frequency of appraisal meetings is most likely to be accurate in responses from 66 principals with an EA. Table 4.11 below shows almost half indicated they had met at least once a term with their appraiser.

Table 4.11: Principals with EA/EC appraiser responses on frequency of meetings

\begin{tabular}{|c|c|c|c|c|c|c|}
\hline Number & \% Once & \% Twice & \% 3 times & \% Per term & \% Monthly & \% Other* \\
\hline 66 & 12.6 & 21.9 & 11.7 & 47.7 & 1.8 & 4.4 \\
\hline
\end{tabular}

Meetings are one indicator of a comprehensive approach to appraisal as a process rather than a one-off event. The collection of data is another indicator.

\subsubsection{Sources of appraisal evidence}

\section{Good Practice Guidelines: MOE 2007}

\section{Process}

6. The board and any delegated party and any contractor are required to objectively collect information.

7. The principal and the appraiser should provide evidence that is relevant to the performance agreement.

8. Evidence should be robust and cross-checked to ensure verification; and may be collected through methods including surveys, interviewing, focus groups, whanau or fono group feedback, observation of teaching (if appropriate) and/or documentary evidence.

Excerpt 4.4: Good Practice Framework, MOE, 2007 


\subsubsection{Principal data}

Existing documentation was widely used as a source of information. Principal reports were a source in $89.5 \%$ of secondary and $81 \%$ of primary appraisals. Just over $63 \%$ of SP and $51 \%$ of PP indicated school newsletters were another source, (see Figure 4.6).

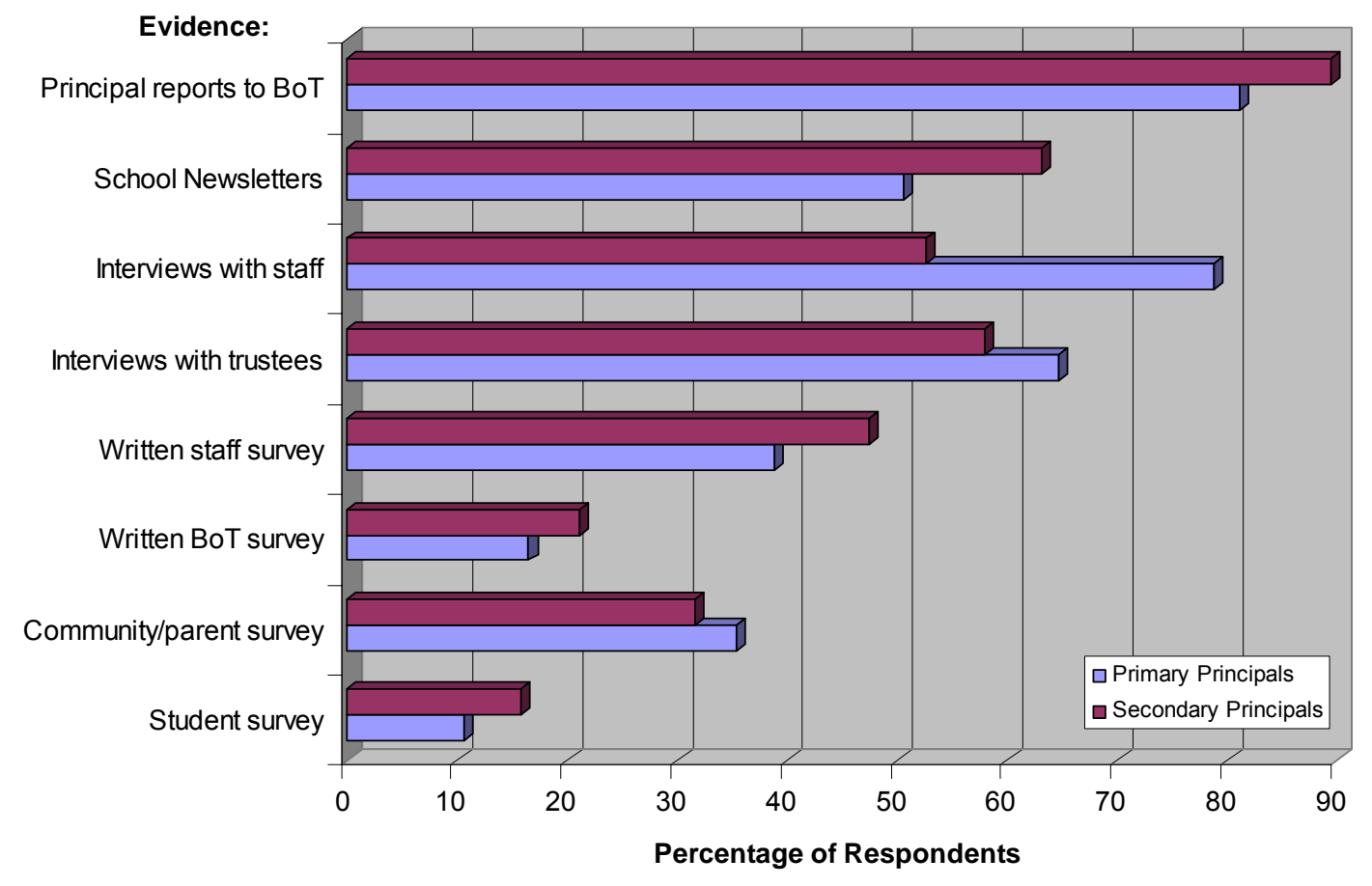

Figure 4.6: Sources of appraisal evidence from principals

Most appraisals involved stakeholders with primary school staff the most widely consulted group. Seventy-nine percent of PP indicated staff had been interviewed and $39 \%$ that staff had been surveyed. Figures for secondary schools where $52.6 \%$ were interviewed and $47.4 \%$ surveyed, also suggest opportunities for staff input.

Principal information on BOT input shows little difference between the two sectors. In almost two-thirds of primary (65\%) and over half of secondary (57.9\%) appraisal interviews took place with trustees. In $16 \%$ of primary and $21 \%$ of secondary appraisals there was a written board survey. Overall these figures are lower than for staff, but the board also has input through its chair.

Responses indicating any contact (phone, interview or survey) with parents were counted as "community survey". Around a third of principals indicated there had 
been some community input into the data gathering and $11 \%$ of PP and $15.8 \%$ of SP indicated there had been feedback from students.

Overall, principal responses suggest primary appraisals were more likely to involve interviews with key stakeholders, whilst there was a greater tendency to look for evidence in existing documentation or written surveys in secondary appraisals.

\subsubsection{Chair data}

Some EA had difficulties answering this question with $28.6 \%$ of primary indicating uncertainty as to what sources had been used. Many were themselves an evidence source, with $64.3 \%$ of primary EA/CE and $83.3 \%$ of secondary EA chairs interviewed.

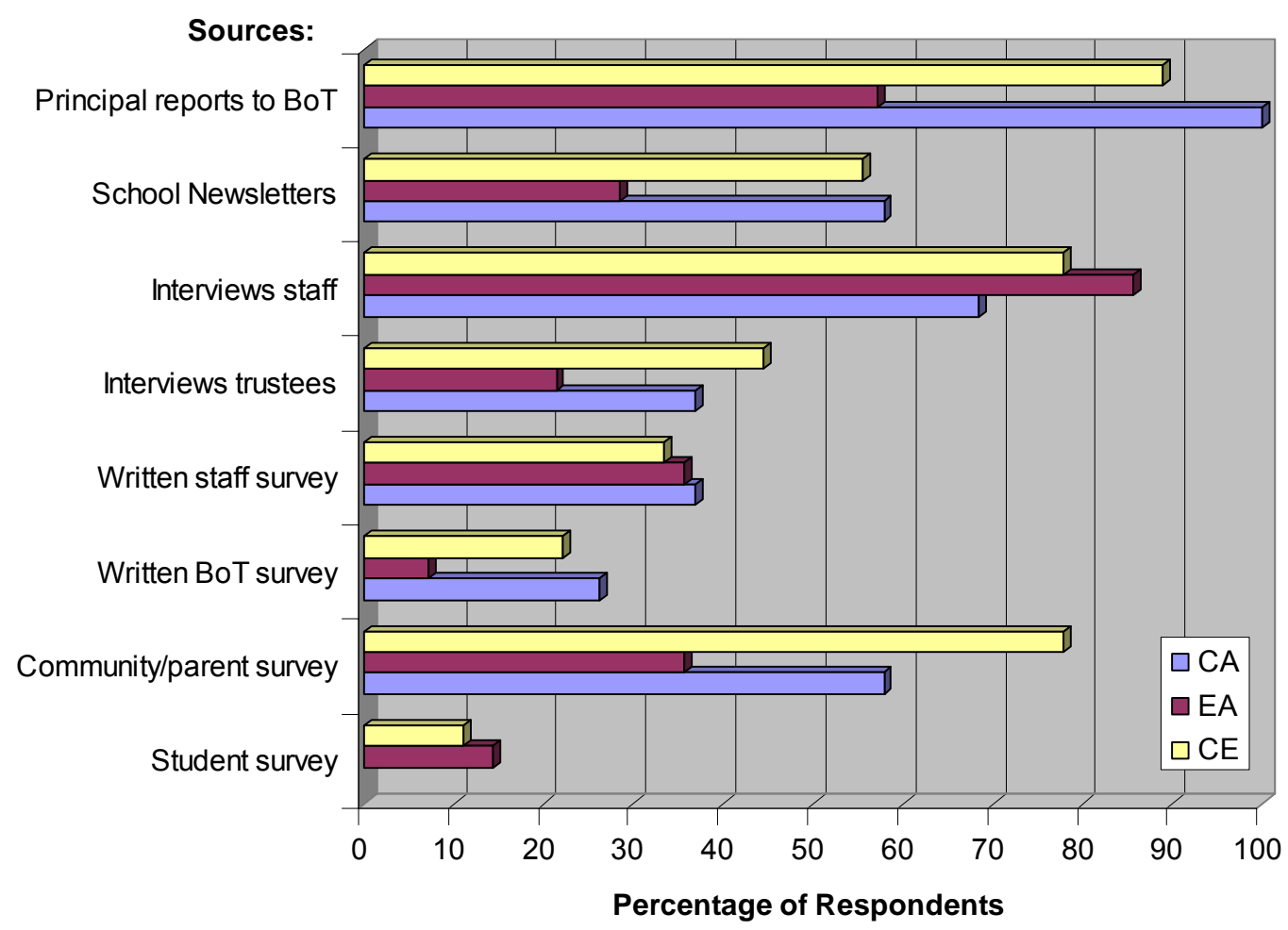

Figure 4.7: Sources of appraisal data from primary chairs

Figures 4.7 and 4.8 indicate principal reports to the board were a source in all primary and secondary CA appraisals, nearly $90 \%$ of primary CE but only just over half $(57.1 \%)$ of primary EA appraisals. The link between principal reporting and appraisal evidence is explored in relation to outcome statements in 4.8.1.

School newsletters, which can provide insights into school life for an off-site appraiser, were most likely to be used as a source in secondary EA appraisals $(83.3 \%)$ and least likely in primary EA $(28.6 \%)$. 


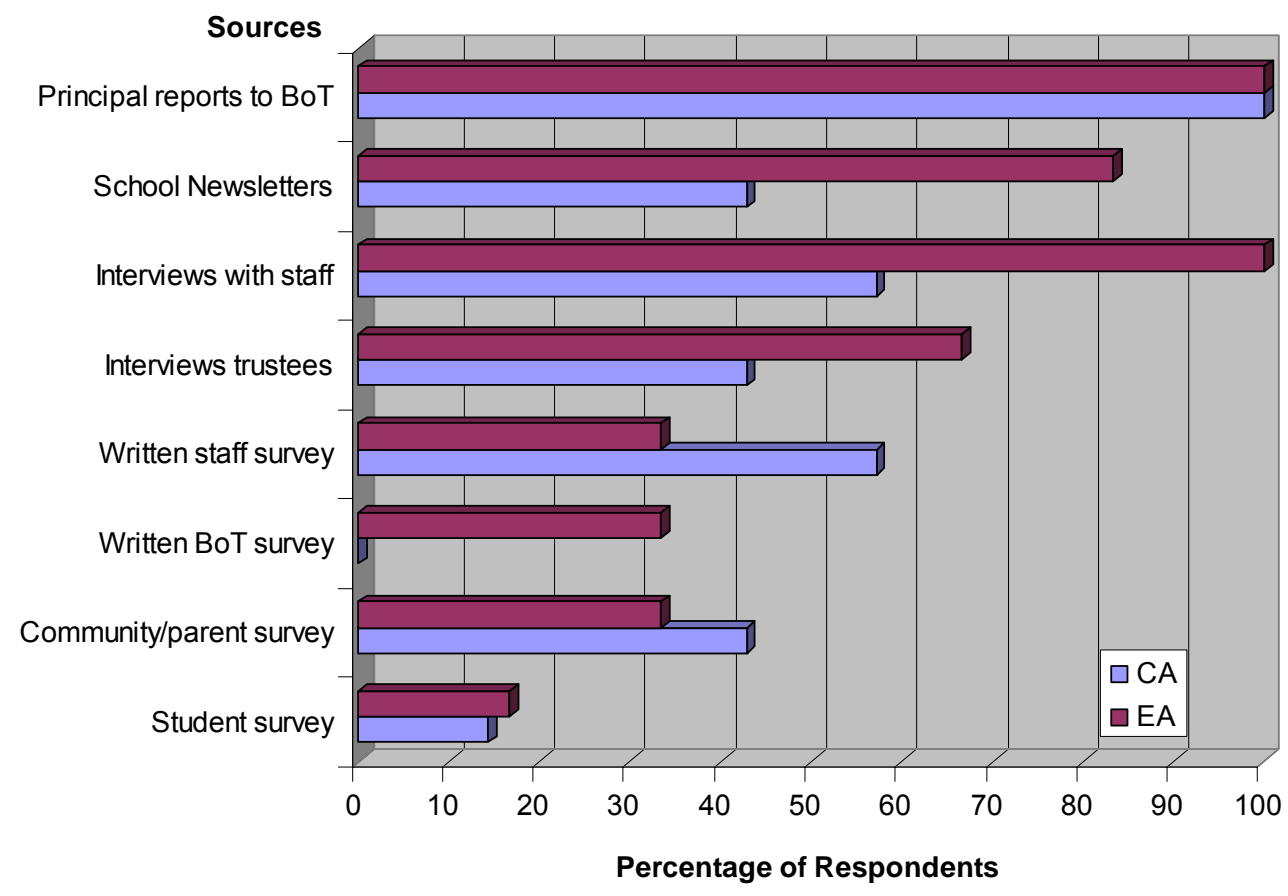

Figure 4.8: Sources of appraisal data from secondary chairs

Chairs also indicated staff input was a major source of evidence. Again staff interviews were most likely to occur in primary, particularly when an EA was involved. This was identified by $74 \%$ of EA/CE compared with $68 \%$ of CA. The gap was wider in secondary: $100 \%$ of CE but only $57 \%$ of CA. In addition $57 \%$ of SCA and around a third of all other chairs indicated staff had been involved in a written survey.

Primary EA were less likely to interview trustees other than the chair. This happened in only $21.4 \%$ of appraisals compared to two thirds of secondary. A third of secondary EA chairs also indicated there had been a written survey of trustees compared to only $7.1 \%$ of primary EA and $22.2 \%$ of CE. Just over a third of PCA, and $42.9 \%$ of secondary SCA interviewed fellow trustees and a quarter of PC also conducted a written survey of the board.

The parent community was most likely to be asked for feedback in primary CE appraisals $(77.8 \%)$ compared to only around a third of EA appraisals in both sectors. In CA appraisals the figures were $58 \%$ for primary and $42.9 \%$ for secondary. 
Chair responses were analysed using the additional student input category that emerged from principal data. No PCA and just over $10 \%$ of all other chairs volunteered that student input had been sought.

Overall, there was a higher reliance on staff interviews in EA appraisals but this form of evidence was least likely to be gathered by secondary CA. Primary appraisals relied less on existing documentation than those in secondary schools.

\subsection{Are appraisal outcomes shared with the BOT and if so in what form?}

\section{Good Practice Guidelines: MOE 2007}

\section{Process}

9. The board (or its delegated trustee/committee) must consider the report of any contractor, make a written evaluative judgment and assemble the final appraisal report for the principal.

10. The principal will receive a copy of the final appraisal report for their consideration and comment.

11. Irrespective of whether the board delegates to a trustee/committee the management of the appraisal process, the final appraisal report, or a summary of it, will be prepared for the full board in accordance with the board's own policy.

12. This final appraisal report, or a summary of it, should always be provided to the full board 'in committee'. Provision should be made for the board's discussion of the report, during which time the principal is able to speak to the report, but in accordance with legislation, will not otherwise be in attendance.

\section{Excerpt 4.5: Good Practice Framework, MOE, 2007}

This question sought to ascertain details of reporting on the appraisal, specifically:

- is a written report prepared and if so who gets to see it?

- is the outcome brought to a BOT meeting?

- is the principal present at any discussion of the appraisal outcome by the BOT? 


\subsubsection{Principal data}

Just under $90 \%$ of principals were supplied with an appraisal report as were almost a third of secondary (31.8\%) and over half (51.8\%) of primary BOT (see Figure 4.9 ). An additional $14.1 \%$ of PC and $5.3 \%$ of SC received a copy of the report.

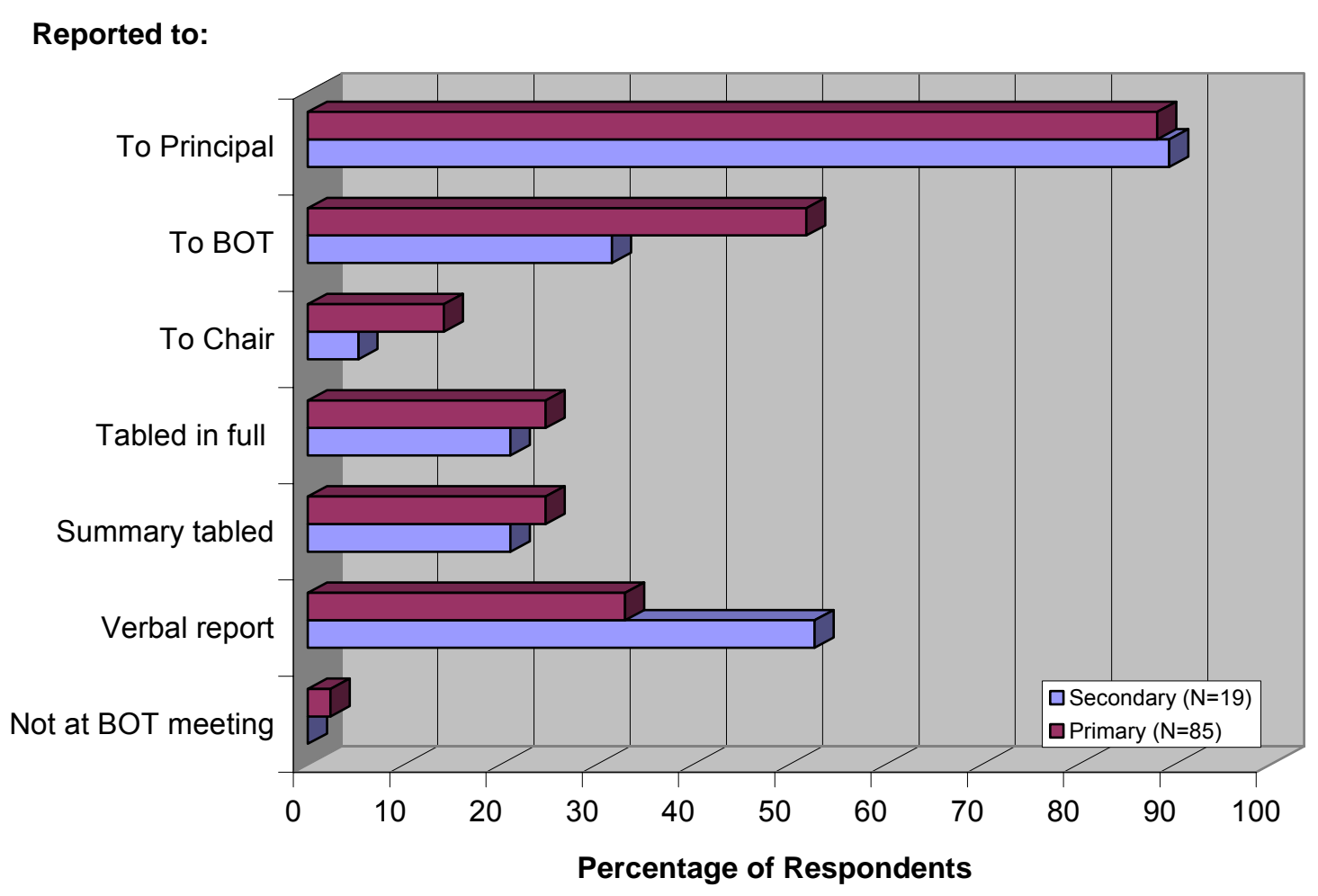

Figure 4.9: Dissemination of appraisal report from principal data

As at April 2007 five PP (5.9\%) and one SP indicated their boards (as distinct from the chair) had received no information on the outcome of the 2006 appraisal. In most instances comments suggested this would occur in due course but one principal noted the board was advised the process had been undertaken, implying no further reporting was intended.

Over half of primary BOT $(57.6 \%)$ and $42.1 \%$ of secondary boards had a summary or full appraisal report tabled at a board meeting. Over half of secondary (52.6\%) and almost a third (32.9\%) of primary received a verbal report. Only $2.4 \%$ of PP indicated that there had been no reporting on the appraisal at a board meeting. 


\subsubsection{Chair data}

Chair responses support the overall picture of reporting suggested by principals. All principals received a copy of the report but only $38.1 \%$ of PC and $46.2 \%$ of SC indicated one had been supplied to the BOT (see Figure 4.10). In their comments a further $14.3 \%$ of PC and $7.7 \%$ of SC indicated they got the report. One EA chair said only the principal received a copy, adding:

Supplying to board would have been relevant. Unfortunately the external appraiser was unavailable to present the findings as there were not any new ones brought to light.

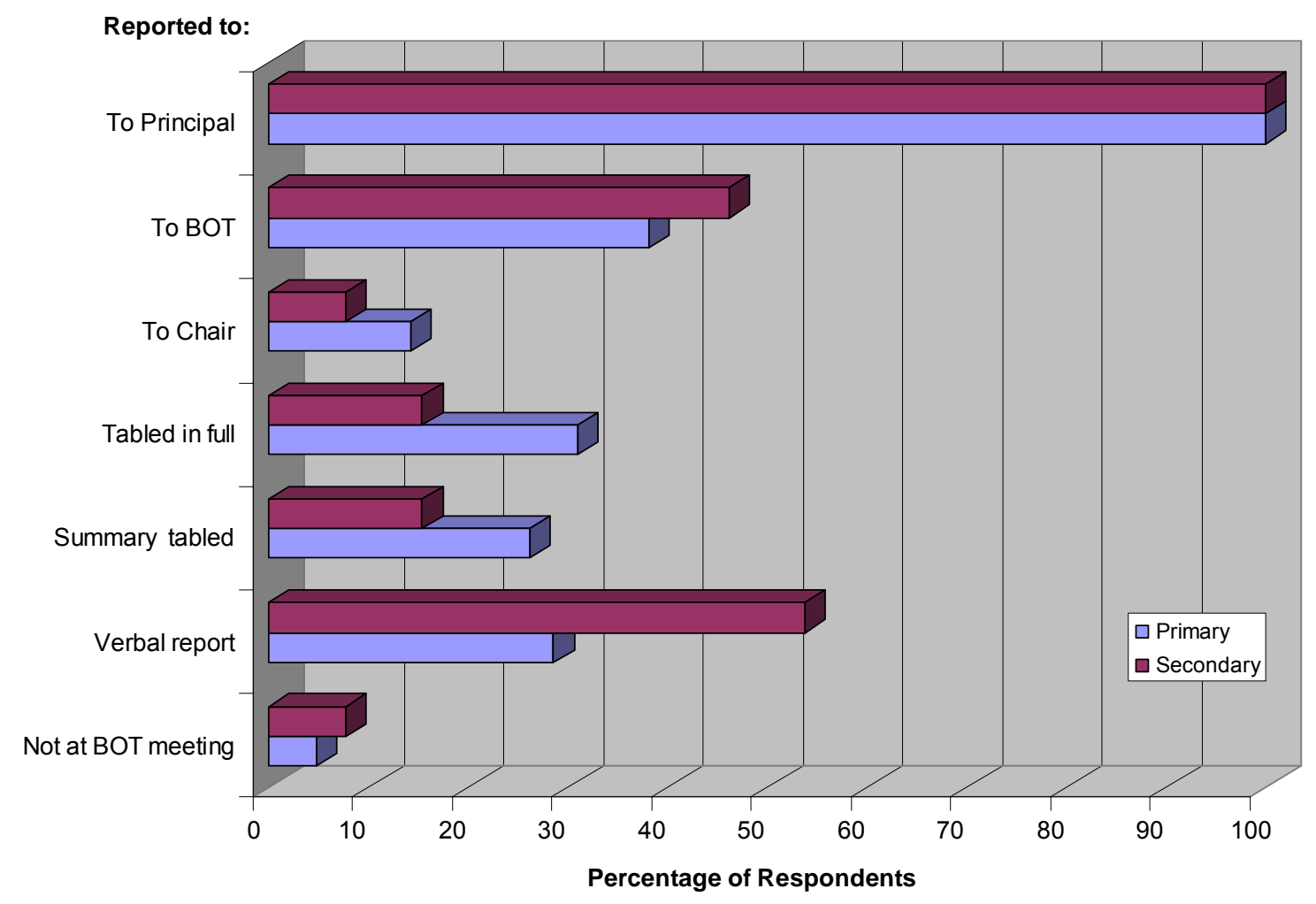

Figure 4.10: Dissemination of appraisal report from chair data

Over half of primary boards (54.8\%) and just under a third of secondary boards $(30.8 \%)$ had a summary or full report tabled at their board meeting. The primary figure was similar to principal data but for secondary was $11 \%$ lower than principal data suggested. Over half of secondary $(53.8 \%)$ and $28.3 \%$ of primary received a verbal report, almost identical to the findings from principal data. Less than $10 \%$ of chairs indicated that there had been no report on the appraisal at a board meeting.

These responses suggest that whilst BOT received some reporting on the appraisal it is unclear whether this was sufficiently detailed to enable them to carry out their role of monitoring principal performance. 


\subsubsection{BOT discussion of outcomes}

It appears the majority of boards receive some information on the outcome of the appraisal, but to what extent do they have an opportunity to fully discuss its implications? The second part of the question asked whether the principal had been present at any meeting of the board to discuss the appraisal outcome. Responses indicate the majority of principals remained present during such discussions (see Table 4.12). However, comparison of PP and SP responses show an $8 \%$ greater likelihood of this happening in primary schools. Chair responses suggest a $25 \%$ greater likelihood of the principal remaining present in secondary schools, with this occurring in over three-quarters of instances reported compared with just over half in primary.

Table 4.12: Whether principal present at board discussion of appraisal outcomes

\begin{tabular}{|l|c|c|c|}
\hline \multicolumn{1}{|c|}{ Group } & \% Yes & \% No & $\begin{array}{c}\text { \% N/A (e.g. not discussed by full board; } \\
\text { appraisal not completed) }\end{array}$ \\
\hline Secondary principals (19) & 57.9 & 26.3 & 15.8 \\
\hline Primary principals (85) & 65.9 & 16.5 & 17.6 \\
\hline Secondary chairs (13) & 76.9 & 15.4 & 7.7 \\
\hline Primary chairs (42) & 52.4 & 33.3 & 14.3 \\
\hline
\end{tabular}

Comments expand on the insights provided by these statistics. In cases where the principal remained present:

Option was given for the board to discuss in absence of principal but this was not considered necessary. (SC EA)

I just said that the process had been successfully completed. (SC CA)

Two primary EA chairs commented on the principal not being present:

Usually present and happy to answer questions but unwell [when meeting held].

This was negotiated with principal in previous year.

Other chairs suggested procedures more in line with the GPF:

Yes and no - it is our practice to invite the principal to leave the meeting for a time, to allow trustees to discuss the appraisal report, but the principal is then invited to return so that a discussion of key points can occur. (PC CA)

Report was supplied with principal present and discussion ensued (no student trustee). When setting goals, board met briefly without principal then full discussion included him. At no point has the student trustee been present. The chair reported to the student trustee. (SC EA) 
The legality of excluding the student trustee is questionable but in my experience is not uncommon. Overall, the fact between half and three-quarters of principals remained present throughout the board's discussion of the report appears to be contrary to the Ministry's good practice guidelines.

\subsection{Outcomes of the appraisal}

This question listed up to eight statements for principals and nine for chairs, aimed at exploring attitudes towards the appraisal and its outcomes. Responses were sought on a five point rating scale ranging from 1 (strongly disagree) to 5 (strongly agree). A comments box was provided below each statement.

\subsubsection{Comparison of responses}

The majority of responses to statements from all groups, and across both sectors, were positive. Comparisons were made of the positive, neutral and negative responses to see whether the involvement of an EA was a factor. Appendix $E$ also shows comparisons between the mean, median and mode for principals, CA and EA/CE chairs. Variability between these groups was not material and was in the range 0.567 to 1.180 for statements 1 to 8 . Variability between CA and EA/CE chairs in relation to the statement on their confidence was slightly higher.

The following analysis is shown under the headings of statements from the BOT chair survey. The wording in the principal survey was closely based on this, statement 1 for instance reading:

The appraisal process has strengthened my working relationship with the board.

\section{The appraisal process strengthened the board's working relationship with} the principal

Table 4.13: Distribution of ratings for appraisal process link with strengthened relationships

\begin{tabular}{|l|c|c|c|c|}
\hline Ratings & $\begin{array}{c}\text { \% CA } \\
\text { Principals } \\
\mathbf{N = 3 8}\end{array}$ & $\begin{array}{c}\text { \% EA/CE } \\
\text { Principals } \\
\mathbf{N = 6 5}\end{array}$ & $\begin{array}{c}\text { \% CA } \\
\text { Chairs } \\
\mathbf{N = 2 6}\end{array}$ & $\begin{array}{c}\text { \% EA/CE } \\
\text { Chairs } \\
\mathbf{N}=\mathbf{2 9}\end{array}$ \\
\hline Positive (4 and 5) & 59.4 & 52.3 & 65.4 & 68.9 \\
\hline Neutral (3) & 40.5 & 40.0 & 30.8 & 24.1 \\
\hline Negative (1 and 2) & 0.0 & 7.7 & 3.8 & 6.9 \\
\hline
\end{tabular}


Over half of PP and two thirds of SP responded positively. There was little difference amongst chair ratings with $65.4 \%$ of $C A$ and $68.9 \%$ of EA/CE agreeing or strongly agreeing with the statement. Affirmative comments on this statement included:

It has established a far more realistic expectation of what the job entails. (PP EA)

Really confirmed what we already know i.e. that we have a fantastic principal! (PC CE)

Approximately $40 \%$ of principals, $30 \%$ of CA chairs and $24 \%$ of EA/CE chairs took a neutral/can't say stance for reasons such as:

A lack of board involvement limited any impact on the relationship. (PC EA)

Not especially, as it was already good for all parties. (PP EA)

A small number of EA principals $(7.7 \%)$ and even fewer chairs disagreed with the statement, identifying specific issues including:

I received virtually no feedback from board. Don't really know what they thought. My personal view very positive. (PP EA)

Taken together with comments, ratings suggest the appraisal had no negative impact on the principal/board relationship and more often than not was a positive force for strengthening it.

\section{The appraisal process helped the board to know whether school goals are being achieved}

Table 4.14: Distribution of ratings for appraisal process link with school goals

\begin{tabular}{|l|c|c|c|c|}
\hline Ratings & $\begin{array}{c}\text { \% CA } \\
\text { Principals } \\
\mathbf{N = 3 8}\end{array}$ & $\begin{array}{c}\text { \% EA/CE } \\
\text { Principals } \\
\mathbf{N = 6 5}\end{array}$ & $\begin{array}{c}\text { \% CA } \\
\text { Chairs } \\
\mathbf{N = 2 6}\end{array}$ & $\begin{array}{c}\text { \% EA/CE } \\
\text { Chairs } \\
\mathbf{N = 2 9}\end{array}$ \\
\hline Positive (4 and 5) & 64.4 & 57.8 & 50.0 & 75.9 \\
\hline Neutral (3) & 30.8 & 28.1 & 26.9 & 10.3 \\
\hline Negative (1 and 2) & 11.1 & 14.0 & 19.2 & 13.7 \\
\hline
\end{tabular}

Strongest agreement with the statement came from EA/CE chairs with just over three-quarters agreeing or strongly agreeing, compared with exactly half of CA chairs. A slightly higher percentage of CA principals than EA principals indicated agreement/strong agreement: $64 \%$ compared with $57.8 \%$. Comments included:

Great tool for this. (PC CE) 
Independent opinion gives added assurance to board that charter/annual plans goals have been achieved. (PP EA)

Over a quarter of CA chairs and just over $30 \%$ of CA principals gave a neutral/don't know rating. The figure was slightly less for EA principals. Only $10.3 \%$ of EA/CE were neutral or uncertain.

Negative responses to this statement ranged from $11.1 \%$ (CA principals) to $19.2 \%$ (CA chairs), with both EA groups $14 \%$. As for neutral ratings, some comments indicated that disagreement related to a perception that this information was obtained through other means:

The principal's goals were directly related to the schools' and teachers' goals anyway. (PC CA)

This comes from the principal's monthly report to board which is quite comprehensive! (SC CA)

The view that data sources in the appraisal (rather than the appraisal process and reporting) provided the board with reassurance was also reflected in responses to Statements 3 and 4 .

\section{The appraisal process provided the board with insights into the principal's strengths}

Table 4.15: Distribution of ratings for appraisal process link with principal strengths

\begin{tabular}{|l|c|c|c|c|}
\hline Ratings & $\begin{array}{c}\text { \% CA } \\
\text { Principals } \\
\mathbf{N = 3 8}\end{array}$ & $\begin{array}{c}\text { \% EA/CE } \\
\text { Principals } \\
\mathbf{N = 6 5}\end{array}$ & $\begin{array}{c}\text { \% CA } \\
\text { Chairs } \\
\mathbf{N = 2 6}\end{array}$ & $\begin{array}{c}\text { \% EA/CE } \\
\text { Chairs } \\
\mathbf{N = 2 9}\end{array}$ \\
\hline Positive (4 and 5) & 65.8 & 92.3 & 76.9 & 89.7 \\
\hline Neutral (3) & 31.6 & 6.2 & 7.7 & 6.9 \\
\hline Negative (1 and 2) & 2.6 & 1.5 & 15.4 & 3.4 \\
\hline
\end{tabular}

There was a strong affirmative response from EA principals (92.3\%) and EA/CE chairs $(89.7 \%)$ indicating external affirmation was highly valued, for instance:

Definitely - I am inclined to "pass over" my achievements and always look for "next steps". (PP CE)

Although lower, the response from CA respondents was also overwhelmingly positive. Almost two-thirds of CA principals, and over three-quarters of chairs agreed or strongly agreed with the statement. 
Virtually all remaining CA principals gave a neutral rating, with many of these again indicating this information was gained by other means:

Generally these are known because of the ongoing reporting/feedback/ observations during the year. (PP CA)

This view was echoed in the small don't know responses from EA principals (6.2\%), and less than $8 \%$ of chairs, for instance:

The culture of our place especially Management Team is such that we speak freely and openly - they tell me my strengths and weaknesses. (PP EA)

Less than $4 \%$ of principals and EA/CE chairs disagreed with the statement. Many of the $15.4 \%$ of CA chairs who responded negatively, reiterated:

Strengths already well known/established. (PC CA)

Responses suggest appraisal was effective in highlighting principal strengths, with a slightly higher likelihood of this occurring when an EA was involved.

\section{The appraisal process identified what the principal can do to improve his/her performance}

Table 4.16: Distribution of ratings for appraisal process link with principal performance improvement

\begin{tabular}{|l|c|c|c|c|}
\hline Ratings & $\begin{array}{c}\text { \% CA } \\
\text { Principals } \\
\mathbf{N = 3 8}\end{array}$ & $\begin{array}{c}\text { \% EA/CE } \\
\text { Principals } \\
\mathbf{N}=65\end{array}$ & $\begin{array}{c}\text { \% CA } \\
\text { Chairs } \\
\mathbf{N = 2 6}\end{array}$ & $\begin{array}{c}\text { \% EA/CE } \\
\text { Chairs } \\
\mathbf{N = 2 9}\end{array}$ \\
\hline Positive (4 and 5) & 73.7 & 86.2 & 80.8 & 75.8 \\
\hline Neutral (3) & 18.4 & 13.8 & 15.4 & 17.2 \\
\hline Negative (1 and 2) & 7.9 & 0.0 & 3.3 & 6.9 \\
\hline
\end{tabular}

Positive responses to this statement by CA principals were around $8 \%$ higher, at $73.7 \%$, than for the previous statements. EA/CE principal ratings were slightly lower than previously (by $6 \%$ ) at $86.2 \%$, but still extremely positive, for instance:

Especially when crossed referenced to other documentation e.g. ERO reports. (PP EA)

Over three-quarters of all chairs, with CA the highest at $80.8 \%$, agreed or strongly agreed with the statement. Comments included: 
As for other statements, there were some neutral responses, ranging from $13.8 \%$ for EA principals to $18.4 \%$ for CA principals. Comments generally indicated this occurred as a matter of course and was not limited to the appraisal, although one PP EA appeared to have a somewhat cynical view:

The process is an "add on". Forward thinking school leaders don't really need appraisals but to keep the bureaucrats happy we add it in to our busy schedules.

Less than $8 \%$ of CA principals and no EA/CE principals disagreed with this statement. There was an even lower (less than $7 \%$ ) negative rating response from chairs, but those who did disagree suggested a lack of focus on this aspect:

Whilst appraiser had lots of experience he did not address any areas for development. He approached the task as a "standards met" task. (PC CE)

As for the previous statement, principals with an EA were slightly more likely to indicate agreement. Interestingly the reverse was true for chairs with $5 \%$ more CA than EA/CE agreeing that the appraisal had identified what the principal could do to improve performance.

\section{The appraisal helped prioritise the principal's professional development focus for the following year}

Table 4.17: Distribution of ratings for appraisal process link with principal professional development

\begin{tabular}{|l|c|c|c|c|}
\hline Ratings & $\begin{array}{c}\text { \% CA } \\
\text { Principals } \\
\text { N=38 }\end{array}$ & $\begin{array}{c}\text { \% EA/CE } \\
\text { Principals } \\
\text { N=65 }\end{array}$ & $\begin{array}{c}\text { \% CA } \\
\text { Chairs } \\
\text { N=26 }\end{array}$ & $\begin{array}{c}\text { \% EA/CE } \\
\text { Chairs } \\
\text { N=29 }\end{array}$ \\
\hline Positive (4 and 5) & 63.2 & 72.3 & 72.0 & 72.4 \\
\hline Neutral (3) & 28.9 & 21.5 & 24.0 & 17.2 \\
\hline Negative (1 and 2) & 7.9 & 6.2 & 4.0 & 10.3 \\
\hline
\end{tabular}

Around $72 \%$ of EA/CE principals, and the same percentage of chairs agreed or strongly agreed with this statement. The figure for CA principals was a little lower at just under two-thirds. Comments included:

Provides specific target to be met. (PC CE)

Except I can't find what I need! (SP CA)

This difficulty of sourcing professional development was picked up by other principals and chairs: 
Ideally yes, but not always easy in practice to find the right kind of development opportunity. (PC CA)

Neutral responses to the statement ranged from $17.2 \%$ of EA/CE chairs to $28.9 \%$ of CA principals. One comment referred to the 2007 triennial board elections:

Not necessarily - looking ahead to 2007 was just touched upon - maybe an old board not looking ahead enough for a new board to take over. (PP CA)

The few respondents who disagreed with this statement ranged from a low of $4 \%$ of CA to a high of $10.3 \%$ for EA/CE chairs. Comments illustrated varying practice, and also the long-term commitment that is required for school-wide professional development:

Already locked into a 3 year p.d. contract. (PP EA)

Appraiser did not demonstrate this to the Board. May have been private discussion with principal. However Principal said this was not an area they expanded upon. (PC EA)

CA principals were least likely to agree but even so there was a promising indication that the links between appraisal and professional development were being made.

\section{The appraisal process enhanced the principal's job satisfaction}

Table 4.18: Distribution of ratings for link between appraisal and principal job satisfaction

\begin{tabular}{|l|c|c|c|c|}
\hline Ratings & $\begin{array}{c}\text { \% CA } \\
\text { Principals } \\
\mathbf{N = 3 8}\end{array}$ & $\begin{array}{c}\text { \% EA/CE } \\
\text { Principals } \\
\mathbf{N = 6 5}\end{array}$ & $\begin{array}{c}\text { \% CA } \\
\text { Chairs } \\
\mathbf{N = 2 6}\end{array}$ & $\begin{array}{c}\text { \% EA/CE } \\
\text { Chairs } \\
\mathbf{N = 2 9}\end{array}$ \\
\hline Positive (4 and 5) & 52.6 & 60.0 & 58.4 & 60.7 \\
\hline Neutral (3) & 36.8 & 30.8 & 33.3 & 39.3 \\
\hline Negative (1 and 2) & 10.6 & 9.2 & 8.4 & 0.0 \\
\hline
\end{tabular}

Over half, but less than two-thirds of all respondents agreed or strongly agreed with this statement, the strongest support coming from EA/CE principals and chairs $(60.7 \%)$. Some principals' responses reflected the importance of affirmation:

A smile, a pat on the back does wonders. A criticism provides a determination to improve. (PP CA)

Around a third of respondents had a neutral response to the statement indicating a limited role for appraisal in enhancing job satisfaction: 
I think it gave him confirmation that he is performing above average and that he is strategically "pointed in the right direction." (PC CE)

No EA/CE chairs and less than $10.6 \%$ of principals and CA chairs indicated disagreement with the statement. One chair who did so observed:

From my experience over the last 6 years the process is time consuming and does not give the principal any satisfaction at all! (SC CA)

A principal who disagreed saw a practical use for the outcome of the appraisal:

It gave me data for my CV if I was going to use it. (PP EA)

Around a third of all respondents were uncertain about this statement with little difference between principals and chairs, but at least half of all respondents believed the appraisal had had a positive impact on the principal's job satisfaction.

\section{Time spent on the appraisal was worthwhile}

Table 4.19: Distribution of ratings for time spent on the appraisal being worthwhile

\begin{tabular}{|l|c|c|c|c|}
\hline Ratings & $\begin{array}{c}\text { \% CA } \\
\text { Principals } \\
\mathbf{N}=\mathbf{3 8}\end{array}$ & $\begin{array}{c}\text { \% EA/CE } \\
\text { Principals } \\
\mathbf{N}=65\end{array}$ & $\begin{array}{c}\text { \% CA } \\
\text { Chairs } \\
\mathbf{N = 2 6}\end{array}$ & $\begin{array}{c}\text { \% EA/CE } \\
\text { Chairs } \\
\mathbf{N}=\mathbf{2 9}\end{array}$ \\
\hline Positive (4 and 5) & 75.6 & 84.6 & 84.6 & 86.2 \\
\hline Neutral (3) & 18.9 & 13.8 & 7.7 & 6.9 \\
\hline Negative (1 and 2) & 5.4 & 1.5 & 7.7 & 6.9 \\
\hline
\end{tabular}

Three-quarters of CA principals and over $84 \%$ of other respondents agreed or strongly agreed with this statement, even when more than the equivalent of a full working week was spent on the appraisal:

Total time spent 55 hours. (PP CE)

Especially good for me to be involved at a "nuts and bolts level putting together the initial appraisal document. It made me think in depth of all the facets of the principal's role to be assessed. (PC CE)

Principals were more likely to take a neutral stance on this statement, but the numbers were relatively low (18.9\% for CA and $13.8 \%$ for EA/CE). Chair neutral responses were even lower at around $7 \%$. None of these respondents provided written comments.

A small minority of between $1.5 \%$ for EA/CE principals and $7.7 \%$ for CA chairs disagreed with the statement, one possibly alluding to the principal professional standards. 
The extreme criteria used to set/measure performance makes the exercise mostly a waste of time, effort and energy. (SC CA)

There was a strong endorsement of the value of appraisal in terms of time from most principals and chairs.

\section{The cost of engaging an external appraiser was worthwhile}

Table 4.20: Distribution of ratings for cost effectiveness of EA involvement

\begin{tabular}{|l|c|c|}
\hline Ratings & $\begin{array}{c}\text { \% EA/CE Principals } \\
\mathbf{N}=65\end{array}$ & $\begin{array}{c}\text { \% EA/CE Chairs } \\
\mathbf{N}=\mathbf{2 9}\end{array}$ \\
\hline Positive (4 and 5) & 85.9 & 86.2 \\
\hline Neutral (3) & 10.9 & 6.9 \\
\hline Negative (1 and 2) & 3.1 & 6.9 \\
\hline
\end{tabular}

This question was only relevant for EA/CE principals and chairs. Their response to the cost effectiveness of EA involvement was overwhelmingly positive at $86 \%$.

Slightly more principals $(10.9 \%)$ than chairs $(6.9 \%)$ took a neutral stance. One commented:

I believe a competent chair can conduct the PA once training has been
received. External appraisers are expensive and tend to create considerable
stress for principals who use them. (PP EA)

The response rate for disagreement with the statement was a very low $3.1 \%$ for principals and $6.9 \%$ for chairs. A PP who gave no rating indicated there had been no cost as such:

Reciprocal payment only through peer appraisal.

Those respondents with experience of EA involvement in the appraisal gave a strong endorsement that this was a cost effective choice. 


\section{I am confident about my ability to undertake the appraisal of a principal}

Table 4.21: Distribution of ratings for confidence level of chairs undertaking the appraisal

\begin{tabular}{|l|c|c|c|c|c|c|}
\hline Ratings & $\begin{array}{c}\text { \% All CA } \\
\text { N=25 }\end{array}$ & $\begin{array}{c}\text { \% CA } \\
\text { Primary } \\
\text { N=19 }\end{array}$ & $\begin{array}{c}\text { \% CA } \\
\text { Secondary } \\
\mathbf{N = 7}\end{array}$ & $\begin{array}{c}\text { \% All } \\
\text { EA/CE } \\
\mathbf{N = 2 9}\end{array}$ & $\begin{array}{c}\text { \% EA/CE } \\
\text { Primary } \\
\text { N=23 }\end{array}$ & $\begin{array}{c}\text { \% EA } \\
\text { Secondary } \\
\text { N=6 }\end{array}$ \\
\hline $\begin{array}{l}\text { Positive } \\
(4 \text { and 5) }\end{array}$ & $\mathbf{7 6}$ & 83.0 & 57.2 & $\mathbf{4 1 . 3}$ & 34.7 & 66.7 \\
\hline $\begin{array}{l}\text { Neutral } \\
(3)\end{array}$ & $\mathbf{1 6}$ & 5.6 & 14.3 & $\mathbf{1 7 . 2}$ & 17.4 & 16.7 \\
\hline $\begin{array}{l}\text { Negative } \\
(1 \text { and } 2)\end{array}$ & $\mathbf{8}$ & 5.6 & 14.3 & $\mathbf{4 1 . 4}$ & 47.8 & 16.7 \\
\hline
\end{tabular}

This statement only appeared in the chair survey. The strongest agreement was from PCA with $83 \%$ responding positively compared with $57.2 \%$ of SCA. These results reflect the earlier finding (see p. 54) on CA self-assessment of the extent to which they possess the important qualities an appraiser should have.

Secondary EA on the other hand were more confident than their primary counterparts with two-thirds of this small group agreeing or strongly agreeing with the statement compared to just over a third of primary EA/CE.

Many of those who agreed with the statement qualified this in their comment:

NB this was not the case when I conducted the first appraisal. (PC CA)

I would not attempt to undertake an appraisal of a principal. The Chair (unless there are no issues or board is a rubber stamping one) would or might be in a very vulnerable position. I am confident about my ability to work effectively with a competent external appraiser. (PC CE)

PCA had the lowest response rate in both the neutral and negative categories at $5.6 \%$. Around $15 \%$ of all other groups were uncertain as to their abilities with some comments indicating a reluctance to take on the task:

The appraisal covers so many facets of the role that one needs a degree in education to be able to undertake the appraisal effectively. (SC EA)

Almost half of primary EA/CE indicated they were not confident in their ability to undertake the appraisal. There was little difference between secondary CA and EA with $14.3 \%$ of the former and $16.7 \%$ of the latter disagreeing with the statement. Reasons for a lack of confidence included: 
I would not undertake appraisal alone of a principal who was under performing or in conflict with the board. (PC CA)

There was a more diverse response to this statement than for any of the others, with an almost $50 \%$ spread between the highest and lowest levels of confidence. Several CA indicated their confidence had grown through successive appraisals, particularly with EA support. It appears varying the choice of internal/external appraiser may provide an opportunity for chairs to develop their confidence in this important aspect of their role.

\subsubsection{Comparison of paired responses}

Comparison of principal and chair responses was possible in 37 schools. This analysis focused on possible reasons for a rating difference of two or more. Over a third $(37 \%)$ of responses fell into this category (see Figure 4.11). Examination of comments showed the differences were not necessarily positive or negative, with most reflecting alternative perceptions of the statement itself rather than conflicting views of the outcome. For reasons of confidentiality it has not been possible to quote verbatim the "matched" principal and chair comments.

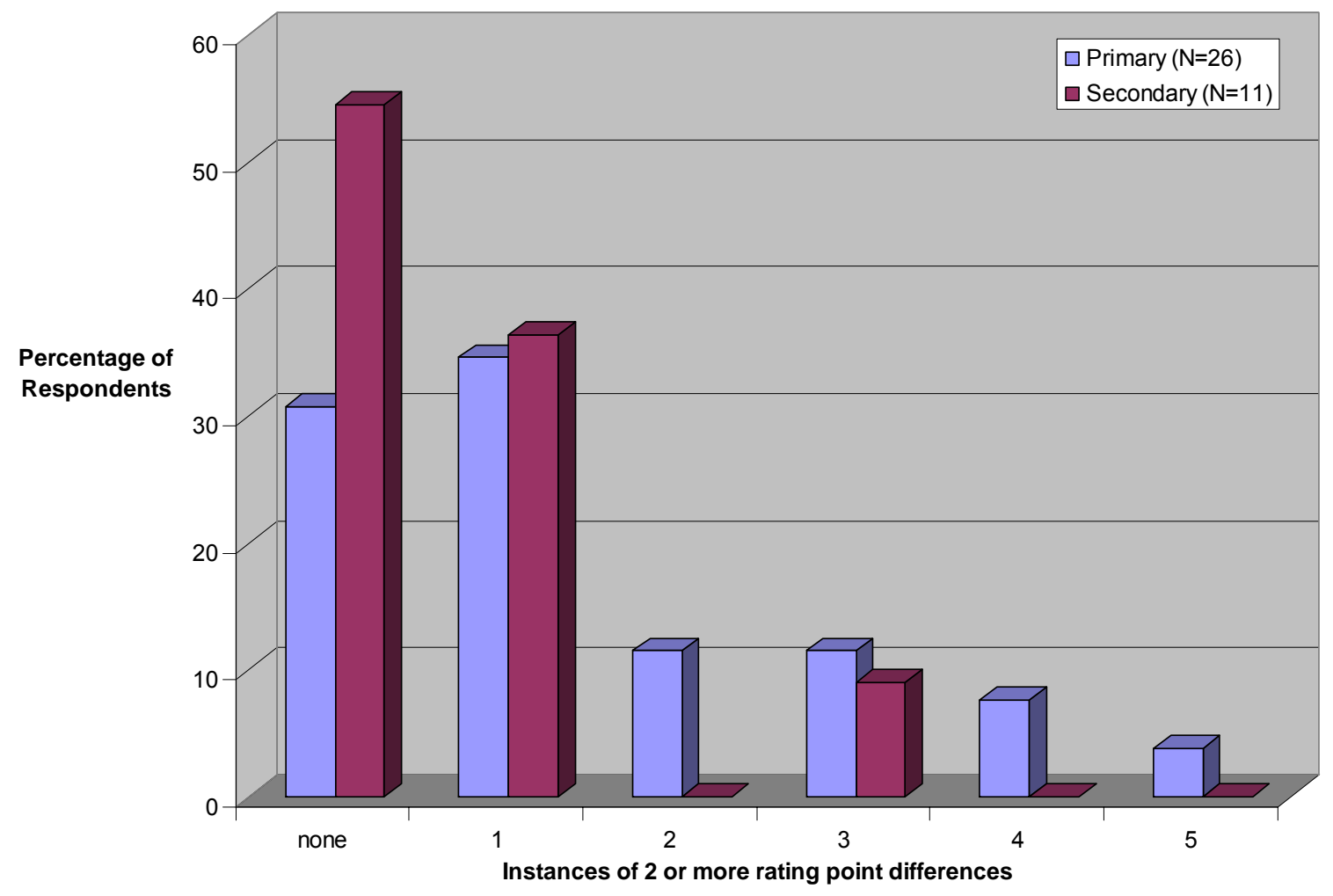

Figure 4.11: Comparison of matched principal and chair ratings 
Three pairs of SP and SC had a gap of two or more rating points for Statement 2 (link to school goals). Three other statements each had one pair of respondents with a gap of two or more points. One CA secondary school had this level of difference in response to three statements, including school goals with the principal strongly agreeing, and the chair strongly disagreeing that the appraisal had helped to determine whether these had been met. However, comments, including the chair's that:

This [information] comes from the principal's monthly report to board which is quite comprehensive!

suggest there were no issues about the flow of information between principal and board and both agreed that the appraisal had strengthened the working relationship.

In the primary sector, one EA pair had five differences of two or more points but was in agreement that the appraisal had strengthened relationships. The principal strongly agreed that the time spent was worthwhile and agreed that the cost had been worthwhile, whilst the chair disagreed with both statements. Comments suggest that the chair's more negative responses were based on a perception that whilst the process had been reasonably transparent, it fell down on its thoroughness and reporting to the board.

For a CA pair with four differences of two or more, the chair's strong agreement with Statements 2 - 4 were contrasted by the principal's neutral response and comments, indicating a lack of meaningful feedback and guidance from the appraisal. The same pattern was reflected in this pair's responses to the time spent on the appraisal.

These findings suggest principals and chairs may be looking for different things from the appraisal, rather than there being problems with relationships. 


\subsection{What aspects of the appraisal process are most and least satisfying?}

All respondents were asked to reflect on their overall experience of the appraisal and identify which aspect they were:

- most satisfied with;

- least satisfied with; and,

- anything they could suggest to improve the appraisal process.

Table 4.22 shows the framework of categories, their properties and descriptive codes developed in the analysis of this section of the questionnaire.

Table 4.22: Coding framework for reflections on the appraisal

\begin{tabular}{|c|c|c|}
\hline Categories & Properties & Descriptive Codes \\
\hline Appraiser & $\begin{array}{l}\text { Choice of } \\
\text { internal/external } \\
\text { appraiser and their level } \\
\text { of competence }\end{array}$ & $\begin{array}{l}\text { AEA: external appraiser (EA) } \\
\text { ACEA: shared appraiser role - chair and EA } \\
\text { AR: appraiser rotation } \\
\text { AQEA: qualities/experience of EA } \\
\text { AQC: qualities/experience/confidence of chair }\end{array}$ \\
\hline Interpersonal & $\begin{array}{l}\text { Type and quality of } \\
\text { feedback; the nature of } \\
\text { relationships; degree of } \\
\text { input by BOT, principal } \\
\text { and staff }\end{array}$ & $\begin{array}{ll}\text { IFB: } & \begin{array}{l}\text { feedback on outcomes including } \\
\text { acknowledgement, praise and affirmation } \\
\text { for principals, reporting to BOT }\end{array} \\
\text { IFF: } & \begin{array}{l}\text { feedforward: direction, goal setting, } \\
\text { challenge, professional support, } \\
\text { identification of professional } \\
\text { development for principals }\end{array} \\
\text { IBC: } & \begin{array}{l}\text { BOT involvement in and understanding } \\
\text { of process; quality of relationship } \\
\text { between principal and chair }\end{array} \\
\text { IP: } & \text { principal attitude, input and self-reflection }\end{array}$ \\
\hline Process & $\begin{array}{l}\text { The focus of the } \\
\text { appraisal; nature and } \\
\text { method of data } \\
\text { collection and reporting } \\
\text { mechanisms. }\end{array}$ & $\begin{array}{l}\text { overall quality of process } \\
\text { objectivity/evidence base } \\
\text { degree of stakeholder input } \\
\text { strategic linkages and flexibility }\end{array}$ \\
\hline Resourcing & $\begin{array}{l}\text { Time, cost and support } \\
\text { issues }\end{array}$ & $\begin{array}{ll}\text { RT: } & \text { time and time management } \\
\text { RSB: } & \begin{array}{l}\text { resourcing support for chair/BOT } \\
\text { training }\end{array} \\
\text { RSP: } & \begin{array}{l}\text { resourcing support for process } \\
\text { clarification, e.g. sample documentation }\end{array} \\
\text { RF: } & \text { financial resourcing }\end{array}$ \\
\hline
\end{tabular}


The number of comments decreased as respondents worked through the sections, as indicated in the tables $4.23,4.24$ and 4.25. Some respondents used the latter two sections to restate their overall satisfaction with the appraisal and indicate no areas of dissatisfaction or suggestions for improvement. The following analysis highlights responses in the four coding categories but many of the quotes used as illustration relate to more than one of these. The most important factor for each group is shown in bold and shaded; the second most important is in bold.

\subsubsection{Most satisfying}

Table 4.23: Coding of most satisfying aspects of the appraisal

\begin{tabular}{|c|c|c|c|c|c|}
\hline Categories & & Descriptive codes & $\begin{array}{c}\text { \%Principals } \\
(\mathrm{N}=99)\end{array}$ & $\begin{array}{c}\% \mathrm{CA} \\
(\mathrm{N}=24)\end{array}$ & $\begin{array}{l}\% E A / C E \\
(\mathrm{~N}=28)\end{array}$ \\
\hline \multirow[t]{5}{*}{ Appraiser } & AEA: & use of EA & 36.4 & 0.0 & 25.0 \\
\hline & ACEA: & $\begin{array}{l}\text { shared appraiser role - chair } \\
\text { and EA }\end{array}$ & 6.1 & 0.0 & 0.0 \\
\hline & AR: & appraiser rotation & 2.0 & 0.0 & 3.6 \\
\hline & AQEA: & qualities/experience of EA & 17.2 & 0.0 & 35.7 \\
\hline & AQC: & $\begin{array}{l}\text { qualities/experience/ } \\
\text { confidence of chair }\end{array}$ & 5.1 & 4.2 & 0.0 \\
\hline \multirow[t]{4}{*}{ Interpersonal } & IFB: & $\begin{array}{l}\text { feedback on outcomes } \\
\text { including acknowledgement, } \\
\text { praise and affirmation for } \\
\text { principals, reporting to BOT }\end{array}$ & 40.4 & 45.8 & 42.9 \\
\hline & IFF: & $\begin{array}{l}\text { feedforward: direction, goal } \\
\text { setting, challenge, } \\
\text { professional support, } \\
\text { identification of professional } \\
\text { development for principals }\end{array}$ & 27.3 & 0.0 & 25.0 \\
\hline & IBC: & $\begin{array}{l}\text { BOT involvement in and } \\
\text { understanding of process; } \\
\text { quality of relationship } \\
\text { between principal and chair }\end{array}$ & 12.1 & 33.3 & 17.9 \\
\hline & IP: & $\begin{array}{l}\text { principal attitude, input and } \\
\text { self-reflection }\end{array}$ & 31.3 & 20.8 & 3.6 \\
\hline \multirow[t]{4}{*}{ Process } & PQ: & overall quality of process & 24.2 & 20.8 & 17.9 \\
\hline & PO: & objectivity/evidence base & 17.2 & 25.0 & 17.9 \\
\hline & PS & degree of stakeholder input; & 14.1 & 8.3 & 21.4 \\
\hline & PL & $\begin{array}{l}\text { strategic linkages and } \\
\text { flexibility }\end{array}$ & 5.1 & 8.3 & 3.6 \\
\hline Resourcing & \multicolumn{2}{|c|}{ N/A as no responses in this category } & & & \\
\hline
\end{tabular}

\subsubsection{Appraiser}

Over a third of principals and a quarter of EA/CE chairs identified having an EA as the most satisfying aspect of the appraisal. 
The fact that another professional was there to support me in my quest for excellence and to assist me with what I should be aiming to achieve, setting realistic and achievable goals. (PP EA)

Having the opportunity to discuss my perceptions and plans with a neutral person; having that person be supportive + assuring me that I was being an effective educational leader. (SP EA)

Over a third of EA/CE chairs highlighted the qualities and experience of the EA. This was also mentioned by $17.2 \%$ of principals.

Very thorough and competent job was done; strengths were highlighted; areas that could usefully be developed/strengthened were identified and described clearly; next steps were outlined; feedback was from many sources and levels. (PC EA)

Some were less effusive in commenting on the benefits of EA involvement, suggesting it had been little more than a compliance exercise:

It simply means that an outsider has spotted your paper trail and there's now proof that you're doing your job. (PP EA)

Basic assessment process was satisfactorily completed. (PC EA)

\subsubsection{Interpersonal}

The highest number of comments related to this category of codes with over $40 \%$ of all respondents referring to feedback (IFB) as the most satisfactory aspect of the appraisal, and one which did not necessarily require an education professional to gather and deliver.

A chance to have positive feedback; ability to change the process yearly to determine the appraisal and outcome; ability to work with people who understand the role. (SP CA)

The provision of feedback as to meeting strategic development goals. I knew we were getting there but to have this confirmed by others was important. We spend a great deal of time providing feedback and support to others - it was good to know that this was appreciated and had benefits to the school. (PP CA)

For around a quarter of principals and EA/CE chairs, challenge and guidance on future direction (IFF) was also as important, for instance:

The discussion time prior to [EA] meeting with the BOT chair. Challenges my thinking and extends it. Gives me a focus for the forthcoming year, sets realistic workload but still a challenge to me professionally. (PP EA) 
Identifying strengths and areas of future improvement with an emphasis on the next step. (SP EA)

A third of chairs undertaking the appraisal highlighted the level of their board's involvement and understanding of the process, as well as the quality of their own relationship with the principal (IBC). Just over $20 \%$ of CA also appreciated the principal's positive approach (IP), something which was reflected in a third of principal comments, for instance:

There has been an improved dialogue between myself and chair. We have always had a good relationship but I feel chair has a better understanding of my role. (PP CA)

A strong sense of partnership is evident in another chair comment:

Principal was focused on achieving our charter goals and improving student learning. Appraisal process supported this. Strengthened an ongoing positive working relationship with board. Good principals are reflective practitioners and are looking to continue to improve opportunities for children and student learning. Not only should it give feedback to board and indicate where to next but it should be a good process for the principal. I think principal is very much part of this process. Don't think a process that just tick boxes is very useful at all. (PC CA)

An EA SP's comments reflected another aspect of this code (IP), satisfaction at being able to "own" their appraisal:

The fact that it was driven by me (in discussions with appraiser) I used the strategic plan and picked out specific goals for me to focus on. It was completely relevant to what was happening in the school.

\subsubsection{Process}

Aspects of the process received less mentions than previous categories but around a quarter of $\mathrm{CA}$ and $17 \%$ of other respondents commented on the objectivity of the process (PO) and there were a few references to its link to school planning and reporting:

Focused, objective based process. Links to strat[egic] and annual plan. (PP CA)

Objectivity of the appraiser and the process. Identified strengths and weaknesses. Was transparent. Professional discussion that resulted from the analysis of the surveys. (PP EA)

The process does not need to be complex to meet all needs. A PP CA appreciated:

The simplicity of it and the fact that it met my needs and the board's needs without undue stress and paperwork. 
The degree of stakeholder input was another aspect of the process mentioned, most notably by $21.4 \%$ of EA/CE, for instance:

Good cross section of comments obtained from both staff and board members. Gave me as the chair good direction as to where future pd for the principal should go. (SC EA)

\subsubsection{Resourcing}

None of the "most satisfying" comments referred to resourcing aspects.

\subsubsection{Least satisfying}

Table 4.24: Coding of least satisfying aspects of the appraisal

\begin{tabular}{|c|c|c|c|c|c|}
\hline Categories & & Descriptive codes & $\begin{array}{c}\% \\
\text { Principals } \\
(N=64)\end{array}$ & $\begin{array}{c}\% \\
\mathrm{CA} \\
(\mathrm{N}=17)\end{array}$ & $\begin{array}{c}\% \\
E A / C E \\
(N=18)\end{array}$ \\
\hline \multirow[t]{2}{*}{ Appraiser } & AQEA: & qualities/experience of EA & 1.6 & 0.0 & 5.6 \\
\hline & AQC: & $\begin{array}{l}\text { qualities/experience/ } \\
\text { confidence of chair }\end{array}$ & 7.6 & 23.5 & 16.7 \\
\hline \multirow[t]{4}{*}{ Interpersonal } & IFB: & $\begin{array}{l}\text { feedback non-affirming for the } \\
\text { principal; inadequate reporting } \\
\text { to BOT }\end{array}$ & 15.6 & 0.0 & 0.0 \\
\hline & IFF: & $\begin{array}{l}\text { lack of feedforward: direction, } \\
\text { goal setting, challenge, } \\
\text { professional support, } \\
\text { identification of professional } \\
\text { development for principals }\end{array}$ & 17.2 & 5.9 & 11.1 \\
\hline & IBC: & $\begin{array}{l}\text { BOT interest/involvement: too } \\
\text { much/too little }\end{array}$ & 20.3 & 0.0 & 16.7 \\
\hline & IP: & $\begin{array}{l}\text { principal attitude or level of } \\
\text { control of the appraisal }\end{array}$ & 12.5 & 11.8 & 11.1 \\
\hline \multirow[t]{4}{*}{ Process } & PQ: & overall quality of process & 21.9 & 35.3 & 11.1 \\
\hline & PO: & $\begin{array}{l}\text { insufficient } \\
\text { objectivity/evidence base }\end{array}$ & 7.8 & 0.0 & 11.1 \\
\hline & PS: & limited stakeholder input & 3.1 & 11.8 & 5.6 \\
\hline & PL & $\begin{array}{l}\text { poor focus, strategic linkages } \\
\text { and flexibility }\end{array}$ & 6.3 & 5.9 & 5.6 \\
\hline \multirow[t]{4}{*}{ Resourcing } & RT: & $\begin{array}{l}\text { time demands resulting in not } \\
\text { enough time with appraiser } \\
\text { and/or heavy workload }\end{array}$ & 31.0 & 41.2 & 22.0 \\
\hline & RST: & $\begin{array}{l}\text { inadequate resourcing support } \\
\text { for chair/BOT training }\end{array}$ & 1.6 & 5.9 & 16.7 \\
\hline & RSP: & $\begin{array}{l}\text { inadequate resourcing support } \\
\text { for process clarification, e.g. } \\
\text { sample documentation }\end{array}$ & 0.0 & 0.0 & 5.6 \\
\hline & RF: & insufficient financial resourcing & 6.3 & 5.9 & 11.1 \\
\hline
\end{tabular}




\subsubsection{Appraiser}

There was a low frequency of comment in this category, an exception being the qualities/experience/confidence of the chair (AQC). A quarter of $C A$ and $16.7 \%$ of EA/CE comments were linked to this, including one from a primary CA:

Initially the concept of somebody knowing very little about the system setting goals for the principal - relying on her own drive and commitment to arrive at a meaningful appraisal.

Even chairs with considerable work experience of appraisals expressed anxiety:

Having previously carried out some 500 appraisals in my previous life of both blue and white collar workers I felt the process somewhat unnerving. I am not an educationalist and unsure how I would have handled a confrontation involving technicalities. (PC CA)

It was not always clear where responsibility for providing guidance lay but this PC suggests the EA could have done more:

I was new to the role of chair and believe that I should have been better informed about the process and more information provided to either the chair or board especially in a short report form.

A small number of EA/CE chairs (5.6\%) were more directly critical of the performance of $E A$, this one also reflecting a desire for greater rigor in the process:

Felt appraiser reported only on the "standards met" point of view and that he did not identify in any of his reports areas for improvement. The school is performing well but it is not an exceptional school hence there must be areas for improvement. These were not identified.

\subsubsection{Interpersonal}

This category also saw relatively few comments. Principals wanted more feedback (15.6\%) and feedforward (17.2\%), for instance:

Little guidance given for where I (and the school) might explore in the future. (PP EA)

Just over $20 \%$ of principal responses expressed concerns about the level of board interest (IBC) as did $16.7 \%$ of EA/CE. One or two cited over-interference:

That part of the process was very stressful for me as I tried to ensure that the agreed process was honoured and the principal not pressured to make changes to suit two new trustees. (SC EA) 
However, most comments related to insufficient interest, for instance:

I think the board could play a bit more attention to it. I seem to drive it. (PP CA)

CA chairs did not raise concerns about insufficient input, reflecting perhaps their own active participation on the board's behalf. However, perspectives in relation to the principal's participation (IP) highlight the delicate balance in getting this right. Around $11 \%$ of comments from chairs were critical of principals for exercising too much control or lacking commitment to the appraisal, for instance:

Assuming too much control over the process on the basis that all is well and the chair would just agree. (PC CA)

\subsubsection{Process}

Over a third of CA chairs and $21.9 \%$ of principal responses indicated dissatisfaction with the overall quality of the process. For this principal with an EA it lacked rigor: A little 'once over lightly' using only one main source of information i.e.
feedback/survey of some staff.

A CA noted:

The tedium of working through the same thing, but under different measurement criteria/standards.

This suggested the process would benefit from greater focus and strategies for grouping objectives, standards and sources of evidence to avoid unnecessary repetition.

\subsubsection{Resourcing}

Time demands of the appraisal was the most frequently cited area of dissatisfaction. Over $40 \%$ of $\mathrm{CA}$ and $22 \%$ of EA/CA comments related to this category.

Amount of time from appraiser point of view plus putting all information together in one report. (PC CA)

I felt very much on the back foot and that it was completed in a rush. (SC CA)

Almost a third of principals' (31\%) comments referred to time factors, including these two EA principals:

It creates extra work unnecessarily.

Would have liked some more time with the appraiser. 
More than $16 \%$ of EA/CE chairs also expressed concerns about lack of support, some strongly:

As is typically the case, MOE support and guidance for this process, most like everything else, is pathetic. No care, no responsibility should be their motto.

Another was more specific about the issues this created:

Inability to find a satisfactory adviser to provide assistance/info to board on extending development of management role and role as educational leader.

Lack of support and resourcing received few mentions by principals, although one lamented the fact no bonuses were forthcoming. A chair appraiser echoed this sentiment:

The employment arrangements for principals, and other factors, make it difficult to appropriately reward a good performer (or a good year's performance) via remuneration/bonuses. The process has real value nevertheless, but not being able to deliver some financial recognition is a frustration.

\subsubsection{Suggestions for improvement}

Table 4.25: Coding of suggestions for improvement

\begin{tabular}{|c|c|c|c|c|c|}
\hline Categories & & Descriptive codes & $\begin{array}{c}\% \\
\text { Principals } \\
(\mathrm{N}=64)\end{array}$ & $\begin{array}{c}\% \\
\mathrm{CA} \\
(\mathrm{N}=15)\end{array}$ & $\begin{array}{c}\% \\
\mathrm{EA} / \mathrm{CE} \\
(\mathrm{N}=19)\end{array}$ \\
\hline \multirow[t]{4}{*}{ Appraiser } & AEA: & use of EA & 17.2 & 6.7 & 5.3 \\
\hline & ACEA: & $\begin{array}{l}\text { strengthened shared } \\
\text { appraisal- chair and EA }\end{array}$ & 1.6 & 6.7 & 31.6 \\
\hline & AR: & $\begin{array}{l}\text { appraiser rotation, alternating } \\
\text { chair with } E A\end{array}$ & 9.4 & 13.3 & 0.0 \\
\hline & AQEA: & trained pool of EAs & 6.3 & 0.0 & 15.8 \\
\hline \multirow[t]{4}{*}{ Interpersonal } & IFP: & $\begin{array}{l}\text { better quality feedback and } \\
\text { reporting }\end{array}$ & 12.5 & 0.0 & 0.0 \\
\hline & IFF: & $\begin{array}{l}\text { more direction/guidance/ } \\
\text { mentoring for principals }\end{array}$ & 18.8 & 6.7 & 5.3 \\
\hline & IBC: & $\begin{array}{l}\text { BOT involvement and } \\
\text { commitment to process and } \\
\text { training }\end{array}$ & 10.9 & 13.3 & 21.1 \\
\hline & IP: & $\begin{array}{l}\text { principal attitude/ } \\
\text { commitment to process }\end{array}$ & 6.3 & 0.0 & 10.5 \\
\hline \multirow[t]{4}{*}{ Process } & PQ: & continuous, reviewed process & 14.1 & 20.0 & 10.5 \\
\hline & PO: & $\begin{array}{l}\text { objective/evidence based } \\
\text { approach }\end{array}$ & 7.8 & 26.7 & 0.0 \\
\hline & PS: & increased stakeholder input & 6.3 & 6.7 & 10.5 \\
\hline & PL: & explicit strategic linkages & 1.6 & 0.0 & 0.0 \\
\hline
\end{tabular}




\begin{tabular}{|c|c|c|c|c|c|}
\hline Categories & & Descriptive codes & $\begin{array}{c}\% \\
\text { Principals } \\
(\mathrm{N}=64)\end{array}$ & $\begin{array}{c}\% \\
\mathrm{CA} \\
(\mathrm{N}=15)\end{array}$ & $\begin{array}{c}\% \\
E A / C E \\
(N=19)\end{array}$ \\
\hline \multirow[t]{4}{*}{ Resourcing } & RT: & $\begin{array}{l}\text { time management: start } \\
\text { process early/more meetings } \\
\text { with appraiser/do less } \\
\text { frequently }\end{array}$ & 23.4 & 13.3 & 26.3 \\
\hline & RS: & $\begin{array}{l}\text { increased support for } \\
\text { chair/BOT training }\end{array}$ & 3.1 & 26.7 & 31.6 \\
\hline & RSP: & $\begin{array}{l}\text { increased support for } \\
\text { process clarification, e.g. } \\
\text { sample documentation }\end{array}$ & 4.7 & 20.0 & 31.6 \\
\hline & RF: & $\begin{array}{l}\text { increased financial resourcing, } \\
\text { including for principal support } \\
\text { and remuneration }\end{array}$ & 9.5 & 6.7 & 10.5 \\
\hline
\end{tabular}

\subsubsection{Appraiser}

Almost a third of EA/CE chair, and a small number of other comments, indicated a strengthened, shared approach to the appraisal as a means for improvement.

Require a closer working relationship between BOT chair and external appraiser so chair can learn from expert what are essential elements to be assessed and what are good assessment/appraisal methods and tools. (PC CE)

Working with an "expert" can also be a valuable learning opportunity:

I strongly believe in involving the chair and I have been fortunate to have used educational consultants to train both principal and chair and this process has been sustained. I also have been fortunate with the calibre of chair over my time at the school. (PP CA)

Fewer than $10 \%$ of principals, and $13.3 \%$ of CA suggestions, proposed appraiser rotation:

Combination of chair every year and an external appraiser some years is the ideal mix.

Some suggestions highlighted the importance of careful appraiser selection. Over $17 \%$ of principal comments advocated an EA, with some expressing concerns about chair capability:

Having experienced two appraisals by my chair and one by an external appraiser I would use the latter in future as they are able to allocate time and create a clear timetable to support the appraisal process throughout the year. My previous appraiser was a principal and demonstrated a far greater understanding and appreciation of my role and was able to be much more rigorous in identifying and interpreting the data supporting appraisal outcomes. 
Access to a trained pool of EA was referred to by $15.8 \%$ of EA/CA chairs and $6.3 \%$ of principals. The fact that no CA referred to it suggests these chairs were not frustrated by efforts to find a professional alternative. A principal, who thought it a good idea to vary the appraisal:

Would like to see more experienced and trained external appraisers.

This was picked up by chairs concerned about the background and accessibility of consultants:

Use external appraiser, but there needs to be a pool of trained people who are not solely current/past principals. (EA)

\subsubsection{Interpersonal}

Just over $18 \%$ of principal comments expressed a need for a greater guidance from the appraisal:

More ideas/analysis of areas for development so I can be more specific about development of my skills (rather than just tasks which typically emerge). (PP)

Some extended this to the notion of a "critical friend" or "mentor":

Regrettably I am so far into the journey that to track me down and give me direction might prove meaningless. A mentoring cycle may prove more useful to pioneers like myself. (PP)

This sentiment was echoed by a few chair comments:

Board members felt it would have been good to see a mentoring and developmental aspect to the appraisal process. Perhaps we will have to pay a higher price to achieve this. (PC EA)

The importance of the role played by the principal (IP) was identified by $10.5 \%$ of EA/CE chairs. Appropriate BOT involvement and commitment (IBC) was advocated by $21.1 \%$ of EA/CE, $13.3 \%$ of $C A$ and $10.9 \%$ of principals including this PP:

For the board to have more fully entered into what my appraisal was all about. 


\subsubsection{Process}

Emphasis on an objective/evidence-based approach (PO) was seen as important in $26.7 \%$ of $\mathrm{CA}$ and a small number of principal comments. For instance, widening the collection of data:

Some data gathering from the community - a sample survey or interview perhaps could be considered for future appraisals. (PP)

It might be helpful if APs and DPs were required to provide a written report together with one or two more junior staff members. Certainly input from the staff representative on the board was valuable, as was the verbal feedback obtained from the AP and DP. (SC)

The chair from an integrated school suggested:

More interviews with Board of Proprietors to get information on 'special character' issues that might impact on the principal's appraisal.

There were suggestions from two primary CA that ERO involvement could be beneficial:

I question the ability of boards of trustees to appraise a principal's future. Some input from the board definitely. How about ERO who are a watchdog on schools being involved in the final process somehow!

A more continuous and reviewed process was mentioned by $20 \%$ of $\mathrm{CA}, 14.1 \%$ of principals and $10.5 \%$ of EA/CE.

I tended to have to remind chair and appraiser to do things on time! (PP EA)

An SC EA highlighted the need for documentation:

The agreed process document needs to be very detailed as we have discovered. As the board changed personnel midway through, the dynamic changed and things "understood" by the previous board were not honoured by the new trustees so everything must be in writing, in minutiae.

Some chairs saw a need for process review but also raised resourcing and support issues:

Redefine and rewrite questionnaire - probably tried to cover too much. It would be helpful to have an idea of what other similar sized schools do - and what does/does not work for them. (SC CA)

Over 3 years a selection of Professional Standards be compiled and appraised against each year; easier compliance (from principal); make the system more simple and it will become more effective and constructive. (PC EA) 


\subsubsection{Resourcing}

Time, and making better use of it, was brought up by $23.4 \%$ of principals, over a quarter of $E A / C E$ and $13.3 \%$ of $C A$.

Having a clearly defined time scale with targets set at the beginning and opportunity to check progress during the year; with further opportunity to meet with the Chair at the end of the year to discuss progress and degree of satisfaction. (SP EA)

One principal recognised their commitment to the process was a factor:

For me to convince myself of its value; to stick to timelines. (PP CE)

There were also suggestions that annual appraisal is unnecessary:

I question whether an appraisal needs to be done every year. We have had about 6 - 7 appraisals in the last so many years, with much the same staff, board and chair. Indeed there is always something to be learnt but perhaps each 2 nd year would be adequate. (SP EA)

Almost a third $(31.6 \%)$ of EA/CE mentioned increased resourcing for training and process clarification. The value of working alongside an experienced consultant was again highlighted, for instance:

No new chair should attempt to undertake the process without training or without consultant in-put. It is far too important a process for amateurs to mess about with and far too potent a weapon for chairs with "agendas" to control. Having been to training and worked with the consultant through the performance agreement and developing a 3 year cycle, I feel well trained. (SC EA)

Twenty percent of $\mathrm{CA}$ and a small number of principals mentioned training or process clarification.

More information about how to actively carry out the process i.e. how to determine objectives; what sort of information to gather; who to talk to; what sort of questions to ask. (PC CA)

A set of guidelines, models of good processes; a list of available appraisers with an outline of their methodology. (PP EA)

A CE PP who had found the management aspect of the appraisal "perfunctory", believed members of the board had an:

Over estimation of skills in this area. Corporate model does not necessarily match the educational model. 
Increased financial resourcing featured in the responses of $10.5 \% \mathrm{EA} / \mathrm{CE}, 9.5 \%$ of principals and $6.7 \%$ of $\mathrm{CA}$, for instance:

Increased funding for Principal Appraisal - \$2,000 plus an allowance for resulting PD - another $\$ 2,000$ as a Ministry of Education grant. (PP CE)

Cost and time are closely related, as this CA PP noted:

The whole school appraisal process is very challenging with the extent of time required to apply the process appropriately. This often lifts stress levels and it is a heavy workload. Additional staffing in management would be appropriate to improve teaching strategies through appraisal.

Other comments from principals in this category were around their own professional development, such as:

More PD available aimed specifically at principals, and

Greater access to the Principal Leadership Centre.

\subsubsection{Summary}

Responses to this question were wide-ranging. Feedback and/or feedforward were the most important factors in a satisfying appraisal. Principals and EA/CE chairs also signalled the value of having an experienced EA. Issues around resourcing, particularly with regard to time demands, were most likely to result in an unsatisfying appraisal experience, particularly for chair appraisers. The largest numbers of suggestions for improving the appraisal were centred on improved resourcing and support. These findings suggest that access to experienced EA, greater support, particularly in the form of training, templates and models, together with having the right attitude and commitment, make it more likely the outcome will be a satisfying one for principals and chairs. 


\subsection{Chapter Summary}

The data suggest a high incidence of EA involvement in primary principal appraisals. Many of those to whom this did not apply in 2006 indicated they had, or intended to use an EA at one time or another. Secondary boards, whilst less likely to employ an EA, make greater use than primary of internal expertise by involving one or more trustees in the appraisal in addition to the chair.

Appraisal processes are reasonably comprehensive, with linkages to school goals and a range of evidence sources. Reporting to the BOT is variable and it is more likely than not that the principal will remain present throughout any discussion of the appraisal outcome.

Principal and chair attitudes and opinions about the process suggest appraisal is valued by the majority and provides a degree of feedback on principal performance. However, there is a sense that both participant satisfaction and effectiveness of outcomes could be improved through reinforcement of good practice, training and information. 


\section{CHAPTER 5: DISCUSSION}

This study describes the 2006 appraisal experience of principals and chairs in around $5 \%$ of New Zealand state and integrated schools. The findings suggest elements of good, if not "best" practice are occurring but also raise questions about principal and chair confidence in the ability of lay appraisers, particularly around the provision of direction and guidance for principals. The attitudes and opinions of the participants suggest no "magic bullet" for improving satisfaction with the appraisal but may provide insights for enhancing the effectiveness of the process for participants and stakeholders.

This chapter identifies limitations of the research and key themes in its findings, and considers the implications of the findings for practice and future research.

\subsection{Limitations of the Study}

\subsubsection{Validity and consistency}

The validity of research is impacted upon by the appropriateness of the method used. The intention of this study was to provide as full a picture as possible of principal appraisals. A case study approach, which produces rich, deep insights, was therefore considered. However, as case studies cannot always be readily generalised, such an approach was felt to be more appropriate as a follow-up study after a broadly based investigation had gathered descriptive information from as large a sample group as possible.

\subsubsection{Sample}

The target group for the survey was the principals and chairs of approximately $10 \%$ of New Zealand state and integrated schools. Responses were received from just under half of the schools but the response from chairs was almost half that of principals. The timing of the survey may have contributed to this imbalance. Questionnaires were posted during school holidays and a lot of principals took the opportunity to complete and return them before the start of Term 2. In many schools the administration staff, who handle and redirect mail for the chair and BOT, do not work during the holidays which may have caused a delay. Added to this 
there had recently been trustee elections, followed by board chair elections, which appear to have resulted in uncertainty as to whom the survey should be directed.

In order to improve the internal validity of the sample, paired responses were identified: that is responses from both the principal and chair of the same school. This enabled comparison of data to occur during the analysis, providing a more comprehensive perspective.

Other than the example cited in the introduction, it is difficult to tell whether those who were particularly disgruntled with the appraisal were less likely to participate. There is some suggestion that the degree of bias in those choosing to participate in a survey increases in relation to the proportion of non-respondents (Marshall, 1998). The fact that non-responses exceeded responses vitiates to some extent the external validity of the sample; however a deliberately large sample group was selected based on the knowledge that the sector receives a high number of survey requests. Sufficient data were gathered to enable a descriptive picture of practice to be developed. Some caution should, however, be exercised in extrapolating from the findings to New Zealand as a whole as regional or contextual variations may exist.

The decision was made at the outset not to include Kura Kaupapa Māori in the survey. These schools, which teach in the medium of Te Reo Māori, are part of the state sector but their approach to governance relies heavily on whānau/community input. Whilst it would have been interesting to investigate this further, it was considered outside the scope of both this project and the cultural expertise of the researcher to include them. Further research to explore a culturally different approach to the appraisal process may be warranted.

\subsubsection{Instrument consistency}

A postal survey is a good way to gather factual information from a large group but less effective if the information sought is complex or sensitive (Pinaonneault \& Kraemer, 1993). It is important that the understanding and interpretation of the questions in the survey is consistent across all participants. To assess this, a pilot was conducted and the participants were asked to describe their understanding of the questions and scales in the instrument and discuss their reaction to them. 
A number of minor adjustments were then carried out to enhance understanding and to minimize error variance. In this way interpretation of questions that differed from that intended were few and immaterial. For instance in response to the outcome statement the appraisal process enhanced the principal's job satisfaction, some chairs gave no rating but wrote a comment along the lines of "you'll have to ask him," when the intent had been to gauge the chair's perception of this. A question about the frequency of meetings was complicated by the need to differentiate between regular, and appraisal principal and chair meetings. Such instances were taken into account in the analysis and did not have an impact on the overall findings.

\subsubsection{Personal bias}

The need for "safeguards against tunnel-vision, bias and self-delusion" (Miles \& Huberman, 1994, p. 56) must be uppermost in any research. However it is impossible for researchers to be totally objective because they are "part of the world" they are researching (Cohen, Manion, \& Morrison, 2000, p. 106).

Every effort was made to minimise personal bias but to some extent this is inevitable given that I have worked in the field of governance, management and leadership with principals and chairs for almost twenty years, including in the area of training and support for principal appraisal. I was known either personally, or by name, to many survey recipients. This underlined the importance of stressing the purpose of the research, the use to which the information would be put and arrangements for protecting confidentiality. It is difficult to determine whether knowledge of the researcher encouraged or discouraged participation but the fact that almost twice as many principals (who because they tend to spend a longer time in their role are more likely to have had contact with me) than chairs responded may suggest it did not have a negative effect. Expert knowledge of the field of study can strengthen the quality of research findings, discussion and recommendations (Glaser \& Strauss, 1967). 


\subsection{Interpretation of the Results}

The findings of the survey suggested four main themes that influence the quality of the principal appraisal experience:

1. the importance of identifying the 'right' appraiser;

2. a well managed and sufficiently documented appraisal process;

3. the expectations and outcomes of the participants; and

4. understanding the appraisal process and having the correct skill set to execute it.

These, together with further insights into the context for principal appraisal as well as a set of recommendations to the main stakeholders, are set out in the following sections.

\subsubsection{Identifying the right appraiser}

An appraiser who can affirm and challenge the principal is critical to an effective appraisal. It is also important that the appraiser has the trust and respect of the principal. Two-thirds of principal respondents had an EA involved in their appraisal. Just over a third of principal respondents (36.45\%) identified this as the most satisfying aspect of the appraisal, second to affirmation and feedback. Principals appraised by their chair also had many positive things to say, particularly about the resulting increase in the chair's understanding of their complex role. However, the findings suggest principals gained greater satisfaction from appraisal by a fellow professional.

Appraisal by committee, that is by the chair and at least one other trustee, is more likely to occur in secondary schools (see Table 4.4). It can be harder for empathy and rapport, important elements in an appraiser/appraisee relationship, to develop if the appraisee is outnumbered by several appraisers. Certainly this is suggested in a comment from a PP CA who said the previous year's appraisal by committee had been a disaster. An alternative perspective is that having more than one board member involved could result in a more objective approach. It is also a useful mechanism for sharing the workload and increasing the numbers of trustees with experience and understanding of the appraisal. This is an aspect which would benefit from case study follow-up. 
Whilst empathy between the principal and appraiser is important, there is a danger if the relationship becomes too cosy (Piggot-Irvine \& Cardno, 2005). One chair alluded to this when commenting on an EA appointed prior to their own involvement:

It is an important process and time should be spent on it. In this case [the] principal had too much of a leading hand in designing the process and helping with selection of [the] sample for interview, I think. It therefore reflected a view of her performance that she felt very comfortable with.

In contrast to other education jurisdictions examined, when EA involvement occurs, principals in New Zealand appear to have a significant say in their selection. This was especially the case in primary schools where two-thirds of principals chose, provided a shortlist or reached mutual agreement with the board as compared to one-third of SP. In New Zealand there is currently no accreditation scheme for appraisers and therefore no guarantee that anyone undertaking the appraisal possesses the appropriate skills. This could therefore be seen as much a case of lay boards seeking guidance from their professional CEO as undue principal influence.

The findings of this study suggest the majority of BOT using external consultants hand the process over, rather than use EA to provide professional input into the board's appraisal of the principal. The GPF underlines the value of seeking a contribution to the process by a principal colleague. This might take the form of "a report on achievement of a professional leadership task" (Piggot-Irvine \& Cardno, 2005, p. 93). Such an approach is consistent with that taken in England and Wales, where the introduction of a revised PM Framework in 2000 included the requirement for governing bodies to employ external appraisal assistance. Almost $70 \%$ of the 3,000 EAdv. accredited in the first year were current or previous headteachers (Crawford \& Earley, 2004). In this study, just over a third (38.4\%) of principals with EA identified their appraiser as a current or former principal. However, the actual number is likely to be higher as some consultants, only identified by their organisation or agency, are also likely to have experience of principalship.

Conducting appraisals is a way of utilising the valuable expertise of retired principals. Studies cited from the UK (Crawford \& Earley, 2004; Cullen, 1997) suggest becoming an appraiser is also a professionally rewarding experience for principals. However, there are also concerns that the demands of a New Zealand principal's job may make it unfeasible for incumbents to undertake an entire appraisal in another school (Piggot-Irvine \& Cardno, 2005). In order to explore this 
aspect and test out findings from the research, I interviewed four current principal appraisers each undertaking between one and seven appraisals annually over a period of several years. Each was very willing to discuss details of their practice and experience. All spoke of the professional benefits they gained, citing specific instances when their own practice had been enriched as a result of carrying out an appraisal of a colleague.

Another facet of this issue is the BOT attitude to its principal taking on the workload involved in appraising his or her peers. The four principal appraisers interviewed reported that they have their board's support and approval because trustees see the professional benefits, both for their principal and the school sector as a whole. The benefits were also material as income from appraisals conducted went to the school. As well as covering actual expenses, the funding was used for such things as principal or senior management team professional development. The insights provided by these appraisers suggest principals make the time for this role because they deem it important, to them personally and to the profession as a whole. These are also areas that would benefit from further research.

\subsubsection{A manageable, documented process}

It is important to make the distinction between a documented process and an overbureaucratic one. Over a third of CA, $22 \%$ of principals and $11 \%$ of EA/CE chairs identified the overall quality of the process as a least satisfying aspect of the appraisal.

Manageable, useful documentation starts with BOT policy being aligned to practice. The survey did not directly seek information about appraisal policy but some principals identified it as the basis for appraiser identification. Because each board is able to develop its own procedures within the PMS framework, the policy should also make clear the board's expectations of the appraisal process.

Virtually all principals had a performance agreement, although it appears over half of primary boards, and just under a third of secondary, had no direct input into its development. The strong linkages to the school's annual plan, which are in effect the board's priorities, mitigate this to some extent. However, principal appraisal is the board's opportunity to manage, as it thinks fit, the performance of the principal and issues may arise if the BOT is kept entirely at arm's length from the 
identification of the appraisal's focus. An open and transparent process for establishing the criteria for appraisal, and recording this in the performance agreement, can provide protection for principals. A comment from an SC EA respondent (see 4.9.3.3) highlighted how vital a detailed agreement proved to be when BOT membership changed and new trustees sought to introduce new expectations of the principal part way through the process.

Findings indicate appraisers are looking at a range of data in order to make objective assessments of performance. This includes feedback from stakeholders by means of survey or interview. Determining whose input will be sought is another aspect that needs to be agreed and documented at the outset. As noted in Chapter 2, improving outcomes for students is an underlying imperative for principal appraisal. Assessment data were not explicitly cited as a source of evidence in the appraisal, but are likely to have been considered in the context of principal reporting to the board.

The final element of a documented appraisal process is reporting the outcome to the BOT. There is little evidence that suggests boards utilise EA feedback to assemble a final report (although the survey did not specifically ask for this information) and the principal is more likely than the board to receive a copy of an EA report. This raises the question of who the client is in this process. The study's findings may lend weight to the view that whilst commissioned and paid by the board, "many appraisers would consider the principal to be the client" (Hampton, 2005, p. 5).

Receiving adequate information on the outcome of the appraisal of its CEO would seem to be a necessity for effective governance. Whilst BOT receive some reporting on the appraisal this appears to fall short of what is envisaged in the GPF. However, very few chairs raised this as a concern: none mentioned it in the context of "least satisfying"; only three mentioned it as an area for improvement, and none of these commented on the principal being present during any discussion as an issue. A well documented process may help prevent hidden agendas emerging if the appraisal is discussed in the principal's absence. Without such safeguards, principals' concerns are understandable as this comment on an unsatisfying experience from a primary principal illustrates:

Not knowing who was spoken to, or what data was used and leaving board meetings knowing that they would be discussing me. 


\subsubsection{Expectations of the appraisal}

The expectations principals and chairs have of the appraisal was a third theme identified in the findings.

The vast majority of principals responding to the survey were positive about their appraisal. They expected affirmation, objective feedback and no surprises, and on the whole this was their experience. The findings also indicate principals have a high level of input into the appraisal: from the selection of the appraiser, development of the performance agreement, and identification of sources of evidence through to the information that is made available for board discussion. This confirms the findings in previous studies (Darling-Hammond and Fontana, as cited in Jericho, 2004) that there is a link between a sense of ownership of the appraisal and belief in its effectiveness.

The GPF highlights the dual role of the appraisal: accountability and development. Meeting the requirements of accountability was clearly important to respondents as these two principals' comments show:

\section{Confirmation of competency + personal professional satisfaction.}

...allows me to have on-going feedback as well as providing accountability.

Whilst principals were appreciative of the feedback, advice and guidance they received through the appraisal there was a sense that they wanted something more. Many expressed a desire for more regular meetings with their EA, something this principal was able to achieve:

Sometimes we had "informal" meetings where he acted as more of a "critical friend" and at other times a "sounding board" to share experiences and feelings.

The notion of a critical friend aligns with approaches Swaffield (2008) has found to be effective in support for headteachers in the UK and is defined as:

....a trusted person who asks provocative questions, provides data to be examined through another lens, and offers critiques of a person's work as a friend. A critical friend takes the time to fully understand the context of the work presented and the outcomes that the person or group is working toward. (Costa \& Kallick, as cited in Department of Education and Early Childhood and Development, 2008) 
In New Zealand, principal advice and guidance had been part of the role of School Inspectors, usually former principals, until the 1989 reforms $^{10}$ (Fitzgerald, 2001). Since then, MOE funded School Support Services (SSS) contracts let to Colleges of Education (all of which are now part of universities), have seen the provision for leadership and management support increase to roughly $25 \%$ of core contracted services. The resource must be targeted according to MOE priorities, for instance first time principals (FTP) or those leading poorly performing schools. SSS provision goes some way but does not fill a gap in developmental support identified by principals. An example of a more explicit form of this type of support is provided by Designated Officers in the Australian state of Victoria (see Chapter 2.2.4).

Responses from chairs about what makes for a satisfying appraisal echoed those of principals. They want to affirm achievement and provide honest, objective feedback that will help the principal to move the school forward. Boards also want to meet their legal responsibility in a cost-effective way. Whilst the operating grant has been regularly increased since 1998, that was the only time an increase was specifically linked to the cost of appraisal. Both time and funding were aspects of the resourcing coding category developed as part of the analysis of the final question in the survey, with time the major issue for chairs. They recognised that appraisal takes time but CA especially found the demands on them a major challenge. When BOT opt for an EA, there is the added cost, although few respondents mentioned this as a "least satisfying aspect" and around $86 \%$ of principals and chairs thought the cost worthwhile.

Another aspect of expectations touched on by a small number of respondents was the relationship between pay and performance. It has been suggested that the very limited link between these elements in the New Zealand regulatory framework encourages "a low-stakes formative approach" which enables practitioners to focus on their own specific context (Sinnema \& Robinson, 2007, p. 327). The New Zealand principal cited at the start of this report might disagree with the notion of appraisal being "low stakes".

\footnotetext{
${ }^{10}$ Latterly only available to primary principals as system abolished in early 1970 s for secondary schools.
} 


\subsubsection{Skills and understanding}

The findings of this research suggest that principal and board knowledge of the requirements of principal appraisal, and the rights and responsibilities of both parties, is incomplete. Some chairs recognised this as an area for improvement with almost a third of EA/CE and around a quarter of CA seeking increased training, support and process clarification. Very few principals highlighted these areas in their suggestions, yet there are indications, particularly in relation to board reporting and discussion, that recommended practice is not being observed.

Where an effective working partnership exists these shortcomings may not create issues, or if they do they are put to one side in an effort to maintain good relationships. I had a recent example of this when a BOT chair rang me for advice about the principal being present throughout discussion of the appraisal report. The principal believed he had a right to be present and had no intention of leaving the meeting. The chair understood this was not necessarily the case but did not want to risk jeopardizing a functional relationship by insisting otherwise. The chair believed the current, largely new board was unaware of its rights and would take its lead from her, but she was not comfortable with withholding this knowledge from trustees. She was also concerned that in avoiding the issue at a time when no major concerns were being raised about principal performance, she was setting a precedent should circumstances change. The recommendations in 5.5 address this issue by encouraging BOT to review policy and procedures so that they are aligned to recommended practice.

\subsection{Principal Appraisal in Context}

The BOT appraisal of the principal needs to be seen in a wider context: firstly as part of performance management processes that include recruitment, induction and professional development; secondly in relation to a growing number of initiatives around school leadership including aspiring and first time principalship programmes, and the Kiwi Leadership Framework for Principals (MOE, 2008b). In collaboration with principal and union groups the MOE has also funded mentoring projects in which trained principal mentors facilitate groups of their peers to share and reflect upon their practice (Stewart, 2000). A more recent development has been the Principals' Development Planning Centre (PDPC) which since 2004 has put principals with at least five years' experience through a rigorous evaluation of their 
strengths, skills, weaknesses and needs. Although the resultant information is solely owned by the principal, it can provide valuable insights for areas in which they might set personal development objectives. At the time of writing the future of this initiative beyond 2008 is uncertain.

Another aspect of placing appraisal in a wider context involves looking at alternative models. For instance, a study group of principals brought together by Hampton (2005) explored options for principal appraisal that included Quality Learning Circles, rating systems such as those used by Interlead Consultancy, and digital portfolios, before focusing on a model of reciprocal principal appraisal. The resulting process saw board requirements met, principal strengths identified, and development for the following year suggested. Whilst peer appraisal is supported by the ERO (ERO, 2002), it is cautioned against in NZSTA advice to boards (New Zealand School Trustees' Association, 2005).

The findings of this research are consistent with earlier studies referred to in Chapter 2, which concluded with recommendations for enhancing the effectiveness of headteacher appraisal in England and Wales (Cullen, 1997; Hellawell \& Hancock, 1998). These recommendations were largely ignored. Instead significant new initiatives were introduced, requiring the gaining of trust and buy-in from the stakeholders to begin all over again. It would be a pity if New Zealand were to go down such a track when, in the experience of the majority of those who responded to this survey, it is working pretty well on the whole, which is not to say it cannot be improved.

\subsection{Conclusion}

The survey results suggest four critical success factors that characterise the appraisals described by participants. These factors, which appear to determine the success or otherwise of principal appraisal, are:

i) the way in which the appraiser is selected and their personal qualities;

ii) the fairness, usefulness and clarity of the appraisal process;

iii) the specific expectations that principals and chairs have of the outcome of the appraisal; and, finally

iv) the completeness and congruity of principals' and boards' understanding of appraisal. 
Table 5.1 uses these factors, to explore the motivators and inhibitors of a satisfying appraisal experience based on responses to the final question in the survey.

Table 5.1 Profiles of satisfying and unsatisfying appraisals

\begin{tabular}{|l|l|l|}
\hline \multicolumn{1}{|c|}{ Categories } & \multicolumn{1}{|c|}{$\begin{array}{c}\text { Factors that make appraisal } \\
\text { satisfying }\end{array}$} & \multicolumn{1}{|c|}{$\begin{array}{c}\text { Factors that make a appraisal } \\
\text { unsatisfying }\end{array}$} \\
\hline Appraiser & $\begin{array}{l}\text { An external appraiser, } \\
\text { predominantly selected by the } \\
\text { principal, preferably with principal } \\
\text { experience, but in any case a } \\
\text { professional }\end{array}$ & $\begin{array}{l}\text { Unskilled, non-professional } \\
\text { appraiser; more often a lack of } \\
\text { confidence in the process on the } \\
\text { part of BOT chair as appraiser }\end{array}$ \\
\hline Interpersonal & $\begin{array}{l}\text { Positive feed-back, including } \\
\text { affirmation; reported to the BOT; } \\
\text { useful feed-forward for principals. } \\
\text { This factor further amplified by the } \\
\text { principal's positive attitude }\end{array}$ & $\begin{array}{l}\text { Non-affirming feed-back; } \\
\text { insufficient or inadequate feed- } \\
\text { forward, especially lack of } \\
\text { challenge and directional } \\
\text { guidance; BOT exhibiting } \\
\text { insufficient interest or seeking too } \\
\text { much involvement }\end{array}$ \\
\hline Process & $\begin{array}{l}\text { A clear, well documented and } \\
\text { sufficiently evidence-based } \\
\text { process with stakeholder input }\end{array}$ & $\begin{array}{l}\text { Flaws in the quality of the process } \\
\text { including insufficient: } \\
\text { - objectivity because of a lack of } \\
\text { an evidence base; and } \\
\text { input from key stakeholders }\end{array}$ \\
\hline Resourcing & $\begin{array}{l}\text { There were no significant } \\
\text { indications that resourcing is a } \\
\text { specific contributor to appraisal } \\
\text { success }\end{array}$ & $\begin{array}{l}\text { Insufficient time to prepare, gather } \\
\text { the evidence for, and conduct the } \\
\text { appraisal (especially felt by } \\
\text { appraising BOT chairs); } \\
\text { inadequate resources for BOT } \\
\text { chair training. However, more } \\
\text { financial resourcing was a minor } \\
\text { point }\end{array}$ \\
\hline
\end{tabular}

Code:

\begin{tabular}{l|}
\hline Most important factor; \\
majority responses
\end{tabular}

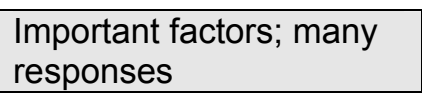

Significant factors; minority responses

The polarisation of positive and negative factors appear to relate to two situational realities, namely:

(a) reported experiences were mostly positive

(b) understanding and resourcing of effective practice is limited.

Mostly positive experiences mean that a professional external appraiser and good interpersonal, constructive chemistry are dominant as critical success factors, reflecting the benefits of careful appraiser/appraisee matching highlighted in a UK study (Clayton-Jones et al., 1993). A functioning process with adequate resourcing to give enough time to participants and provide for ample evidence gathering and evaluation appear to be "hygiene" factors (Herzberg, 2003): they are important 
prerequisites for a satisfying appraisal but do not by themselves guarantee it or contribute to a satisfactory outcome.

The hygiene role of process and resourcing factors is underlined by their significant contribution in unsatisfying appraisal experiences. This can be traced to a lack of clear understanding of appraisal aims and best practice, together with resources to support their development. It is further compounded by the transient nature of BOT and their chairs, which can cause periodic loss of organisational memory and experience. The failure to adequately support the implementation of performance appraisal by lay people has been a criticism levelled at government in the UK (Kerry, 2005).

The suggestions for improvement are aligned to these motivators and inhibitors and address the shortcomings in a direct and practical way. They can be summarised in four key action programmes:

1. Strengthening the principal/chair/appraiser relationship through increased training and information. This could be further complemented with clear priorities for appraiser selection towards experienced, external professionals with good (and tested) interpersonal skills.

2. Feed-forward, guidance that is constructive, challenging and convincing, should be a key outcome of the appraisal process.

3. Appraisal should be a continuous process, rather than an event, with clear guidelines for a documented, evidence-based approach.

4. Provision and acceptance of sufficient resourcing to enable:

a) more time to be dedicated to a thorough appraisal;

b) more training for all key participants; this, however, needs to be predicated upon

c) clear, practical and comprehensively disseminated guidelines and templates for the appraisal process for each key player: principal, chair and external appraiser.

The recommendations in the following section address these suggestions as well as other findings in this research. 


\subsection{Recommendations}

The findings of this research raise a number of issues which, if addressed, could improve the effectiveness of principal appraisal for three key stakeholder groups, identified in the following sections.

\subsubsection{The Ministry of Education}

The Ministry should consider:

i) Strategies for increasing the dissemination of the GPF

Promulgating information on good practice beyond the NZSTA newsletter and website may enable expert knowledge and understanding of effective appraisal to be shared by greater numbers of principals, BOT and appraisal consultants.

ii) Increased provision of training for BOT in relation to appraisal regulation and good practice

This relates to the previous recommendation, with one strategy for increasing training opportunities being through the Ministry's Board Training and Support contracts. Additional resourcing would enable increased depth of training and provide mentoring support for chair appraisers new to the role.

iii) Provision of training for principals and other current or potential consultant appraisers

There has been no national provision of appraiser and appraisee training since the Appraisal Skills for Teachers contract in 1998. Local initiatives have seen occasional joint venture training programmes for principal appraisers. The provision of incentives to run affordable training programmes, together with periodic re-training for current appraisers, would help provide quality assurance to boards contracting external appraisers. 


\subsubsection{Boards of Trustees}

BOT should consider:

i) Proactively accessing training and information on principal appraisal Boards would benefit from increased participation in training and access to information. Over two-thirds of secondary CA, a third of primary CA and around three-quarters of CE chairs had attended no principal appraisal related training. Attendees of 2008 trustee training on principal appraisal were unaware of the GPF despite it being featured in the NZSTA newsletter of November/December 2007.

ii) Reviewing current policy and procedures to bring then into line with good practice

The issuing of the GPF provides a timely opportunity to re-visit documentation that is likely to have been developed by previous boards, to ensure it reflects recommended practice and aligns with procedures.

iii) Regularly reviewing principal appraisal as part of a planned programme of school self-review

Again, this recommendation is about BOT being proactive rather than reactive and waiting until a problem arises before it is addressed. Ensuring principal appraisal is part of a regular review cycle enables the board to consider whether it is carrying out its responsibilities as effectively as possible.

\subsubsection{Principals}

i) participating in training and information sharing on principal appraisal with the board

As the board's CEO, principals have a responsibility to ensure they fully understand the regulatory framework for principal appraisal. Participating in training and discussion on the topic with trustees enables a shared understanding and the development of contextually appropriate processes. 
ii) encouraging the ВОТ to review current policy and procedures to bring them into line with good practice

iii) ensuring principal appraisal is part of a planned programme of school self-review

These recommendations are made for the same reasons outlined in 5.5.2 above. Again they reflect an expectation that as the board's CEO, the principal will provide guidance on legislative and professional matters.

\subsubsection{Summary}

Increased understanding of the regulatory framework and recommended practice will enhance the potential for appraisal to provide accountability assurance for boards and professional motivation for principals. Reviewing policy and procedures, as part of a regular cycle of school self-review, shifts the focus to the issues, not the people involved. This is consistent with Fitzgerald et al.'s (2003) focus on taking a holistic view and ensuring participants are actively involved in reviewing and refining the process.

\subsubsection{Follow-up research}

Further academic study should consider investigation of:

- in-depth case studies that compare and contrast different approaches and models of principal appraisal;

- culturally different approaches to appraisal, including a whānau approach as used in Kura Kaupapa Māori settings;

- the relationship between attitudes to the appraisal and length of experience in role;

- the motivation, benefits and challenges faced by incumbent principals undertaking appraisals of peers; and finally,

- the role of the ERO in monitoring principal appraisal. A search of the ERO website (www.ero.govt.nz) was made on 22/3/08 to check if "principal appraisal" had been mentioned since 2004 in reports for any of the schools responding to the survey. No results were found. 


\subsection{Final Thoughts}

Performance appraisal at its best can be one of the most satisfying, supportive and beneficial experiences for those engaged in it. At its worst, it can be a threatening and even destructive tool for control and compliance. (Cardno, 2001, p. 144)

Significantly for the current study Cardno also warns of the dangers of settling for the in-between. Simply going through the motions will not harness the potential for appraisal to motivate improved practice. Barriers to gaining commitment to the process have been highlighted in this research, including confusion as to purpose and a lack of skills, time, resources and trust. Overcoming these is largely dependent upon the interpersonal relationships that exist between the principal and the BOT. A principal who told me in 1990 that he would find it professionally insulting to be appraised by his board still felt that way when he retired a decade later. The principal cited in the introduction had some faith in the process restored by a change of board membership. Fortunate is the board, and school, whose principal views him/herself as a leading learner who actively seeks feedback to improve; luckier still the principal with a board that understands the challenges and complexities of the role and takes seriously its responsibility to provide honest, constructive feedback coupled with support to enhance future performance. As this research has shown, both can and do exist and the willingness of principals and chairs to share their experience for this research provides valuable insights for those in search of effective principal appraisal. 


\section{REFERENCES}

Adams, P., \& Townsend, D. (2006). Principal effectiveness: Exploring the gap between real and ideal. Alberta Teachers' Association Magazine, 87, 52-55. Retrieved April 82008 from http://proquest.umi.com/pqdweb?did=1153858621\&Fmt=3\&clientld=7511\&R QT=309\&VName=PQD.

Bartlett, S. (2000). The development of teacher appraisal: A recent history. British Journal of Educational Studies, 48. Retrieved August 27, 2008, from http://www.jstor.org/stable/1555845.

Brown, A. (2005). Implementing performance management in England's primary schools. International Journal of Productivity and Performance Management, 54(5/6), 468.

Bush, T., \& Middlewood, D. (2005). Leading and managing people in education. Padstow, Cornwall: SAGE Publications.

Cardno, C. (2001). Managing dilemmas in appraising performance: An approach for school leaders. In D. Middlewood \& C. Cardno (Eds.), Managing teacher appraisal and performance: A comparative approach (pp. 143-159). New York: Routledge Falmer.

Catano, N., \& Stronge, J. H. (2007). What do we expect of school principals? Congruence between principal evaluation and performance standards. International Journal of Leadership in Education, 10(4), 379-399.

Chapman, T. (2000). Managing teacher performance in Today's Schools. In I. Livingstone (Ed.), New Zealand Annual Review of Education, 9, 1999, 4362.

Clayton-Jones, L., McMahon, J., Rodwell, K., Skehan, J., Bourke, S., \& Holbrook, A. (1991). Performance appraisal of principals in the Hunter region of the NSW Department of School Education. Paper presented at the Australian Association for Research in Education. Retrieved February 10, 2008, from http//:pandora.nla.gov.au/pan/24691/200503010000/www.aare.edu.au/91.pap/clay191.

Clayton-Jones, L., McMahon, J., Rodwell, K., Skehan, J., Bourke, S., \& Holbrook, A. (1993). Appraisal of school principals in an Australian Department of Education. Peabody Journal of Education, 68(2), 110-131.

Coens, T., \& Jenkins, M. (2000). Abolishing performance appraisals: Why they backfire and what to do instead. San Francisco: Berrett-Koehler.

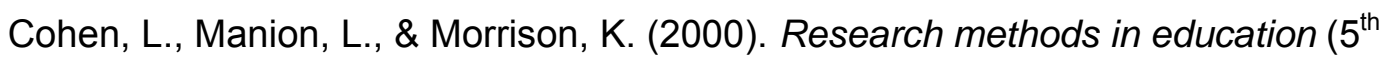
ed.). London: Routledge.

Council of Ministers of Education. (2008). Education in Canada. Retrieved April 18, 2008, from http://www.cmec.ca/international/educationcanada.en.pdf. 
Crane, M. (2005). Winning hearts and minds: Leadership and performance management. Practitioner Enquiry Report, 1-27. Retrieved March 24, 2008, from http://www.ncsl.org.uk/media/DCA/C8/crane-winning-hearts-full.pdf.

Crawford, M., \& Earley, P. (2004). Headteacher performance management: An investigation of the role of the external adviser. School Leadership \& Management, 24(4), 377-389.

Cullen, K. (1997). An evaluation of the United Kingdom's national system of headteacher appraisal. Studies in Educational Evaluation, 23(2), 103-130.

Department for Children, Schools \& Families. (2007). A new relationship with schools: The school improvement partner's brief. Retrieved June 15, 2008, from http://ncsl.org.uk/de/media-13c-f7-sips-brief-edition-3.pdf.

Department of Education and Early Childhood Development. (2008). Guidelines for principal class performance and development 2008. Retrieved July 1, 2008, from http://www.eduweb.vic.gov.au/edulibrary/public/teachlearn/leader/pcpdguidelines-v1-20080219adobe.pdf.

Department for Education \& Employment. (2000). Performance management in schools: Performance management framework. Retrieved April 1, 2008, from http://www.dcsf.gov.uk/publications/guidanceonthelaw/dfeepub/ apr00/word/050400g.doc.

Department for Education \& Skills. (2003). Performance management 2003: Support guide for governors \& headteachers workbook. London. Retrieved April 8, 2008, from http://www.emeraldinsight.com/Insight/ViewContent Servlet?Filename=/published/emeraldfulltextarticle/pdf/0790540511_ref.html

Drucker, P. (1954). The practice of management. New York: Harper.

Education Review Office. (1995). Managing staff performance in schools. Wellington: Author.

Education Review Office. (2002). Good practice in principals' appraisal (pp.1-22). Wellington: Author.

Edwards, W. L. (2001). Ethics in principal appraisal. In D. Middlewood \& C. Cardno (Eds.), Managing teacher appraisal and performance: A comparative approach (pp. 58-71). New York: Routledge Falmer.

Fitzgerald, T. (2001). Potential paradoxes in performance appraisal: Emerging issues for New Zealand schools. In D. Middlewood \& C. Cardno (Eds.), Managing teacher appraisal and performance: A comparative approach (pp.112-124). New York: Routledge Falmer.

Fitzgerald, T., Youngs, H., \& Grootenboer, P. (2003). Bureaucratic control or professional autonomy? Performance management in New Zealand schools School Leadership \& Management, 23(1), 99-105.

Frean, A. (2007, June 5). School governors have a lot to learn. The Times, p. 23.

Fullan, M. (1991). The new meaning of educational change. New York: Teachers College Press. 
Fullan, M., \& Mascall, B. (2000). Human resource issues in education: A literature review for the NZ Ministry of Education, Ontario Institute for Studies in Education [Electronic Version]. Retrieved December 1, 2006, from http://www.minedu.govt.nz/index.cfm?layout=document\&documentid=6040\& CFID $=1360057 \&$ CFTOKEN $=86842062$.

Gann, N. (2003, September 12). Question time for inquisitors. The Times Educational Supplement.

Gilbert, J. (1995). Introduction to management in New Zealand $\left(2^{\text {nd }}\right.$ ed. $)$. Sydney: Elsevier Australia.

Glaser, B.G., \& Strauss, A.L. (1967). The discovery of grounded theory: Strategies for qualitative research. Chicago: Aldine Publishing.

Government of New Zealand. (1988). Tomorrow's Schools: The reform of education administration in New Zealand. Wellington: Government Print.

Government of Ontario. (2008a). Leadership development. Retrieved April 18, 2008, from http://www.edu.gov.on.ca/eng/policyfunding/leadership/principal.html

Government of Ontario. (2008b). The role of the Ministry of Training, colleges and universities. Retrieved April 18, 2008, from

http://www.edu.gov.on.ca/eng/tcu/about/role.html.

Hallinger, P. (1997). Taking charge of change: Surrender! International Studies in Educational Administration, 25(1), 23-29.

Harris, A. (2005). Leading or following educational change? School Leadership and Management, 25, 417-419.

Hampton, H. (2005). A study of principal appraisal. Sabbatical leave report, 1-9. Retrieved April 1, 2008, from

http://www.leadspace.govt.nz/leadership/pdf/hampton-sabbatical-05.pdf.

Hancock, N., \& Hellawell, D. (1998). Primary school governing bodies and headteacher appraisal. Educational Management \& Administration 26(3), 257-268.

Haynes, G., Wragg, T., Wragg, C., \& Chamberlin, R. (2003). Performance management for teachers: Headteachers' perspectives. School Leadership \& Management, 23(1), 75-89.

Heck, R. H., \& Marcoulides, G. A. (1996). The assessment of principal performance: A multilevel evaluation approach. Journal of Personnel Evaluation in Education, 10(1), 11-28.

Hellawell, D., \& Hancock, N. (1998). Some benefits of primary headteacher appraisal: An experience potentially too good to lose? School Leadership \& Management, 18(2), 213-229.

Herzberg, F. (2003). One more time: How do you motivate employees? Harvard Business Review 14. Retrieved July 28, 2008, from http://www.hbrreprints.org. 
Herzberg, F., Mausner, B., \& Synderman, B. B. (1993). The motivation to work Edison, NJ: Transaction Publishers.

Institute for Educational Leadership. (2006). A detailed review of the research on leadership and student achievement. Retrieved April 18, 2008, from http://www.edu.gov.on.ca/eng/policyfunding/leadership/pdfs/Suport_LongLit.pdf.

Isherwood, M., Johnson, H., \& Brundrett, M. (2007). Performance management motivating and developing good teachers? The experiences of teachers in a small special school. International Journal of Primary, Elementary and Early Years Education, 3(13), 71-81. Retrieved April 8, 2008, from http://dx.doi.org/10.1080/03004270601103384.

James, C., \& Colebourne, D. (2004). Managing the performance of staff in LEAs in Wales: Practice, problems and possibilities. Educational Management Administration \& Leadership, 32(1), 45-65.

Jericho, A. J. (2004). Perceptions of principal appraisal: Experience in Australian Lutheran schools.. Unpublished PhD thesis, Griffith University of Queensland. Retrieved April 23, 2008, from Australian Digital Theses Program.

Kerry, C. (2005). Headteacher performance management: An investigation of the role of the governor. School Leadership \& Management, 25(5), 473.

Kochan, F. K., Bredeson, P., \& Riehl, C. (2002). Rethinking the professional development of school leaders. Yearbook of the National Society for the Study of Education, 101, 289-306. Retrieved April 13, 2008, from http://www.blackwell-synergy.com/doi/abs/10.1111/j.17447984.2002.tb00013.x.

Leithwood, K. (2001). Criteria for appraising school leaders. In D. Middlewood \& C. Cardno (Eds.), Managing teacher appraisal and performance: $A$ comparative approach (pp. 43-57). New York: Routledge Falmer.

Lingard, B., Hayes, D., \& Mills, M. (2002). Developments in school-based management: The specific case of Queensland, Australia. Journal of Educational Administration, 40(1), 6-30.

Marshall, G. (1998). A dictionary of sociology. Retrieved July 20, 2008, from http://www.encyclopedia.com/doc/1088--nonresponse.html.

Middlewood, D. (2001). The future of managing teacher performance and its appraisal. In D. Middlewood \& C. Cardno (Eds.), Managing teacher appraisal and performance: A comparative approach (pp. 180-195). New York: Routledge Falmer.

Middlewood, D., \& Cardno, C. (2001). The significance of teacher performance and its appraisal In D. Middlewood \& C. Cardno (Eds.), Managing teacher appraisal and performance: A comparative approach (pp. 1-16). New York: Routledge Falmer.

Miles, M.B., \& Huberman, A.M. (1994). Qualitative data analysis: An expanded sourcebook $\left(2^{\text {nd }}\right.$ ed.). Thousand Oaks, CA: SAGE Publications. 
Ministry of Education. (1993). The national education guidelines: The national administration guidelines. Retrieved August 7, 2008, from http://www. minedu.govt.nz/index.cfm?layout=document\&documentid=8187\&data=1.

Ministry of Education. (1995). Draft national guidelines for performance management in schools (pp. 1-39): Wellington: Learning Media.

Ministry of Education. (1997a). Prescribing performance appraisal: Performance management in schools. Education Gazette, 76(2).

Ministry of Education. (1997b). Performance management systems: PMS1 Performance appraisal (pp. 1-16). Wellington: Author.

Ministry of Education. (1997c). Performance management systems: PMS2 Issues for rural schools and small schools with teaching principals (pp. 1-8). Wellington: Author.

Ministry of Education. (1997d). Performance management systems: PMS3 Appraisal of the principal (pp. 1-12). Wellington: Author.

Ministry of Education. (1998, October 5). Introduction of interim professional standards for primary school teachers and primary school deputy and assistant principals. Education Gazette. Wellington: Author.

Ministry of Education. (1999). Principal performance management. Wellington: School Labour Market Development.

Ministry of Education. (2007). Managing principal appraisal (performance review) good practice guidelines. Retrieved February 20, 2008, from http://www.nzsta.org.nz/RexDefault.aspx?PagelD=e5e70cdc-1663-448a8b76-f9690b9406ca.

Ministry of Education. (2008a). School roll summary report July 2006. Retrieved June 22, 2008, from http://www.educationcounts.govt.nz/publications/series/2259/july_school_roll _returns/school_roll_summary_report_july_2006.

Ministry of Education. (2008b). Kiwi leadership for principals: Principals as educational leaders. Wellington: Author.

Mongan, J. L. (1999). Managing performance: A review of the performance management program for principals in Victorian state schools. Paper presented at the AARE-NZARE Conference, Melbourne. Retrieved April 21, 2007, from http://www.aare.edu.au/99pap/mon99397.htm.

Mulford, B. (2003). School leaders: Challenging roles and impact on teacher and school effectiveness. OECD commissioned paper, 1-66. Retrieved March 16, 2008, from OECD database.

National Association of School Governors. (2005a). Governors: Who they are \& what they do. NASG Papers, 8(38), 1-15.

National Association of School Governors. (2005b). The role of the chair. NAGM Papers, 6(39), 1-7. 
National Governors' Association. (2007). Performance management arrangements: NGA News Spring Term 2007. Retrieved September 5, 2008, from http://eduwight.iow.gov.uk/governors/images/NGANewsletterSPRING2007.pdf.

New Zealand School Trustees' Association. (1999). Guidelines for boards of trustees: The management of the principal by the school board of trustees. Wellington: Author.

New Zealand School Trustees' Association. (2005). Guidelines for boards of trustees: Managing principal appraisal ( $2^{\text {nd }}$ ed.). Wellington: Author.

Normore, A. H. (2004). Recruitment and selection: Meeting the leadership shortage in one large Canadian school district. Canadian Journal of Educational Administration and Policy, (30), 1-17.

O'Brien, P., \& Down, B. (2002). What are teachers saying about new managerialism? Journal of Educational Enquiry, 1(1), 111-128.

OECD. (1989). Schools and quality: An international report. Paris: Author.

Ontario State Government. (2001). School councils: A guide for members Retrieved April 21, 2007, from

http://www.edu.gov.on.ca/eng/general/elemsec/council/councile.pdf.

Piggot-Irvine, E. (2003). Key features of appraisal effectiveness. The International Journal of Educational Management, 17(4/5), 170.

Piggot-Irvine, E., \& Cardno, C. (2005). Appraising performance productively. Auckland: Eversleigh Publishing.

Pinaonneault, A., \& Kraemer, K.L. (1993). Survey research methodology in management information systems: An assessment. Journal of Management Information Systems, 10(2), 75-105.

Pointing, R. J. (2005). Implementation of school councils in Queensland state primary schools. Unpublished PhD Thesis, University of Southern Queensland. Retrieved March 16, 2008, from University of Southern Queensland Digital Theses.

Punch, K.F. (2005). Introduction to social research: Quantitative and qualitative approaches $\left(2^{\text {nd }}\right.$ ed.). London: SAGE Publications.

Sassoon, D. (2006). No room for improvement. The Times Educational Supplement. Retrieved April 23, 2008, from http://proquest.umi.com/pqdweb?did $=1083504821 \& \mathrm{Fmt}=7 \&$ clientld=7511\&RQT=309\&VName=PQD.

Simmons, J., \& lles, P. (2001). Performance appraisals in knowledge-based organisations: Implications for management education. International Journal of Management Education, 2(1), 3-19. Retrieved March 10, 2008, from Monash University Library Interloan.

Sinnema, C. E. L., \& Robinson, V. H. J. (2007). The leadership of teaching and learning: Implications for teacher evaluation. Leadership and Policy in Schools, 6(4), 319-343. 
Stewart, D. (2000). Tomorrow's principals today. Palmerston North: Kanuka Grove Press, Massey University.

Swaffield, S. (2008, January 6). Support for school principals and headteachers. Paper presented at the 21st International Congress for School Effectiveness \& Improvement, Auckland.

Teaching Times. (2006). Performance management regulations. Retrieved March 7, 2008, from http://www.teachingtimes.co.uk.

Thomas, D. W., Holdaway, E. A., \& Ward, K. L. (2000). Policies and practices involved in the evaluation of school principals. Journal of Personnel Evaluation in Education, 14(3), 215-240.

Timperley, H.S., \& Robinson, V.H.J. (1996). Appraisal and accountability: Views of secondary school principals. New Zealand Journal of Educational Administration, 11.

Training \& Development Agency for Schools. (2008). Performance management for teachers and head teachers: Briefing for governors. Performance Management. Retrieved April 5, 2008, from http://www.tda.gov.uk/teachers/ professionalstandards/performance_management.aspx.

U.S. Office of Personnel Management. (1994). 360-degree appraisal: A case study. Retrieved September 5, 2008, from http://www.opm.gov/perform/articles/002.asp.

Voisin, S. (2003). Secondary school principals and school councils: Practices and perceptions. Toronto: Ontario Institute for Studies in Education, University of Toronto.

West-Burnham, J. (2001). Appraising headteachers or developing leaders? Headteacher appraisal in the UK. In D. Middlewood \& C. Cardno (Eds.), Managing teacher appraisal and performance: A comparative approach (pp. 19-28). New York: Routledge Falmer.

Wilson, D., Croxson, B., \& Atkinson, A. (2006). What gets measured gets done: Headteachers' responses to the English Secondary School Performance Management System. Policy Studies, 27(2), 153-171.

\section{Legislation}

Constitution Act. (1867). Retrieved April 18, 2008, from http://www.solon.org/Constitutions/Canada/English/ca_1867.html.

Education Act. (1989). Retrieved April 21, 2008, from http://gpacts. knowledgebasket.co.nz/gpacts/public/text/1989/an/080.html.

State Sector Act. (1988). Retrieved April 21, 2008, from http://gpacts.knowledgebasket.co.nz/gpacts/public/text/1988/an/020.html. 


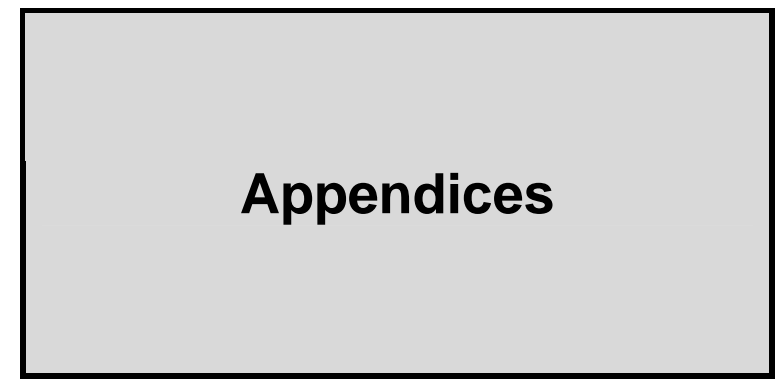




\section{Appendix A: Letter to accompany survey}

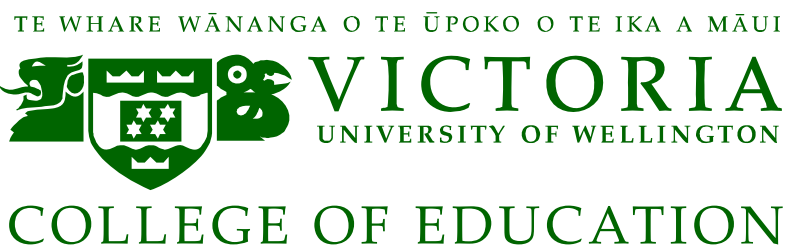

12 April 2007

Dear Principal

\section{In search of effective principal appraisal}

You are invited to take part in a research project that will document the impact and effectiveness of current performance appraisal practices for school principals. Overleaf you will find further information about this project. A similar letter and questionnaire have been sent to your board chair.

This survey relates to the principal appraisal process carried out in 2006 . If you have moved schools this year please respond in relation to your previous school. If you were not a principal, or acting principal, in 2006 please ignore this request.

The survey should take you no more than 20 minutes to complete. I realise that being asked to complete yet another survey form may not be a welcome prospect, but I very much hope you will be able to assist in furthering understanding of a key process in the governance and management of our schools.

As well as the information overleaf, this mailing contains a questionnaire, return envelope and optional return slip. If you would prefer to receive and complete an electronic version please email me (details below) putting "appraisal" in the subject line and I will email a copy to you.

Please return your questionnaire to me by 4 May 2007.

Yours sincerely

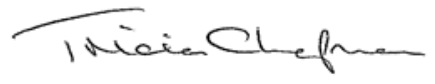

Tricia Chapman

Researcher's contact details:

Phone: (04) 4639600

Fax: (04) 4639579

Email: Tricia.Chapman@vuw.ac.nz

Box 17-310 Karori, Wellington 


\title{
Appendix B: Research Project Information Sheet
}

\author{
TE WHARE WĀNANGA O TE ŪPOKO O TE IKA A MĀUI

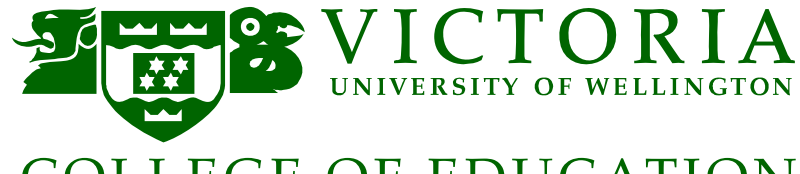 \\ COLLEGE OF EDUCATION \\ RESEARCH PROJECT INFORMATION SHEET

\section{In search of effective principal appraisal - a survey exploring how principal appraisal is carried out}

I am studying for a Master of Education degree with Victoria University and have been granted ethical approval to conduct this research in connection with my thesis project.

You are invited to take part in a survey of all school principals in the $X X X$ region seeking feedback on the experience of being appraised in 2006 . A related survey is being sent to board chairs seeking their view of the process.

Boards of Trustees are responsible for ensuring the appraisal of the principal's performance. I am exploring ways in which the appraisal is being undertaken in order to gain insights into the effectiveness of the process for both the board and the principal. I have a personal interest in the findings, having had twelve years experience as a school trustee, and an involvement in the development of performance appraisal in schools through my work as a Senior Lecturer/Facilitator in Leadership \& Management with Victoria University of Wellington College of Education.

Information gathered from both the principal and chairperson surveys will be treated confidentially and all reasonable steps will be taken to protect the identity of all respondents. The identity of respondents will be known only to me and my supervisor and schools will not be identified in the resulting report. Material will be securely stored and used only for the purposes for which it is collected. All questionnaires will be destroyed within two years of the completion of the research.

A summary of the findings of the research will be available in 2008 to those indicating they wish to receive this. The results may be used for conference presentations or journal articles. It will also provide useful data for the Wellington Leadership Network, a group made up of principal organisations, professional development providers and Ministry of Education personnel in this region of which I am a member and which is exploring strategies for supporting and promoting effective principal appraisal. However, no individual or school will be identified in any discussions with the Network or any publication resulting from this research.

If you have any questions about the project, please contact me using the details below, or my supervisor Liz Jones, Lecturer at the School of Education Studies, Victoria University of Wellington, Karori Campus, P.O. Box 17 - 310, Karori, Wellington, email Liz.Jones@vuw.ac.nz, phone (04) 4635939. 
Appendix C: Principal Survey

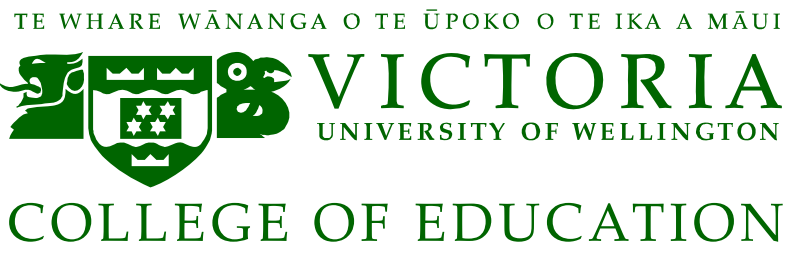

Survey on Principal Appraisal in 2006

\section{Background information}

1.1 School Name

1.2 Approx Roll at 1 July 2006:

1.3 Decile rating:

1.4 When did you become principal of this school?

Term

Year

Please answer the following questions in relation to your appraisal for 2006

\section{Appraiser}

2.1 Did you have an identified appraiser for 2006? $\quad \square$ YES $\square$ NO

2.2 If NO, please comment on whether an appraisal was undertaken

2.3 If YES, was your appraiser (tick one)

$\square$ a) the board chairperson

b) the board chair and another board member or members

c) the board chair and an external consultant

d) an external appraiser - if possible please specify (e.g. principal of another school, education consultant, Catholic Education Officer etc.)

$\square$ e) other - please add details 
2.4 How was your appraiser identified?

a) I was given a free choice

b) I was given a shortlist to choose from

c) The board chose a consultant

d) The board decided on the chairperson

e) Other - please specify...

2.5 Ideally, what would you say were the three most important qualities an appraiser should have? Please indicate the extent to which your appraiser possessed these using the scale:

$1=$ not at all. $2=$ hardly. $3=$ to a limited extent.

4 = to a satisfactory extent. $5=$ completely

\begin{tabular}{|c|c|c|c|c|c|}
\hline 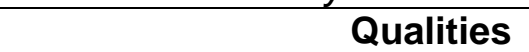 & : & & :) & & (;) \\
\hline i) & 1 & 2 & 3 & 4 & 5 \\
\hline ii) & 1 & 2 & 3 & 4 & 5 \\
\hline iii) & 1 & 2 & 3 & 4 & 5 \\
\hline
\end{tabular}

3. Performance Agreement

3.1 Did you have a signed performance agreement for 2006 ? $\square$ YES NO

3.2 If YES would you say your performance agreement was:

(tick one only)
a) negotiated with your appraiser only
b) negotiated with input from the board
c) largely determined by the board
d) largely determined by you

comments:

3.3 Were your development objectives for the year:

(tick any that are appropriate)
a) linked to charter strategic goals
b) linked to the school annual plan
c) supported by professional development

Comments: 


\section{Data Gathering}

4.1 Approximately how often did you meet with your appraiser to discuss progress in relation to the appraisal?

a) Once $\square$ b) Every month $\square$ c) Every term $\square$ d) Other - please specify

Comments:

4.2 What sources of data were used in order to provide feedback for the appraisal? tick any that are appropriate)

a) principal reports to the board

b) school newsletters

c) interviews with staff

d) interviews with trustees

e) written staff survey

f) written board survey

g) community survey

h) other - please list:

\section{Reporting}

5.1 Was a written report from the appraiser (tick any that are appropriate)
a) supplied to you
b) supplied to the board
c) tabled in full at a meeting of the board of trustees
d) tabled in a summarised version at a board meeting
e) not tabled but verbally reported on at a board meeting
f) not tabled or verbally reported on at a board meeting
g) other - please add comments (e.g. no report prepared)

5.2 Were you present at any meeting of the board to discuss the outcome of the appraisal? 


\section{Outcomes}

Please indicate your response to the following statements, using the rating scale given and adding any comments you wish to make in the boxes below each statement

1 = strongly disagree. 2 = disagree. $3=$ neutral/can't say. $4=$ agree. $5=$ strongly agree

\begin{tabular}{|l|lllll|}
\hline $\begin{array}{l}\text { Circle the number that best matches your } \\
\text { response }\end{array}$ & $\bullet$ & & $*$ & & $*$ \\
\hline $\begin{array}{l}\text { 6.1 The appraisal process has strengthened my } \\
\text { working relationship with the board }\end{array}$ & 1 & 2 & 3 & 4 & 5 \\
\hline
\end{tabular}

6.2 The appraisal process helped the board to

$\begin{array}{lllll}1 & 2 & 3 & 4 & 5\end{array}$
know whether school goals are being achieved

\begin{tabular}{l}
$\begin{array}{l}\text { 6.3 The appraisal process provided me with } \\
\text { feedback on my strengths }\end{array}$ \\
\hline
\end{tabular}

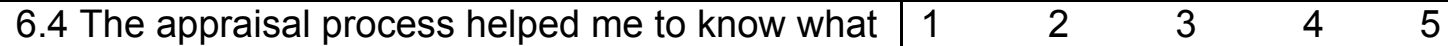 I can do to improve my performance

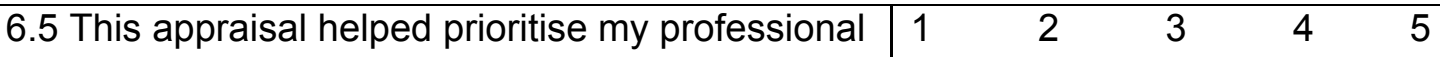 development focus for the following year

\begin{tabular}{|l|lllll}
\hline $\begin{array}{l}6.6 \text { The appraisal process enhanced my job } \\
\text { satisfaction }\end{array}$ & 1 & 2 & 3 & 4 & 5 \\
\hline
\end{tabular}

\begin{tabular}{l|lllll}
\hline 6.7 Time spent on the appraisal was worthwhile & 1 & 2 & 3 & 4 & 5
\end{tabular}

\begin{tabular}{|l|lllll}
\hline $\begin{array}{l}\text { 6.8 The cost of engaging an external appraiser } \\
\text { was worthwhile (where relevant) }\end{array}$ & 1 & 2 & 3 & 4 & 5 \\
\hline
\end{tabular}




\section{Reflection}

7.1 Overall, what aspect/s of the appraisal were you most satisfied with?

7.2 Overall, what aspect of the appraisal were you least satisfied with?

7.3 Is there anything you can suggest to improve the appraisal process for you?

\section{Consent to participation in research}

I acknowledge that completion of this survey signals my consent to participate in the research under the conditions set out in the accompanying information sheet.

Name:

Date

Signature:

Thank you for taking the time to complete this

Your assistance is very much appreciated 
Appendix D: BOT Chair Survey

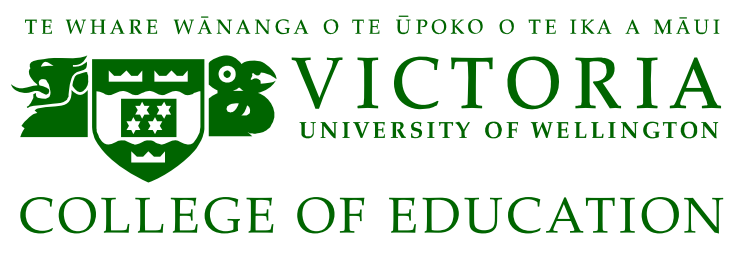

IN SEARCH OF EFFECTIVE PRINCIPAL APPRAISAL

Chairperson Survey on Principal Appraisal in 2006

All respondents are asked to complete Section $A$.

Depending upon your involvement in the appraisal process you will be asked to complete EITHER: Section B (blue) OR Section C (yellow) OR Section D (green)

\section{SECTION A}

\section{Background information}

1.1 School Name 1.2 Decile rating:

1.3 When did you become Chairperson of this board?

If possible please give month or term as well as the year

Please answer the following questions in relation to the appraisal of your principal in 2006.

\section{Appraiser selection}

2.2 Did your principal have an identified appraiser for 2006? $\square$ YES $\square$ NO

2.3 If NO, please comment on whether appraisal was undertaken and complete as much of Section B (blue pages) as possible.

2.4 If YES, was the appraiser

a) the board chairperson (i.e. you) - if so please go to Section B on the blue pages

b) you and another board member/s working jointly together - if so please go to Section $B$ on the blue pages

c) you and an external appraiser working jointly together - if so please go to Section $\mathbf{C}$ on the yellow pages

$\square$ d) an external appraiser - if so please go to Section $D$ on the green pages

e) other - please give brief details overleaf and select the Section that seems to be most relevant to the circumstances

Thank you for taking the time to complete this

Your assistance is very much appreciated 


\section{SECTION B}

This section relates to the Chairperson as appraiser in 2006. It should also be completed by Chairs working jointly with another board member or members

\section{The appraiser role}

3.1 Was the 2006 principal appraisal the first you have been involved in?

$\square$ YES $\square$ NO

3.2 Was the appraisal role shared with at least one other board member?

$\square$ YES $\square$ NO

If YES, please add brief details (e.g. Trustee with HR background, or 3 member Personnel

Committee)

3.2 Please tick any of the following statements that apply:

a) I have received training in school principal appraisal

b) I have read information on principal appraisal that was helpful to me

c) I have had experience of being an appraiser in another setting (e.g. in my workplace)

d) I have had experience of my performance being appraised

Comments

3.3 Ideally, what would you say were the three most important qualities an appraiser should have? Please indicate the extent to which you feel confident you possess these using the following scale:

$1=$ not at all. $2=$ hardly. $3=$ to a limited extent.

$4=$ to a satisfactory extent. $5=$ completely

\begin{tabular}{|c|c|c|c|c|c|}
\hline 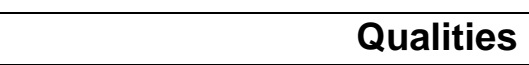 & : & & 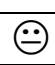 & & (;) \\
\hline i) & 1 & 2 & 3 & 4 & 5 \\
\hline ii) & 1 & 2 & 3 & 4 & 5 \\
\hline iii) & 1 & 2 & 3 & 4 & 5 \\
\hline
\end{tabular}


4. Performance Agreement

4.1 Did the principal have a signed performance agreement for 2006 ?

$\square$ YES $\square$ NO

4.2 If YES would you say the performance agreement was:

(tick one only)

a) negotiated with the chairperson only

b) negotiated with input from the board

c) largely determined by the principal

d) developed before I became involved/don't know much about it

Comments:

4.3 Was the principal's development objective(s) for the year: (tick any that are appropriate)

a) linked to charter strategic goals

b) linked to the school annual plan

c) supported by professional development

Comments:

\section{Data Gathering}

5.1 Approximately how often did you meet with the principal to discuss progress in relation to the appraisal?
a) Once
$\square$ b) Every month
c) Every term
d) Other - please specify

Comments:

5.2 What sources of data were used in order to provide feedback for the appraisal? (tick any that are appropriate)

$\square$ a) principal reports to the board

$\square$ b) school newsletters

$\square$ c) interviews with staff

$\square$ d) interviews with trustees

$\square$ e) written staff survey

$\square$ f) written board survey

g) community survey

h) other - please list: 


\section{Reporting}

6.1 Was an appraisal report (tick any that are appropriate)

$\square$ a) supplied to the board

$\square$ a) supplied to the principal

$\square$ c) tabled in full at a meeting of the board of trustees

$\square$ d) tabled in a summarised version at a board meeting

$\square$ e) not tabled but verbally reported on at a board meeting

$\square$ f) not tabled or verbally reported on at a board meeting

$\square$ g) other - please add comments (e.g. no written report prepared)

6.2 Was the principal present at any meeting of the board to discuss the outcome of the appraisal?

$\square$ YES $\square$ NO

Comments: 


\section{Outcomes}

Please use the rating scale below to indicate your response to the following statements, adding any comments you wish to make below each statement

1 = strongly disagree. 2 = disagree. $3=$ neutral/can't say. 4 =agree. $5=$ strongly agree

\begin{tabular}{|l|llllr|}
\hline $\begin{array}{l}\text { Circle the number that best matches your } \\
\text { response }\end{array}$ & $*$ & & $*$ & & :; \\
\hline $\begin{array}{l}7.1 \text { The appraisal process strengthened the board's } \\
\text { working relationship with the principal }\end{array}$ & 1 & 2 & 3 & 4 & 5 \\
\hline
\end{tabular}

\begin{tabular}{|l|llllll|}
\hline $\begin{array}{l}\text { 7.2 The appraisal process helped the board to know } \\
\text { whether school goals are being achieved }\end{array}$ & 1 & 2 & 3 & 4 & 5 \\
\hline & \\
\hline $\begin{array}{l}7.3 \text { The appraisal process provided the board with } \\
\text { insights into the principal's strengths }\end{array}$ & 1 & 2 & 3 & 4 & 5 \\
\hline
\end{tabular}

\begin{tabular}{|c|lllll|}
\hline $\begin{array}{c}7.4 \text { The appraisal process identified what the } \\
\text { principal can do to improve his/her performance }\end{array}$ & 1 & 2 & 3 & 4 & 5 \\
\hline
\end{tabular}

\begin{tabular}{|l|lllll|}
\hline $\begin{array}{l}7.5 \text { The appraisal helped prioritise the principal's } \\
\text { professional development focus for the following } \\
\text { year }\end{array}$ & 1 & 2 & 3 & 4 & 5 \\
\hline
\end{tabular}

\begin{tabular}{|l|lllll|}
\hline $\begin{array}{l}\text { 7.6 The appraisal process enhanced the principal's } \\
\text { job satisfaction }\end{array}$ & 1 & 2 & 3 & 4 & 5 \\
\hline
\end{tabular}

\begin{tabular}{|l|llllll}
\hline 7.7 Time spent on the appraisal was worthwhile & 1 & 2 & 3 & 4 & 5
\end{tabular}

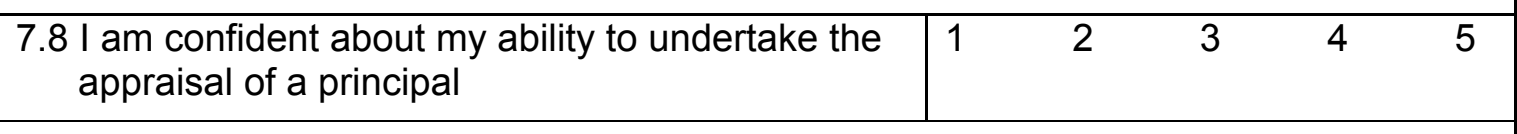


8. Reflection

8.1 Overall, what aspect of the principal's appraisal were you most satisfied with?

8.2 Overall, what aspect of the appraisal were you least satisfied with?

8.3 Is there anything you can suggest to improve the appraisal process?

\section{Consent to participation in research}

I acknowledge that completion of this survey signals my consent to participate in the research under the conditions set out in the accompanying information sheet.

Name:

Date

Signature: 


\section{SECTION C}

This Section relates to the Chairperson and an external appraiser working jointly together on the 2006 appraisal

\section{The appraiser role}

3.1 Was the 2006 principal appraisal the first you have been involved in?

$\square$ YES $\square$ NO

3.2 Please tick any of the following statements that apply:

$\square$ a) I have received training in school principal appraisal

b) I have read information on principal appraisal that was helpful to me

c) I have had experience of being an appraiser in another setting (e.g. in my workplace)

$\square$ d) I have had experience of my performance being appraised

comments

3.3 Was the external appraiser

$\square$ a) the current principal of another school

$\square$ b) a former principal

$\square$ c) a consultant known to have carried out principal appraisal

$\square$ d) a consultant without previous experience of principal appraisal

$\square$ e) Other please specify (e.g. employee of Catholic Education Office)

3.4 How was the external appraiser selected?

$\square$ a) The Principal was given a free choice/asked to identify someone

b) The Principal was given a shortlist to choose from

$\square$ c) The board chose a consultant/selected someone

d) Other - please specify 
3.5 How was the work divided between you and the external appraiser?

$\square$ a) The appraiser did most of the work

$\square$ b) The work was evenly balanced

$\square$ c) I did most of the work

d) Other - please add details

3.6 Ideally, what would you say were the three most important qualities an appraiser should have? Please circle a number in each column that best describes the extent to which you feel you and the external appraiser possess these qualities using the following scale:

$1=$ not at all. $2=$ hardly. $3=$ to a limited extent.

$4=$ to a satisfactory extent. $5=$ completely

\begin{tabular}{|c|c|c|c|c|c|c|c|c|c|}
\hline \multirow[b]{2}{*}{ Ideal Qualities } & \multicolumn{5}{|c|}{ Chairperson } & \multicolumn{4}{|c|}{ External Appraiser } \\
\hline & 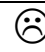 & & 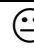 & & & & $\ddot{\theta}$ & & (;) \\
\hline i) & 1 & 2 & 3 & 4 & & & 3 & 4 & 5 \\
\hline ii) & 1 & 2 & 3 & 4 & 5 & & 3 & 4 & 5 \\
\hline iii) & 1 & 2 & 3 & 4 & & & 3 & 4 & 5 \\
\hline
\end{tabular}

\section{Performance Agreement}

4.1 Did the principal have a signed performance agreement for 2006 ?

$\square$ YES $\square$ NO

4.2 If YES would you say the performance agreement was:

(tick one only)

a) negotiated with the appraisers only

b) negotiated with input from the board

c) largely determined by the principal

d) developed before I became involved / don't know much about it Comments: 
4.3 Were the principal's development objectives for the year: (tick any that are appropriate)

a) linked to charter strategic goals

b) linked to the school annual plan

c) supported by professional development

Comments:

\section{Data Gathering}

5.1 Approximately how often did you meet with the principal to discuss progress in relation to the appraisal?
a) Once
b) Every month
c) Every term
d) Other - please specify

\section{Please comment on whether meetings involved both you and the external} appraiser

5.2 What sources of data were used in order to provide feedback for the appraisal? (tick any that are appropriate)

$\square$ a) principal reports to the board

b) school newsletters

c) interviews with staff

d) interviews with trustees

e) written staff survey

f) written board survey

g) community survey

h) other - please list:

i) not sure 


\section{Reporting}

6.1 Was an appraisal report (tick any that are appropriate)
a) supplied to the board
b) supplied to the principal
c) tabled in full at a meeting of the board of trustees
d) tabled in a summarised version at a board meeting
e) not tabled but verbally reported on at a board meeting
f) not tabled or verbally reported on at a board meeting
g) other - please add comments (e.g. no written report prepared)

6.2 Was the principal present at any meeting of the board to discuss the outcome of the appraisal?

$\square$ YES $\square$ NO

Comments: 


\section{Outcomes}

Please use the rating scale below to indicate your response to the following statements, adding any comments you wish to make in the box below each statement

1 = strongly disagree. 2 = disagree. $\quad 3=$ neutral/can't say. 4 = agree. $5=$ strongly agree

\begin{tabular}{|l|lllll|}
\hline $\begin{array}{l}\text { Circle the number that best matches your } \\
\text { response }\end{array}$ & $\bullet$ & & $*$ & & ; \\
\hline $\begin{array}{l}7.1 \text { The appraisal process strengthened the board's } \\
\text { working relationship with the principal }\end{array}$ & 1 & 2 & 3 & 4 & 5 \\
\hline
\end{tabular}

\begin{tabular}{|l|lllll|}
\hline $\begin{array}{l}7.2 \text { The appraisal process helped the board to know } \\
\text { whether school goals are being achieved }\end{array}$ & 1 & 2 & 3 & 4 & 5 \\
\hline
\end{tabular}

\begin{tabular}{|l|lllll}
\hline $\begin{array}{c}7.3 \text { The appraisal process provided the board with } \\
\text { insights into the principal's strengths }\end{array}$ & 1 & 2 & 3 & 4 & 5 \\
\hline
\end{tabular}

\begin{tabular}{|c|c|c|c|c|c|}
\hline $\begin{array}{l}\text { 7.4 The appraisal process identified what the principal } \\
\text { can do to improve his/her performance }\end{array}$ & 1 & 2 & 3 & 4 & 5 \\
\hline
\end{tabular}

\begin{tabular}{|l|lllll|}
\hline $\begin{array}{l}\text { 7.5 The appraisal helped prioritise the principal's } \\
\text { professional development focus for the following } \\
\text { year }\end{array}$ & 1 & 2 & 3 & 4 & 5 \\
\hline
\end{tabular}

\begin{tabular}{|l|llllll|}
\hline $\begin{array}{c}7.6 \text { The appraisal process enhanced the principal's } \\
\text { job satisfaction }\end{array}$ & 1 & 2 & 3 & 4 & 5 \\
\hline
\end{tabular}

\begin{tabular}{|l|lllll|}
\hline 7.7 Time spent on the appraisal was worthwhile & 1 & 2 & 3 & 4 & 5 \\
\hline
\end{tabular}

\begin{tabular}{|l|lllll|}
\hline $\begin{array}{l}7.8 \text { The cost of engaging an external appraiser was } \\
\text { worthwhile }\end{array}$ & 1 & 2 & 3 & 4 & 5 \\
\hline
\end{tabular}

\begin{tabular}{l}
$\begin{array}{l}7.9 \text { I am confident about my ability to undertake the } \\
\text { appraisal of a principal }\end{array}$ \\
\hline
\end{tabular}




\section{Reflection}

8.1 Overall, what aspect of the principal's appraisal were you most satisfied with?

8.2 Overall, what aspect of the appraisal were you least satisfied with?

8.3 Is there anything you can suggest to improve the appraisal process?

\section{Consent to participation in research}

I acknowledge that completion of this survey signals my consent to participate in the research under the conditions set out in the accompanying information sheet.

Name:

Date

Signature: 


\section{SECTION D}

\section{This Section relates to the 2006 appraisal being carried out by an external appraiser}

\section{The appraiser role}

3.1 Was the external appraiser

a) the current principal of another school

$\square$ b) a former principal

$\square$ c) a consultant known to have carried out principal appraisal

$\square$ d) a consultant without previous experience of principal appraisal

e) other please specify e.g. employee of Catholic Education Office

3.2 How was the external appraiser selected?
a) The Principal was given a free choice/asked to identify someone
b)The Principal was given a shortlist to choose from
c) The board chose a consultant/selected someone
d) Other - please specify...

3.3 Ideally, what would you say were the three most important qualities an appraiser should have? Pease circle the number that best indicates the extent to which you feel the appraiser has these qualities using the following scale:

$1=$ not at all. $2=$ hardly. $3=$ to a limited extent.

$4=$ to a satisfactory extent. $5=$ completely

\begin{tabular}{|c|c|c|c|c|c|}
\hline Ideal qualities & (2) & & (:) & & (;) \\
\hline i) & 1 & 2 & 3 & 4 & 5 \\
\hline ii) & 1 & 2 & 3 & 4 & 5 \\
\hline iii) & 1 & 2 & 3 & 4 & 5 \\
\hline
\end{tabular}




\section{Performance Agreement}

4.1 Did the principal have a signed performance agreement for $2006 ?$

YES $\square$ NO

4.2 If YES would you say the performance agreement was:

(tick one only)

a) negotiated with the principal by the appraiser

b) negotiated with input from me as chair

c) negotiated with input from the board

d) largely determined by the principal

e) developed before I became involved/don't know

Comments:

4.3 Were the principal's development objectives for the year: (tick any that are appropriate)

a) linked to charter strategic goals

b) linked to the school annual plan

c) supported by professional development

Comments

\section{Data Gathering}

5.1 Approximately how often did the appraiser meet with the principal to discuss progress?
a) Don't know
b) Once
c) Every month
d) Every term
e) Other

Comments

5.2 What other sources of data were gathered in order to provide feedback for the appraisal (tick any that are appropriate)
$\square$ a) principal reports to the board
b) school newsletters
$\square$ c) interviews with staff
d) interview with board chair
$\square$ e) interviews with other trustees
$\square$ f) written staff survey
$\square$ g) written board survey
$\square$ h) community survey
$\square$ i) other - please list
$\square$ j) not sure 


\section{Reporting}

6.1 Was an appraisal report (tick any that are appropriate)

$\square$ a) supplied to the board

$\square$ a) supplied to the principal

$\square$ c) tabled in full at a meeting of the board of trustees

$\square$ d) tabled in a summarised version at a board meeting

$\square$ e) not tabled but verbally reported on at a board meeting

$\square$ f) not tabled or verbally reported on at a board meeting

$\square$ g) other - please add comments (e.g. no written report prepared)

6.2 Was the principal present at any meeting of the board to discuss the outcome of the appraisal?

$\square$ YES $\square$ NO

Comments 


\section{Outcome}

Please use the rating scale below to indicate your response to the following statements, adding any comments you wish to make in the box below each statement

$1=$ strongly disagree. 2 = disagree. $3=$ neutral/can't say. $4=$ agree. $5=$ strongly agree

\begin{tabular}{|l|lllll|}
\hline $\begin{array}{l}\text { Circle the number that best matches your } \\
\text { response }\end{array}$ & $\bullet$ & & $*$ & & : \\
\hline $\begin{array}{l}7.1 \text { The appraisal process strengthened the board's } \\
\text { working relationship with the principal }\end{array}$ & 1 & 2 & 3 & 4 & 5 \\
\hline
\end{tabular}

\begin{tabular}{|c|lllll|}
\hline $\begin{array}{c}7.2 \text { The appraisal process helped the board to know } \\
\text { whether school goals are being achieved }\end{array}$ & 1 & 2 & 3 & 4 & 5 \\
\hline
\end{tabular}

\begin{tabular}{l}
$\begin{array}{l}\text { 7.3 The appraisal process provided the board with } \\
\text { insights into the principal's strengths }\end{array}$ \\
\hline
\end{tabular}

\begin{tabular}{|c|lllll|}
\hline $\begin{array}{c}7.4 \\
\text { The appraisal process identified what the } \\
\text { principal can do to improve his/her performance }\end{array}$ & 1 & 2 & 3 & 4 & 5 \\
\hline
\end{tabular}

\begin{tabular}{|l|lllll|}
\hline $\begin{array}{l}7.5 \text { The appraisal helped prioritise the principal's } \\
\text { professional development focus for the following } \\
\text { year }\end{array}$ & 1 & 2 & 3 & 4 & 5 \\
\hline
\end{tabular}

\begin{tabular}{|l|lllll|}
\hline $\begin{array}{l}\text { 7.6 The appraisal process enhanced the principal's } \\
\text { job satisfaction }\end{array}$ & 1 & 2 & 3 & 4 & 5 \\
\hline
\end{tabular}

\begin{tabular}{|l|lllll} 
7.7 Time spent on the appraisal was worthwhile & 1 & 2 & 3 & 4 & 5
\end{tabular}

\begin{tabular}{|l|lllll|}
\hline $\begin{array}{l}7.8 \text { The cost of engaging an external appraisal was } \\
\text { worthwhile }\end{array}$ & 1 & 2 & 3 & 4 & 5 \\
\hline
\end{tabular}

\begin{tabular}{l}
$\begin{array}{l}7.9 \text { I am confident about my ability to undertake the } \\
\text { appraisal of a principal }\end{array}$ \\
\hline
\end{tabular}




\section{Reflection}

8.1 Overall, what aspect of the principal's appraisal were you most satisfied with?

8.2 Overall, what aspect of the appraisal were you least satisfied with?

8.3 Is there anything you can suggest to improve the appraisal process?

Consent to participation in research

I acknowledge that completion of this survey signals my consent to participate in the research under the conditions set out in the accompanying information sheet.

Name:

Date

Signature: 


\section{Appendix E: Further analysis of outcomes}

This work-in-progress analysis was used to enable a first-cut overview of the magnitude (or otherwise) of differences between the main groups, i.e. Principals, CA chairs and EA/CE chairs

1. The appraisal process strengthened the board's working relationship with the principal

\begin{tabular}{|c|c|c|c|c|}
\hline Group & Mean & Median & Mode & Std Deviation \\
\hline Principals $\quad(\mathrm{No}=103)$ & 3.789 & 4 & 4 & 0.631 \\
\hline CA chairs & 3.808 & 4 & 4 & 0.801 \\
\hline EA/CE chairs $(\mathrm{No}=29)$ & 3.793 & 4 & 4 & 0.819 \\
\hline
\end{tabular}

2. The appraisal process helped the board to know whether school goals are being achieved

\begin{tabular}{|c|c|c|c|c|}
\hline Group & Mean & Median & Mode & Std Deviation \\
\hline Principals $\quad(\mathrm{No}=103)$ & 3.368 & 3 & 4 & 1.012 \\
\hline CA chairs & 3.885 & 3.5 & 4 & 0.993 \\
\hline EA/CE chairs $(\mathrm{No}=29)$ & 3.793 & 4 & 4 & 1.013 \\
\hline
\end{tabular}

3. The appraisal process provided the board with insights into the principal's strengths

\begin{tabular}{|c|c|c|c|c|}
\hline Group & Mean & Median & Mode & Std Deviation \\
\hline Principals $\quad(\mathrm{No}=103)$ & 4.211 & 4 & 4 & 0.631 \\
\hline CA chairs $\quad(\mathrm{No}=25)$ & 3.885 & 4 & 4 & 0.993 \\
\hline EA/CE chairs $(\mathrm{No}=29)$ & 4.276 & 4 & 4 & 0.751 \\
\hline
\end{tabular}

4. The appraisal process identified what the principal can do to improve his/her performance

\begin{tabular}{|c|c|c|c|c|}
\hline Group & Mean & Median & Mode & Std Deviation \\
\hline Principals $\quad(\mathrm{No}=103)$ & 4.105 & 4 & 4 & 0.567 \\
\hline CA chairs & 3.960 & 4 & 4 & 0.889 \\
\hline EA/CE chairs $(\mathrm{No}=29)$ & 3.931 & 4 & 4 & 1.067 \\
\hline
\end{tabular}

5. The appraisal helped prioritise the principal's professional development focus for the following year

\begin{tabular}{|c|c|c|c|c|}
\hline Group & Mean & Median & Mode & Std Deviation \\
\hline Principals $\quad(\mathrm{No}=103)$ & 4.158 & 4 & 4 & 0.688 \\
\hline CA chairs & 4.040 & 4 & 5 & 1.020 \\
\hline EA/CE chairs $(\mathrm{No}=29)$ & 3.966 & 4 & 5 & 1.180 \\
\hline
\end{tabular}


6. The appraisal process enhanced the principal's job satisfaction

\begin{tabular}{|c|c|c|c|c|}
\hline Group & Mean & Median & Mode & Std Deviation \\
\hline Principals $\quad(\mathrm{No}=103)$ & 3.579 & 4 & 4 & 0.838 \\
\hline CA chairs & 3.625 & 4 & 4 & 0.970 \\
\hline EA/CE chairs $(\mathrm{No}=29)$ & 3.821 & 4 & 4 & 0.772 \\
\hline
\end{tabular}

7. Time spent on the appraisal was worthwhile

\begin{tabular}{|c|c|c|c|c|}
\hline Group & Mean & Median & Mode & Std Deviation \\
\hline Principals $\quad(\mathrm{No}=103)$ & 4.263 & 4 & 4 & 0.653 \\
\hline CA chairs & 4.192 & 4 & 5 & 0.895 \\
\hline EA/CE chairs $(\mathrm{No}=29)$ & 4.310 & 5 & 5 & 0.891 \\
\hline
\end{tabular}

8. The cost of engaging an external appraiser was worthwhile

\begin{tabular}{|c|c|c|c|c|}
\hline Group & Mean & Median & Mode & Std Deviation \\
\hline Principals (No=103) & 4.444 & 5 & 5 & 1.014 \\
\hline EA/CE chairs (No=29) & 4.345 & 5 & 5 & 0.897 \\
\hline
\end{tabular}

9. I am confident about my ability to undertake the appraisal of a principal

\begin{tabular}{|c|c|c|c|c|}
\hline Group & Mean & Median & Mode & Std Deviation \\
\hline CA chairs $\quad(\mathrm{No}=25)$ & 3.920 & 4 & 4 & 0.997 \\
\hline EA/CE chairs $(\mathrm{No}=29)$ & 2.966 & 3 & 4 & 1.426 \\
\hline
\end{tabular}




\section{Glossary of Abbreviations}

BOT

CA

CD

CE
Board of Trustees

\section{Chair appraiser}

Chair appraised

Cluster Director (New South Wales)

Chair working with external appraiser Appraised by chair working with external appraiser

Department for Education and Employment (England and Wales)

Department for Education and Skills (England and Wales)

Designated Officer (Victoria, Australia)

Eternal appraiser

Externally appraised

External Adviser (England and Wales)

Education Review Office

Local Authority: agencies with responsibilities for children (England and Wales post 2004

Local Education Authority (England and Wales pre 2004)

Ministry of Education

Primary school chair

Primary chair appraiser

Performance management

Performance measures

Performance Management Framework (UK)

Performance Management Systems

Primary school principal

Secondary school chair

Secondary chair appraiser

School district boards (Canada)

School Improvement Partners (UK)

Secondary school principal 